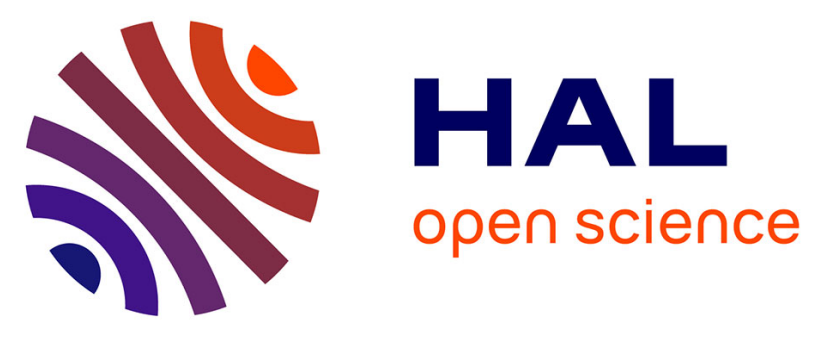

\title{
Mechanism of stimulation of DNA binding of the transcription factors by human apurinic/apyrimidinic endonuclease 1, APE1
}

Milena Bazlekowa-Karaban, Paulina Prorok, Sonia Baconnais, Sabira Taipakova, Zhiger Akishev, Dominika Zembrzuska, Alexander Popov, Anton Endutkin, Regina Groisman, Alexander Ishchenko, et al.

\section{To cite this version:}

Milena Bazlekowa-Karaban, Paulina Prorok, Sonia Baconnais, Sabira Taipakova, Zhiger Akishev, et al.. Mechanism of stimulation of DNA binding of the transcription factors by human apurinic/apyrimidinic endonuclease 1, APE1. DNA Repair, 2019, 82, pp.102698. 10.1016/j.dnarep.2019.102698 . hal-02322130

\section{HAL Id: hal-02322130 https://hal.science/hal-02322130}

Submitted on 21 Dec 2020

HAL is a multi-disciplinary open access archive for the deposit and dissemination of scientific research documents, whether they are published or not. The documents may come from teaching and research institutions in France or abroad, or from public or private research centers.
L'archive ouverte pluridisciplinaire HAL, est destinée au dépôt et à la diffusion de documents scientifiques de niveau recherche, publiés ou non, émanant des établissements d'enseignement et de recherche français ou étrangers, des laboratoires publics ou privés. 


\section{Mechanism of stimulation of DNA binding of the transcription factors by human apurinic/apyrimidinic endonuclease 1, APE1}

Milena BAZLEKOWA-KARABAN ${ }^{a, b, c, 1}$, Paulina PROROK ${ }^{a, b, d, 1}$, Sonia BACONNAIS ${ }^{e}$, Sabira TAIPAKOVAf, Zhiger AKISHEVf, Dominika ZEMBRZUSKA ${ }^{c}$, Alexander V. POPOV ${ }^{g, h}$, Anton V. ENDUTKIN $^{g, h}$, Regina GROISMAN ${ }^{a}$, Alexander A. ISHCHENKO ${ }^{a}$, Bakhyt T. MATKARIMOV ${ }^{i}$, Amangeldy BISSENBAEVf, Eric LE CAM ${ }^{e}$, Dmitry O. ZHARKOV ${ }^{g, h}$, Barbara TUDEK $^{b, c}, *$, and Murat SAPARBAEV $V^{a *}$

a Groupe «Réparation de l'ADN», Equipe Labellisée par la Ligue Nationale Contre le Cancer, CNRS UMR8200, Université Paris-Sud, Gustave Roussy Cancer Campus, F-94805 Villejuif Cedex, France.

${ }^{b}$ Institute of Biochemistry and Biophysics, Polish Academy of Sciences, 02-106 Warsaw, Poland.

${ }^{c}$ Institute of Genetics and Biotechnology, University of Warsaw, Warsaw, Poland.

${ }^{d}$ Institute of Human Genetics, UMR 9002, CNRS and the University of Montpellier, Replication and Genome Dynamics, 141 rue de la Cardonille, 34396, Montpellier, France;

e CNRS UMR8126, Université Paris-Sud, Université Paris-Saclay, Gustave Roussy Cancer Campus, F-94805 Villejuif Cedex, France.

${ }^{f}$ Department of Molecular Biology and Genetics, Faculty of Biology, al-Farabi Kazakh National University, 0530040, Almaty, Kazakhstan.

${ }^{g}$ Institute of Chemical Biology and Fundamental Medicine, SB RAS, Novosibirsk 630090, Russia.

${ }^{h}$ Novosibirsk State University, Novosibirsk 630090, Russia.

${ }^{i}$ National laboratory Astana, Nazarbayev University, Astana 010000, Kazakhstan.

*Corresponding author. M.S.: phone: +33 1 42115404; Email: murat.saparbaev@gustaveroussy.fr

${ }^{1}$ These authors contributed equally to this work.

Keywords: oxidative damage; transcription factors; redox regulation; AP endonuclease; base excision repair; nucleotide incision repair.

\section{HIGHLIGHTS}

- APE1 forms a stable complex with ssDNA longer than 15 mer;

- APE1-catalyzed repair and TF-stimulating activities depend on the structure of DNA duplex;

- APE1 acts synergistically with reducing agents to stimulate DNA binding of AP-1 and p50;

- APE1 stimulates DNA binding of p50-C62S redox-insensitive mutant;

- APE1 forms stable multiprotein oligomers on intrinsically curved DNA regions.

\section{ABBREVIATIONS}

ROS, reactive oxygen species; AP, apurinic/apyrimidinic site; THF, 3-hydroxy-2hydroxymethyltetrahydrofuran or tetrahydrofuran; $\alpha \mathrm{dA}, \alpha$-anomeric 2'-deoxyadenosine; Z, 3nitropyrrole; BER, base excision repair; NIR, nucleotide incision repair; APE1 (a.k.a. APEX1, HAP-1, or Ref-1), human major AP endonuclease 1; Nfo, Escherichia coli endonuclease IV; ARP, Arabidopsis thaliana major AP endonuclease; wARP, wheat Triticum aestivum AP endonuclease. 
Milena BAZLEKOWA-KARABAN et al., Mechanism of stimulation of DNA binding of the transcription factors by human apurinic/apyrimidinic endonuclease 1, APE1.

\section{HIGHLIGHTS}

- APE1 forms a stable complex with ssDNA longer than 15 mer;

- APE1-catalyzed repair and TF-stimulating activities depend on the structure of DNA duplex;

- APE1 acts synergistically with reducing agents to stimulate DNA binding of AP-1 and p50;

- APE1 stimulates DNA binding of p50-C62S redox-insensitive mutant;

- APE1 forms stable multiprotein oligomers on intrinsically curved DNA regions. 


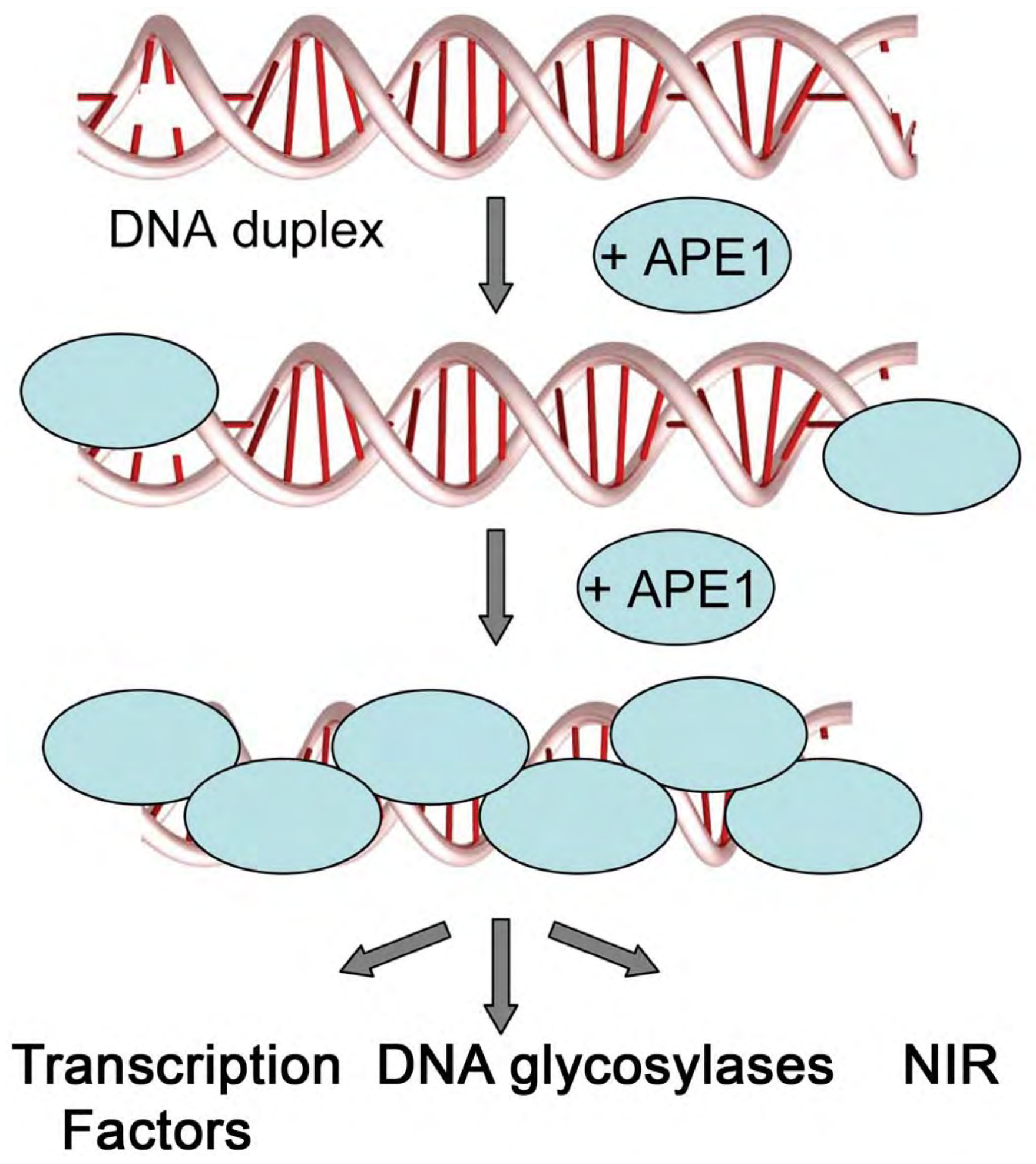




\begin{abstract}
Aerobic respiration generates reactive oxygen species (ROS), which can damage nucleic acids, proteins and lipids. A number of transcription factors (TFs) contain redox-sensitive cysteine residues at their DNA-binding sites, hence ROS-induced thiol oxidation strongly inhibits their recognition of the cognate DNA sequences. Major human apurinic/apyrimidinic (AP) endonuclease 1

(APE1/APEX1/HAP-1), referred also as a redox factor 1 (Ref-1), stimulates the DNA binding activities of the oxidized TFs such as AP-1 and NF- $\mathrm{KB}$. Also, APE1 participates in the base excision repair (BER) and nucleotide incision repair (NIR) pathways to remove oxidative DNA base damage. At present, the molecular mechanism underlying the TF-stimulating/redox function of APE1 and its biological role remains disputed. Here, we provide evidence that, instead of direct cysteine reduction in TFs by APE1, APE1-catalyzed NIR and TF-stimulating activities may be based on transient cooperative binding of APE1 to DNA and induction of conformational changes in the helix. The structure of DNA duplex strongly influences NIR and TF-stimulating activities. Homologous plant AP endonucleases lacking conserved cysteine residues stimulate DNA binding of the p50 subunit of NF$\kappa B$. APE1 acts synergistically with low-molecular-weight reducing agents on TFs. Finally, APE1 stimulates DNA binding of the redox-insensitive p50-C62S mutant protein. Electron microscopy imaging of APE1 complexes with DNA revealed preferential polymerization of APE1 on the gapped and intrinsically curved DNA duplexes. Molecular modeling offers a structural explanation how fulllength APE1 can oligomerize on DNA. In conclusion, we propose that DNA-directed APE1 oligomerization can be regarded as a substitute for diffusion of APE1 along the DNA contour to probe for anisotropic flexibility. APE1 oligomers exacerbate pre-existing distortions in DNA and enable both NIR activity and DNA binding by TFs regardless of their oxidation state.
\end{abstract}

\title{
Significance Statement
}

The major human apurinic/apyrimidinic (AP) endonuclease, APE1, stimulates DNA binding of oxidized transcription factors. At present, the mechanism of stimulation remains unclear. We report that APE1 TF-stimulating activity depends on DNA conformation and acts in a synergistic manner with the reducing agents. Electron microscopy revealed that APE1 generates stable oligomers on intrinsically curved DNA to induce helix distortions. Computer modelling revealed that N-terminal fragment of APE1 can fold into distinct structural model and participate in APE1 multimerization. We propose that the cooperative binding of APE1 to DNA exacerbates pre-existing distortions in the helix to catalyze nucleotide incision and TF-stimulating activities. 


\section{Introduction}

Reactive oxygen species (ROS) generated during oxidative stress react with cellular macromolecules resulting in chemical and structural alterations of nucleic acids, proteins and lipids. In particular, oxidative damage to proteins often results in a loss of their function through the formation of disulfide bonds. Importantly, ROS-mediated protein alterations can be used as a cell signaling system because an increase in $\mathrm{O}_{2}{ }^{\bullet}$ and $\mathrm{H}_{2} \mathrm{O}_{2}$ concentrations activates various signaling pathways through a specific gene expression pattern. Gene expression is controlled by transcription factors (TFs, sequence-specific DNA-binding proteins), which are often regulated by post-translational modifications. Particularly, the DNA-binding activity of mammalian TFs such as AP-1 (Fos/Jun heterodimer protein) and NF- $\kappa \mathrm{B}$ (p50 subunit) is a subject to reduction-oxidation (redox) regulation. This regulation is implemented via post-translational modification of a conserved cysteine residue in the DNA-binding domains of Fos/Jun and p50 [1-2]. Notably, oxidation of the cysteines by ROS strongly inhibits the DNA-binding activities of AP-1 and NF- $\kappa$ B. This inhibition can be reversed by reduction of the cysteines by thiol compounds including thioredoxin, glutaredoxin, glutathione (GSH) and in the case of nuclear proteins, by the multifunctional apurinic/apyrmidinic (AP) endonuclease 1 (APE1/APEX1/HAP1) also referred as the redox factor 1 (Ref-1) [3-4]. Human APE1 is a ubiquitous $36 \mathrm{kDa}$ multifunctional protein that performs essential functions in DNA repair, transcription, RNA biogenesis, and cell proliferation [5-6]. APE1 was independently discovered as an abasic site-specific DNA endonuclease homologous to the E. coli Xth protein [7-8] and as a redox factor (Ref-1) that regulates the DNA-binding domain of the Fos and Jun subunits of the AP-1 protein, the p50 subunit of NF- $\kappa B$ and several other transcription factors [3]. Based on its activities, the APE1 protein can be subdivided into two functionally distinct and partially overlapping regions, with the N-terminal domain 1-127 amino acid residues possessing the TF-stimulating activity and the C-terminal domain 61-318 amino acid residues which are responsible for the AP site cleavage activity [9-10]. Importantly, the first $61 \mathrm{~N}$-terminal amino acid residues of APE1 are essential for stimulation of AP-1, since deletion of the first 40-60 amino acids resulted in more than $90 \%$ loss in DNA binding $[9,11]$.

It was proposed that APE1 activates AP-1 and NF- $\mathrm{BB}$ via a redox mechanism by mediating the reduction of a cysteine residue in their DNA-binding domains. In this model, APE1 uses its C65 amino acid residue to reduce the disulfide bond in another protein [11]. This would lead to formation of a disulfide bond between C65 and C93 of APE1. However, this model is not universally accepted due to a number of contradicting findings. First, crystallographic studies revealed that C65 and C93 are buried inside of the APE1 protein globule and cannot interact with other proteins [12]. Furthermore, none of the other six cysteine residues in APE1 are located appropriately in the 3dimensional structure to facilitate disulfide bond formation with C65 [13]. Second, mutation of either critical C64 residue in mouse APE1, or all seven cysteine residues in human APE1 did not affect the AP endonuclease-mediated stimulation of DNA binding of AP-1 and NF- $\kappa B$ [14-15]. Third, the plant AP endonuclease, the Arabidopsis thaliana ARP protein, which is only distantly related to APE1, stimulates DNA-binding activity of human AP-1 [16]. Noteworthy, ARP lacks the conserved C65, C99, C138, C208 and C296 and shares no or very little homology with the redox domain of APE1, making specific protein-protein interactions with mammalian TFs unlikely. At the same time, in support to the thiol-mediated redox reaction model, it was shown that zebrafish homologue of APE1, Danio rerio zAPE1, which also lacks the conserved C65, cannot stimulate human AP-1 [17]. Furthermore, it has been proposed that human APE1 undergoes significant unfolding to expose cysteine residues to catalyze the redox reaction [18]. At present, the molecular mechanism underlying the TF-stimulating activity of APE1 remains unclear and disputed, and further experiments are required to delineate the precise molecular mechanism of the stimulation of TFs. Indeed, it is not clear whether APE1 directly reduces TFs or acts indirectly as a molecular chaperone to facilitate their reduction.

In addition to protein oxidation, ROS generate non-bulky oxidized DNA bases which are specifically recognized by DNA glycosylases and apurinic/apyrimidinic (AP) endonucleases in the base excision repair (BER) and nucleotide incision repair (NIR) pathways, respectively [19-22]. Human APE1 plays essential roles in the both repair pathways. In BER, it acts downstream of DNA glycosylases by incising a DNA duplex at AP sites and removing 3'-blocking sugar phosphate moieties. Alternatively, in NIR, APE1 makes an incision $5^{\prime}$ to a damaged base and generates a single- 
strand break with a 5'-dangling modified nucleotide and a 3'-hydroxyl group [23-24]. This dichotomy in the repair pathways is explained by the fact that DNA substrate specificity of APE1 is modulated by concentrations of divalent cations, $\mathrm{pH}$, and ionic strength in an apparently allosteric manner [23]. Changes in intracellular $\mathrm{Mg}^{2+}$ concentration induce conformational alterations in the APE1 protein that result in the change in its DNA substrate specificity [23, 25]. Indeed, under low concentrations of $\mathrm{Mg}^{2+}(\leq 1 \mathrm{mM})$ and acidic or neutral $\mathrm{pH}(\leq 7)$, APE1 exerts NIR endonuclease activity. At high concentrations of $\mathrm{Mg}^{2+}(\leq 5 \mathrm{mM})$ and neutral or alkaline $\mathrm{pH}(\geq 8)$, NIR is strongly inhibited, but AP site cleavage activity is dramatically activated mainly due to the increased enzyme turnover rate. Due to these $\mathrm{Mg}^{2+}$ induced changes in protein conformation, APE1 can recognize diverse types of DNA base lesions including $\alpha$-anomeric 2'-deoxynucleotides $(\alpha \mathrm{dN})$ and oxidized pyrimidines $[23,26]$.

The first $42 \mathrm{~N}$-terminal disordered amino acid residues of APE1 are highly enriched in positively charged basic lysine and arginine residues, which can engage in electrostatic interactions with DNA phosphates. Tell and co-workers demonstrated that the first 33 amino acid residues mediate the binding of APE1 to RNA and to negative calcium responsive sequence elements (nCaRE) of certain gene promoters [27-28]. Moreover, the deletion of the first $61 \mathrm{~N}$-terminal amino acid residues of APE1 (APE1-N $\Delta 61$ ) results in a dramatic decrease of the TF-stimulating, NIR and $3^{\prime} \rightarrow 5^{\prime}$ exonuclease, but not in AP site cleavage activity [9, 23, 26]. In our previous study, using SPRi technology we showed that APE1 binds with high efficiency to regular single-stranded (ss), DNA but failed to interact with hairpin DNA [29]. Noteworthy, APE1 showed similar binding affinity for both regular double-stranded (ds) DNA and to damaged dsDNA containing modified residues [29]. These observations may suggest that additional interactions of the N-terminal amino acid residues of APE1 with DNA via binding to ssDNA and possibly to extremities of linear DNA duplexes promote the NIR activity.

Besides the role of redox domain of APE1 in NIR, recent studies by our laboratory revealed that the redox-domain truncated APE1-N $\triangle 61$ protein shows a dramatic decrease in the stimulation of human DNA glycosylases [30], again pointing to a common mechanism of action for the both APE1catalyzed repair and TF-stimulating activities. Furthermore, transmission electron microscopy (TEM) and atomic force microscopy (AFM) imaging of APE1-DNA complexes revealed oligomerization of APE1 along the DNA duplex and APE1-mediated DNA bridging followed by DNA aggregation [30]. Noteworthy, APE1 multimerizes on both undamaged and damaged DNA in apparently cooperative mode. These observations prompted us to investigate the mechanism of APE1-catalyzed stimulation of DNA binding of the Fos/Jun subunits of AP-1 heterodimer and the p50 subunit of NF-kB. Here we demonstrate that APE1 TF-stimulating function depends on DNA conformation and acts in a synergistic manner with the reducing agents. Two homologous plant AP endonucleases lacking six out of seven conserved cysteine residues stimulate DNA binding of the human p50 subunit. TEM demonstrates that APE1 can oligomerize onto a circular, linear gapped and intrinsically curved duplex DNA. Furthermore, APE1 can stimulate DNA binding of the redox-insensitive p50-C62S mutant protein. The structural basis, evolutionary conservation and potential biological importance of the APE1-catalyzed stimulatory function of TFs which link the DNA repair and transcription regulation are discussed. 


\section{Materials and Methods}

\subsection{Oligonucleotides and proteins}

Sequences of all the oligodeoxyribonucleotides used in this work are shown in Table 1. All the oligonucleotides were purchased from Eurogentec (Seraing, Belgium) including those containing tetrahydrofuran (THF), alpha-anomeric 2'deoxyadenosine ( $\alpha \mathrm{dA})$ and 3'-nitropyrrole $(\mathrm{Z})$. The complementary oligonucleotides contained either $\mathrm{T}$ or $\mathrm{Z}$ opposite the lesion. Prior to enzymatic assays, oligonucleotides were either 3'-end-labeled by terminal deoxynucleotidyl transferase (New England Biolabs, France) in the presence of $\left[\alpha^{-32} \mathrm{P}\right] 3$ '-dATP (cordycepin 5'-triphosphate, 5,000 Ci/mmol) or 5'end-labeled by means of T4 polynucleotide kinase (New England Biolabs) in the presence of $[\gamma$ ${ }^{32}$ P]ATP (3,000 Ci/mmol, PerkinElmer - Life Science Research, Courtaboeuf, France), as recommended by the manufacturers. The radioactively labeled oligonucleotides were desalted on a Sephadex G-25 column equilibrated with water and then annealed to a desired complementary strand for $3 \mathrm{~min}$ at $95^{\circ} \mathrm{C}$ in a buffer consisting of $20 \mathrm{mM}$ HEPES-KOH (pH 7.6) and $50 \mathrm{mM} \mathrm{KCl}$ and then slowly cooled to room temperature.

Purified human APE1, E. coli Nfo, Arabidopsis thaliana and wheat Triticum aestivum major AP endonucleases (ARP and wARP, respectively) were from the laboratory stock. Nfo, ARP and wARP were purified as described elsewhere [31-32]. Human major AP endonuclease APE1 and its mutant version APE1-N $\triangle 61$ were expressed and purified in their native form without tags or other modifications as described previously [26]. The histidine-tagged C-terminal truncated version of APE1 (APE1-C $\Delta 128$ ) comprising amino acids 1-190 (containing the redox domain) were expressed in E. coli BL21 (DE3) Rosetta 2 strain (Merck) harbouring pET28c-APE1-C $\Delta 128$ plasmid vector and purified using HiTrap Chelating HP column (GE Healthcare) chromatography, as recommended by the manufacturer.

\subsection{Preparation of the purified transcription factors}

The pDS56-6xHis vectors: wbFos and wbJun, carrying gene fragments encoding C-terminal DNA-binding and leucine-zipper domains of rat Fos and Jun proteins, respectively, were a kind gift of Dr Tom Curran (The Children's Hospital of Philadelphia, U.S.A.) [33]. pET14b plasmid with cloned gene encoding the wild-type p50 subunit of NF-кB protein was a kind gift of Dr Hiroshi Handa (Tokyo Institute of Technology, Japan) [34]. Site-directed mutation within the p50 coding sequences in pET14b-p50 was generated using the QuikChange site-directed mutagenesis kit (Quickchange ${ }^{\circledR}$ XL, Site-Directed Mutagenesis Kit, Stratagene). The following oligonucleotide primers (shown in the $5^{\prime} \rightarrow 3^{\prime}$ direction) were used to generate p50-C62S mutant protein: Forward, d(GTTTCCGTTATGTATCTGAAGGCCCATCCCA) and Reverse, d(TGGGATGGGCCTTCAGATACATAACGGAAAC).

The c-Fos, c-Jun, p50, p50-C62S proteins were expressed and purified from E. coli BL21 (DE3) Rosetta 2 strain (Merck) harbouring wbFos, wbJun, pET14b-p50-WT and pET14b-p50-C62S respectively. Briefly, single colonies were picked and inoculated in $40 \mathrm{ml}$ of LB with $50 \mu \mathrm{g} \cdot \mathrm{ml}^{-1}$ ampicillin and grown overnight in orbital shaker at $37^{\circ} \mathrm{C}$. The overnight culture was diluted at the 1:100 ratio in 2 liters of fresh LB with $50 \mu \mathrm{g} \cdot \mathrm{mL}^{-1}$ ampicillin and grown at $37^{\circ} \mathrm{C}$ in orbital shaker $(250$ $\mathrm{rpm}$ ) to $\mathrm{OD}_{600}=0.6$ and then induced by $400 \mu \mathrm{M}$ isopropyl $\beta$-D-1-thiogalactopyranoside (IPTG) for $16 \mathrm{~h}$ at $30^{\circ} \mathrm{C}(100 \mathrm{rpm})$. Bacteria were harvested by centrifugation and cell pellets were lysed using a French press at 14,000 psi in a buffer containing $20 \mathrm{mM}$ HEPES-KOH pH 7.6, $40 \mathrm{mM} \mathrm{NaCl}, 0.1 \%$ NP-40 supplemented with Complete Protease Inhibitor Cocktail (Roche Diagnostics, Switzerland). The lysates were cleared by centrifugation at $40,000 \times g$ for $1 \mathrm{~h}$ at $4^{\circ} \mathrm{C}$, the resulting supernatant was adjusted to $500 \mathrm{mM} \mathrm{NaCl}$ and $40 \mathrm{mM}$ imidazole and loaded onto a HiTrap Chelating HP column (GE Healthcare) charged with $\mathrm{Ni}^{2+}$. The proteins were eluted using linear gradient of buffer $\mathrm{B}(20 \mathrm{mM}$ HEPES-KOH pH 7.6, $500 \mathrm{mM} \mathrm{NaCl}, 500 \mathrm{mM}$ imidazole), fractions containing the recombinant proteins were pooled and stored at $-80^{\circ} \mathrm{C}$ in $10 \%$ glycerol. The homogeneity of the protein preparations was verified by SDS-PAGE. It should be noted that the recombinant APE1, c-Fos, c-Jun, p50 and p50-C62S proteins were purified in the buffers lacking reducing agents in order to obtain oxidized forms of TFs which unable to bind to DNA as described in [35]. In addition, the purified 


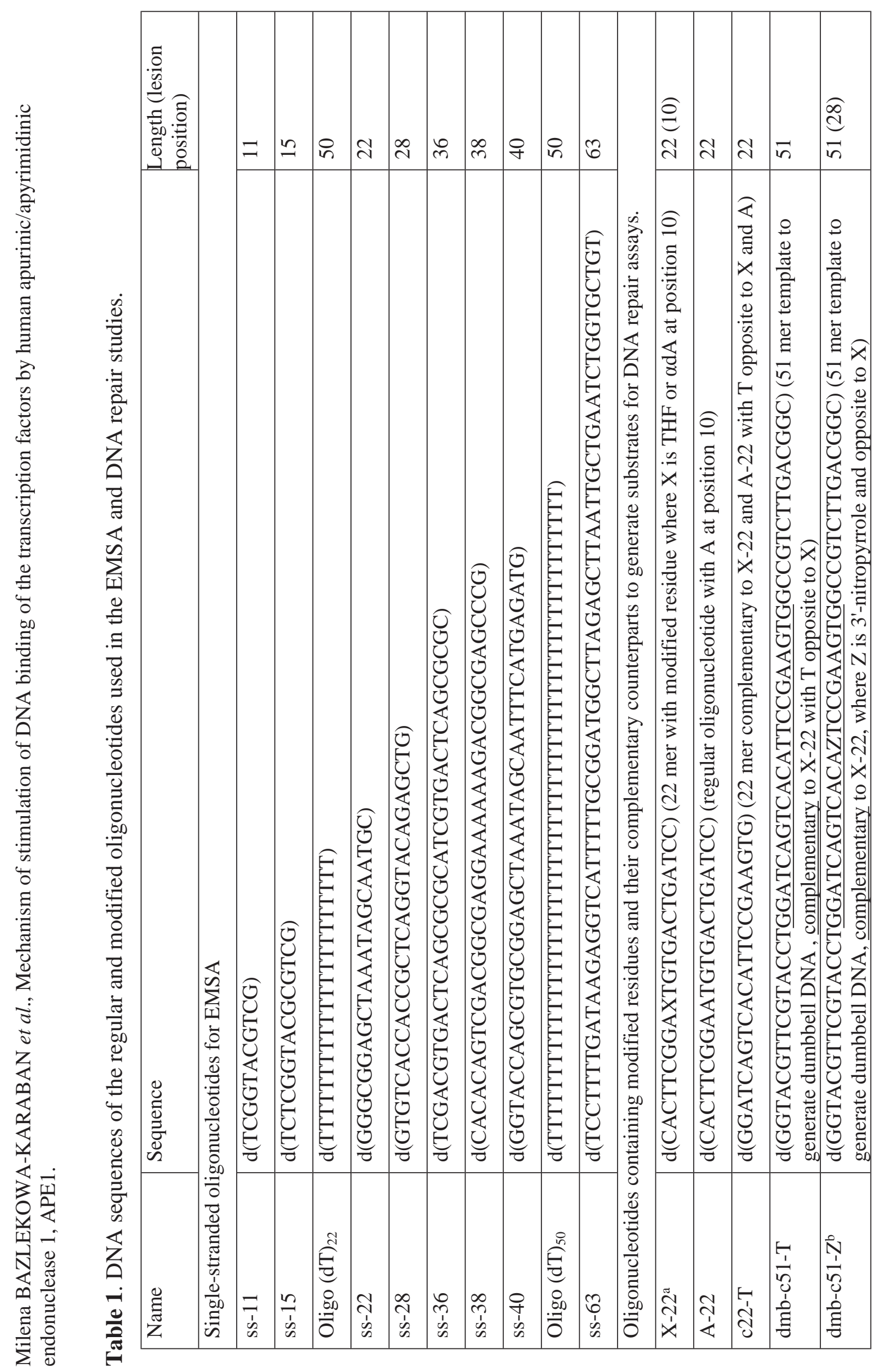




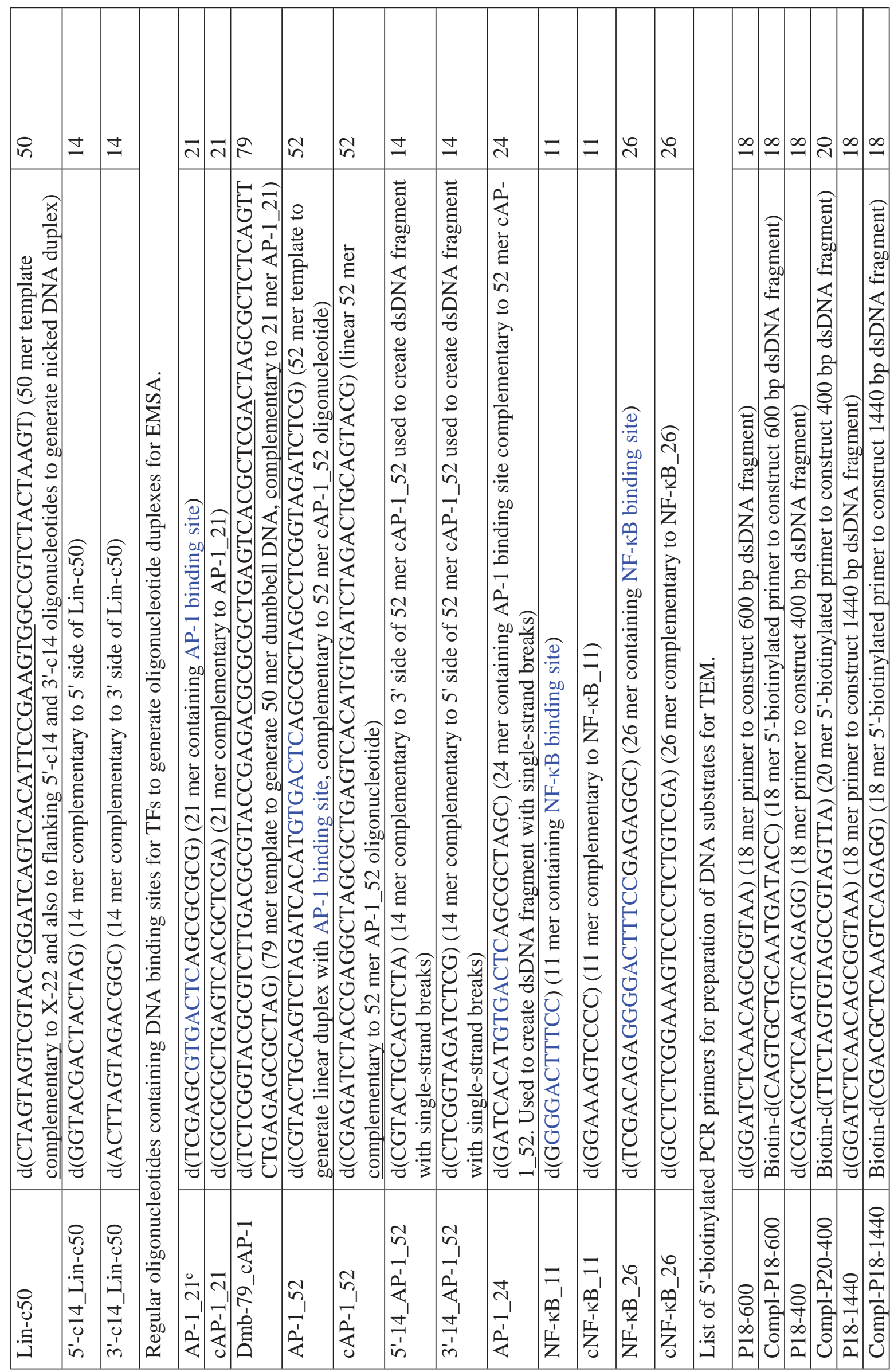




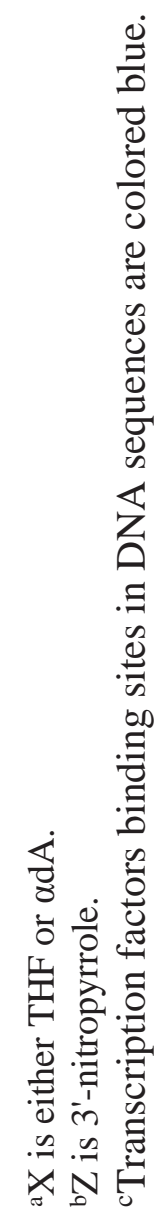


redox-insensitive mutant p50-C62S protein was treated with $70 \mu \mathrm{M}$ diamide for $30 \mathrm{~min}$ at $16^{\circ} \mathrm{C}$ to ensure the complete oxidation of cysteine residues.

\subsection{DNA repair assays}

The standard AP endonuclease assay was conducted at a high $\mathrm{Mg}^{2+}$ concentration $(\geq 5 \mathrm{mM})$ and $\mathrm{pH} 7.6$ (BER conditions): the reaction mixture $(20 \mu \mathrm{L})$ consisted of $10 \mathrm{nM}^{32} \mathrm{P}$-labeled THF•T duplex oligonucleotide, $5 \mathrm{mM} \mathrm{MgCl} 2,100 \mathrm{mM} \mathrm{KCl}, 20 \mathrm{mM}$ Hepes-KOH pH 7.6, $0.1 \mathrm{mg} \cdot \mathrm{mL}^{-1} \mathrm{BSA}$ and $0.1 \mathrm{nM}$ enzyme, unless specified otherwise. The standard NIR assay was performed at a low $\mathrm{Mg}^{2+}$ concentration $(\leq 1 \mathrm{mM})$ and acidic/neutral $\mathrm{pH}(\leq 7)$ (NIR conditions): the reaction mixture $(20 \mu \mathrm{L})$ consisted of $10 \mathrm{nM}{ }^{32} \mathrm{P}$-labeled $\alpha \mathrm{dA} \cdot \mathrm{T}$ duplex oligonucleotide, $0.1 \mathrm{mM} \mathrm{MgCl}_{2}, 25 \mathrm{mM} \mathrm{KCl}, 20 \mathrm{mM}$ Hepes- $\mathrm{KOH} \mathrm{pH}$ 6.8, $0.1 \mathrm{mg} \bullet \mathrm{mL}^{-1} \mathrm{BSA}$ and $2 \mathrm{nM}$ APE1, unless specified otherwise. The reaction mixture $(20 \mu \mathrm{L})$ for the $E$. coli $\mathrm{Nfo}$ protein contained $50 \mathrm{mM} \mathrm{KCl}, 20 \mathrm{mM}$ HEPES-KOH (pH 7.6), 0.1 $\mathrm{mg} \bullet \mathrm{mL}^{-1} \mathrm{BSA}, 1 \mathrm{mM}$ DTT and $1 \mathrm{nM} \mathrm{Nfo}$, unless specified otherwise. All the reactions were stopped by addition of $10 \mu \mathrm{L}$ of a stop solution consisting of $0.5 \%$ SDS and $20 \mathrm{mM}$ EDTA.

After the reactions, all the samples were desalted on hand-made spin-down columns filled with Sephadex G25 (Amersham Biosciences) equilibrated with 7.5 M urea. The purified reaction products were separated by electrophoresis in a denaturing $20 \%(\mathrm{w} / \mathrm{v})$ polyacrylamide gel ( $7.5 \mathrm{M}$ urea, $0.5 \times$ Tris-borate-EDTA buffer, $42{ }^{\circ} \mathrm{C}$ ). The gels were exposed to a Storage Fuji FLA-3000 Phosphor Screen, which was then scanned using Typhoon FLA 9500, and the digital images were obtained and quantified in the FUJI Image Gauge v.4.0 software. At least three independent experiments were conducted for all kinetic measurements.

\subsection{Electrophoretic Mobility Shift Assay (EMSA)}

The EMSA buffer for APE1 binding to ssDNA and dsDNA $(20 \mu \mathrm{l})$ contained $10 \mathrm{mM}$ Tris- $\mathrm{HCl}$ (pH 7.5), $50 \mathrm{mM} \mathrm{NaCl}, 1 \mathrm{mM}$ EDTA, $5 \%$ glycerol, $5 \%$ saccharose, $0.01 \% \mathrm{NP}-40$ and $0.1 \mathrm{mg} \cdot \mathrm{mL}^{-1}$ BSA. After mixing the EMSA buffer with $2 \mathrm{nM}$ of 5'-[ $\left.{ }^{32} \mathrm{P}\right]$-labelled oligonucleotides and varying amounts of poly $(\mathrm{dI}-\mathrm{dC}) \bullet \operatorname{poly}(\mathrm{dI}-\mathrm{dC})(0-100 \mathrm{ng})$ and APE1 $(0-500 \mathrm{nM})$ the reactions were incubated for $30 \mathrm{~min}$ at $6^{\circ} \mathrm{C}$. The EMSA mixture for AP-1 $(20 \mu \mathrm{l})$ contained $10 \mathrm{mM}$ Tris- $\mathrm{HCl}(\mathrm{pH} 7.5), 50 \mathrm{mM}$ $\mathrm{NaCl}, 5 \mathrm{mM} \mathrm{MgCl}{ }_{2}, 1 \mathrm{mM}$ EDTA, $5 \%$ glycerol, $5 \%$ saccharose, $0.01 \% \mathrm{NP}-40,0.1 \mathrm{mg} \cdot \mathrm{mL}^{-1} \mathrm{BSA}, 5$ $\mathrm{nM}$ of 5'-[32P]-labelled duplex oligonucleotide, either 0.1-1.0 mM DTT or 1-5 mM GSH (as reducing agents), 250-500 nM APE1 and 250-500 nM AP-1 heterodimer c-Fos/c-Jun (as transcription factors). The EMSA mixture for NF- $\kappa B$ subunit p50 $(20 \mu \mathrm{l})$ contained $20 \mathrm{mM}$ HEPES-KOH (pH 7.9), $100 \mathrm{mM}$ $\mathrm{KCl}, 0.2 \mathrm{mM}$ EDTA, $0.1 \% \mathrm{NP}-40,10 \%$ glycerol, $5 \mathrm{nM}$ of 5'-[ $\left.{ }^{32} \mathrm{P}\right]$-labelled oligonucleotides, 250-500 $\mathrm{nM}$ APE1 and 5-50 nM p50. Prior to incubation with DNA, $1 \mu \mathrm{M}$ c-Fos, c-Jun and p50 proteins were incubated in their respective EMSA buffer $(25 \mu \mathrm{L})$ at $37^{\circ} \mathrm{C}$ for $25 \mathrm{~min}$ in the presence or absence of reducing agents, and then $1 \mu \mathrm{g}$ of poly $(\mathrm{dI}: \mathrm{dC}) \bullet \operatorname{poly}(\mathrm{dI}: \mathrm{dC})$ was added to each mixture and incubated further for $5 \mathrm{~min}$ at room $\mathrm{T}^{\circ} \mathrm{C}$. After, the reaction mix containing radio-labeled DNA, APE1, TFs, poly $(\mathrm{dI}: \mathrm{dC}) \bullet \operatorname{poly}(\mathrm{dI}: \mathrm{dC})$ and reducing agents were incubated further for $30 \mathrm{~min}$ at room temperature. The binding reactions were stopped by putting on ice and adding $6 \mu \mathrm{L}$ of $80 \%$ glycerol and loading immediately the mixture on native, non-denaturing $8 \%$ polyacrylamide gel (PAG) (AA:BA=80:1) in 1xTris-glycine buffer (195 mM Glycine and $25 \mathrm{mM}$ Tris Base). The DNA/protein complexes were separated from free DNA by electrophoresis at constant $80 \mathrm{~V}$ for $12-14 \mathrm{~h}$ at $4^{\circ} \mathrm{C}$.

Exposure of protein/DNA complexes to ultraviolet light (UV) generates covalent bonds between the DNA bases and certain amino acids in close contact with the DNA molecule [36]. Here, we used UV crosslinking to characterize the interactions between APE1 and synthetic oligonucleotides. The reaction mixture contained 1 or $2 \mu \mathrm{M}$ APE1, $200 \mathrm{nM}$ of 5'-[32P]-labelled oligo $(\mathrm{dT})_{22}$ or oligo $(\mathrm{dT})_{50}, 20 \mathrm{mM}$ HEPES-NaOH (pH 7.5), $50 \mathrm{mM} \mathrm{KCl} 50 \mathrm{mM}, 5 \mathrm{mM} \mathrm{MgCl}_{2}$, and $1 \mathrm{mM}$ DTT. The samples $(30 \mu \mathrm{l})$ were exposed to UV irradiation $(254 \mathrm{~nm})$ in a Bio-Link crosslinker (Vilber Lourmat, Collégien, France) for $30 \mathrm{~min}$ at $0.5 \mathrm{~J} /\left(\mathrm{cm}^{2} \cdot \mathrm{min}\right)$ on ice. Fifteen $\mu 1$ of the loading dye $(62.5 \mathrm{mM}$ Tris$\mathrm{HCl} \mathrm{pH} 6.8,10 \%$ glycerol, $2 \%$ SDS, 5\% 2-mercaptoethanol, $12.5 \mu \mathrm{g} / \mathrm{ml}$ bromophenol blue) was added, the samples were heated for $5 \mathrm{~min}$ at $95^{\circ} \mathrm{C}$ and resolved by discontinuous SDS-PAGE.

After electrophoresis the gels were exposed to a Storage Fuji FLA-3000 Phosphor Screen, which was then scanned using Typhoon FLA 9500 and digital images were obtained as described 
above. At least three independent experiments were conducted for all quantitative measurements. Statistical analysis was performed using independent two-sample Student's t-test. P values $<0.05$ were considered significant. Single asterisks denote $0.01<\mathrm{P}<0.05$ as statistically significant, double asterisks denote $\mathrm{P}<0.01$ as very significant and "ns" denotes $\mathrm{P}>0.05$ as non-significant.

\subsection{Equipment and settings.}

The acquisition of images of denaturing PAGE and non-denaturing PAGE gels was performed by exposure to a Storage Phosphor Screen BAS (GE Healthcare Life Sciences) overnight. Phosphor Screens were then imaged using the Typhoon ${ }^{\mathrm{TM}}$ FLA 9500 Laser Scanner (GE Healthcare Life Sciences) with an pixel resolution of $100 \mu \mathrm{M}$. Retrieved images in TIFF format were then processed in Adobe Photoshop CS6 software, to adjust brightness and contrast settings for appropriate visualisation of ${ }^{2}{ }^{32} \mathrm{P}$ labelled DNA. Consistent adjustment of brightness and contrast was used across the entirety of the gel image. Quantification of DNA binding and cleavage was facilitated by use of the FUJIFILM Science Lab Image Gauge Ver. 4.0 software (Fujifilm), with quantification adjusted by removal of standardised background values on each gel image. GraphPad Prism 7 software was used for the generation of graphical representations of percentage of DNA binding and cleavage quantifications. Schema were generated with use of Adobe Photoshop CS6.

\subsection{Electron microscopy}

Transmission electron microscopy (TEM) samples were prepared by positive staining as previously described [37]. All nucleoprotein complexes were formed by incubation at $4^{\circ} \mathrm{C}$ for $10 \mathrm{~min}$ in binding buffer $(10 \mathrm{mM}$ Tris- $\mathrm{HCl} \mathrm{pH} 8,50 \mathrm{mM} \mathrm{NaCl})$ containing $5 \mathrm{nM}$ of DNA fragment in the presence of varying concentrations of APE1-WT or APE1-C $\Delta 128$ proteins. After incubation the complexes were purified on Superpose 6 gel filtration column using a SMART chromatography system (GE Healthcare Life Sciences). The purified samples were immediately spreading on the microscopy grid (600-mesh copper grid coated with a thin carbon film) pre-activated by glowdischarge in the presence of amylamine (Sigma-Aldrich, France). The grids were washed with aqueous $2 \%(\mathrm{w} / \mathrm{v}$ ) uranyl acetate (Merck, France) and then dried with ashless filter paper (VWR, France). TEM examination was carried out under a Zeiss $912 \mathrm{AB}$ transmission electron microscope in filtered crystallographic dark-field mode. Electron micrographs were captured using Tengra highresolution CCD camera and iTEM software (Olympus, Soft Imaging Solutions).

\subsection{DNA preparation for TEM}

The double-stranded DNA (dsDNA) fragments (1440, 600 and $400 \mathrm{bp}$ dsDNA) were obtained by PCR amplification of a region of the PBR322 plasmid and were purified on a Mini Q anion exchange column using a SMART chromatography system (GE Healthcare Life Sciences). PCRs were done using biotinylated 5' primers (Sigma) indicated in Table 1 and the Taq polymerase (New England Biolabs, France) in order to generate blunt-ended products. The purified dsDNA fragments were precipitated with ethanol and re-suspended in TE buffer (10 mM Tris-HCl pH 7.5, 1 mM EDTA). Linear $1440 \mathrm{bp}$ dsDNA containing a specific intrinsic curvature called $\mathrm{C} 7$ region was prepared as described [37-38]. Linear 1440 bp fragment containing a single-stranded gap of $440 \mathrm{nt}$ at the center with two adjacent dsDNA regions of $600 \mathrm{bp}$ and $400 \mathrm{bp}$ was prepared as follows, the purified 5'biotinylated 1440, 600 and 400 bp dsDNA fragments were injected on affinity column (Hi-Trap streptavidin HP, GE Healthcare Life Sciences) and then the 1440, 600 and 400 ssDNA fragments were eluted and hybridized to form the gapped linear 1440 bp DNA fragment.

The supercoiled DNA (scDNA) was a commercial negatively supercoiled plasmid pUC19 (New England Biolabs, France).

\subsection{Molecular modeling}

Elastic network analysis of vibrational motions in APE1 structures [39-40] was done using Anisotropic Network Model Web Server v2.1 [41-42]. Twenty lowest-frequency normal modes were calculated with a $15 \AA$ cutoff for interaction between the network nodes. Ab initio folding of the N- 
terminal fragment of human APE1 (46 amino acid residues, APE1 $1_{1-46}$ ) was done using QUARK [4344]. Ten best-scoring models were subject to rigid body protein-protein docking with the structure of free APE1 (PDB ID 1BIX [45]) lacking the first 31 residue and additionally truncated to start with Asp47 (APE1 47-318). Protein-protein docking was performed using GRAMM-X server [46-47]. Homology modeling of APE1 catalytic domain (Leu62-Leu316) was done using SWISS-MODEL [48] with human and mouse TDP2 s templates (PDB IDs 5INL, 5INO, 5INP, and 5INQ [49].

Full-length APE1 model (APE1 $1_{\text {full }}$ ) was assembled into tetramers by repeatedly docking the $\mathrm{APE}_{1-46}$ fragment onto APE1 $1_{\text {full }}$. Four 15-mer DNA duplexes containing a lesion were taken from the crystal structure of APE1 ${ }_{40-318}$-DNA complex (PDB ID 1DEW), aligned using Kabsch algorithm [50] and incorporated into the tetramer model with THF moieties changed to AP sites. The final model preparation and refinement was performed in LEaP, a part of the AMBER Tools Package. The force field parameters for AP site were kindly communicated by Dr. Carlos Simmerling (Stony Brook University). Energy of the model was minimized in 2500 steps of steepest descent method followed by 2500 steps of conjugate gradients method using Sander, a part of the AMBER Tools Package. 


\section{Results}

\subsection{Differential binding of APE1 to single- and double-stranded DNA oligonucleotides in gel- shift assay}

Previously, using Surface Plasmon Resonance imagery (SPRi) we demonstrated that APE1 binds to non-damaged linear single-stranded (ss) DNA with higher efficiency as compared to doublestranded (ds) DNA fragments [29]. Noteworthy, APE1 failed to bind to a regular hairpin structured DNA oligonucleotide that lacks double-stranded ends [29]. Here, we used electrophoretic mobility shift assay (EMSA) to study the interaction of APE1 with DNA and the role of APE1/DNA complexes in the AP endonuclease-dependent stimulation of DNA binding of transcription factors. To characterize the binding of APE1 to ssDNA, $2 \mathrm{nM}$ of 5'-[ $\left.{ }^{32} \mathrm{P}\right]$-labelled oligonucleotide of varying lengths (from 11 to 63 nucleotides) was incubated in the presence of $500 \mathrm{nM} \mathrm{APE} 1$, and formation of the APE1/ssDNA complexes were analyzed by EMSA. As shown in Fig. 1, APE1 binds in a stable manner to 22 mer and other longer ssDNA fragments, generating high-molecular weight APE1/ssDNA complexes in the gel (lanes 6, 8, 10,12, 14 and 16), but not to 11 and 15 mer fragments (lanes 2 and 4). Close analysis of the migration pattern of APE1/ssDNA complex in the gel points to the presence of a multi-protein organization with several molecules of APE1 bound to a single ssDNA molecule. Also, note that 22 mer oligonucleotide contains small amount of impurity which migrates more slowly than the major band (lane 5).

In our precedent work, by employing EMSA we showed that APE1 binds to short duplex oligonucleotides in transient and unstable manner, generating a smeared pattern of migration of the DNA bands in the native gel [29]. Here, we examined APE1 binding to varying concentration of the regular, non-damaged 22 mer ssDNA, 22 mer dsDNA and 51 mer dumbbell shaped oligonucleotide (dmbDNA). As expected, APE1 binds to ssDNA and forms a stable APE1/ssDNA complex in the EMSA gel (Fig. 2, lanes 2-6). Noteworthy, formation of the stable APE1/ssDNA complex, when more than $50 \%$ of ssDNA fragments are in bound state, is the most efficient under high molar excess of APE1 over DNA (molar ratio of ssDNA/APE1 from 1/100 to 1/500) (Fig. 2, lanes 2-4 and SI Appendix, Table S1). Whereas, the decrease of the ssDNA/APE1 molar ratio down to 1/10 and 1/5 due to the increase of ssDNA concentration, resulted in the disappearance of the super-shifted DNA band (lanes 7-8 and SI Appendix, Table S1), possibly due to the insufficient concentration of APE1 to form a stable APE1/ssDNA complex. Incubation of APE1 with 5'-[32P]-labelled 22 mer duplex and 51 mer dmbDNA produced highly smeared super-shifted bands on the EMSA gel, suggesting that APE1 fails to form stable protein/DNA complexes with dsDNA and dmbDNA in the gel (lanes 10-16 and 18-23). Noteworthy, the migration patterns of the APE1/dsDNA complexes in the gel indicate that at high molar excess of APE1 to DNA (ratio 1/500 and 1/100) dmbDNA exhibited more smearing as compared to that of the duplex oligonucleotide (lanes 10-11 versus 18-19 and SI Appendix, Table S1). Our data with dsDNA are in agreement with the previous studies which demonstrated that under the conditions used for EMSA, APE1 does not interact with dsDNA oligonucleotide probe containing recognition site for a TF $[3,9,11,17-18]$. Nevertheless, we may suggest that highly smeared appearance of dsDNA bands on the native gels is due to transient, unstable APE1/dsDNA interactions such as inter-molecular bridges occurring between different DNA molecules and oligomers along dsDNA as previously described [30].

\subsection{Characterization of APE1 binding to single-stranded oligo (dT) by UV crosslinking}

The 22-63 mer ssDNA oligonucleotides used in our work can, in principle, adopt secondary structures, which may influence the formation of a stable APE1/ssDNA complexes detected by EMSA. Noteworthy, previous studies have shown that APE1 recognizes AP site in ssDNA substrates that can adopt secondary structures, and cleaves such ssDNA with higher efficiency than dsDNA [51]. On the contrary, APE1 has a low affinity for oligo (dA) and oligo (dT) oligonucleotides containing a defined AP site, implying that the presence of secondary structures is important for APE1 binding to damaged ssDNA [52]. It is, however, unclear to what extent secondary structures are important for interactions between APE1 and undamaged DNA. To examine the role of structural properties of DNA in the APE1 binding, we used 22- and 50-mer oligo (dT), which do not form secondary structure and can also be used for UV crosslinking to proteins. EMSA showed that APE1 binds oligo (dT) 22 with an 

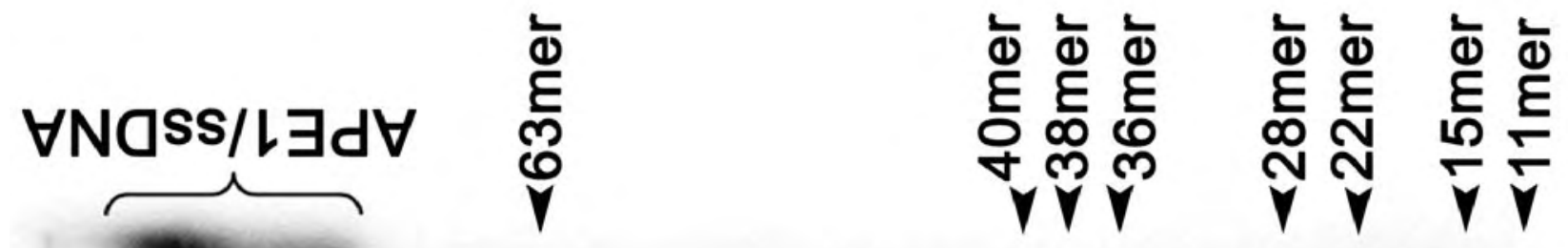

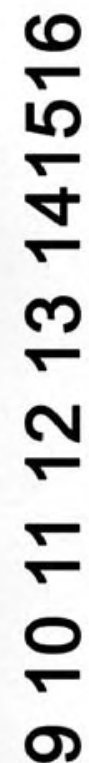

$\infty$

$N$

6

م

A

$\checkmark$

$m$

온

N 
o!̣ed sejou

I $\exists d \forall: \forall N O$

$$
\text { G:L }
$$

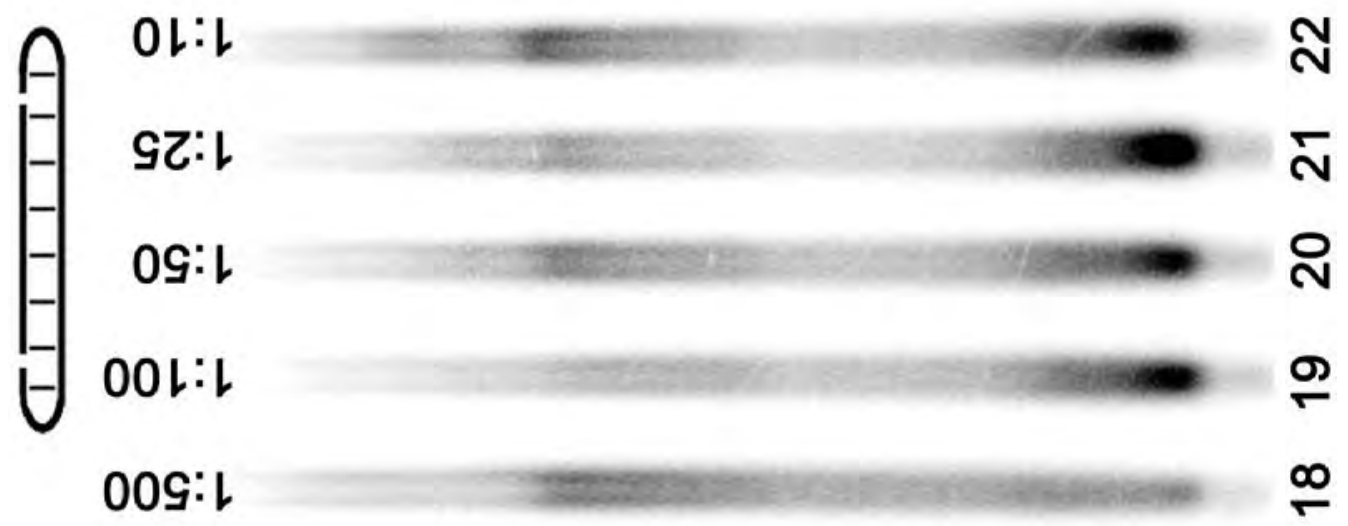

$0: 1$

G:L №sp/L

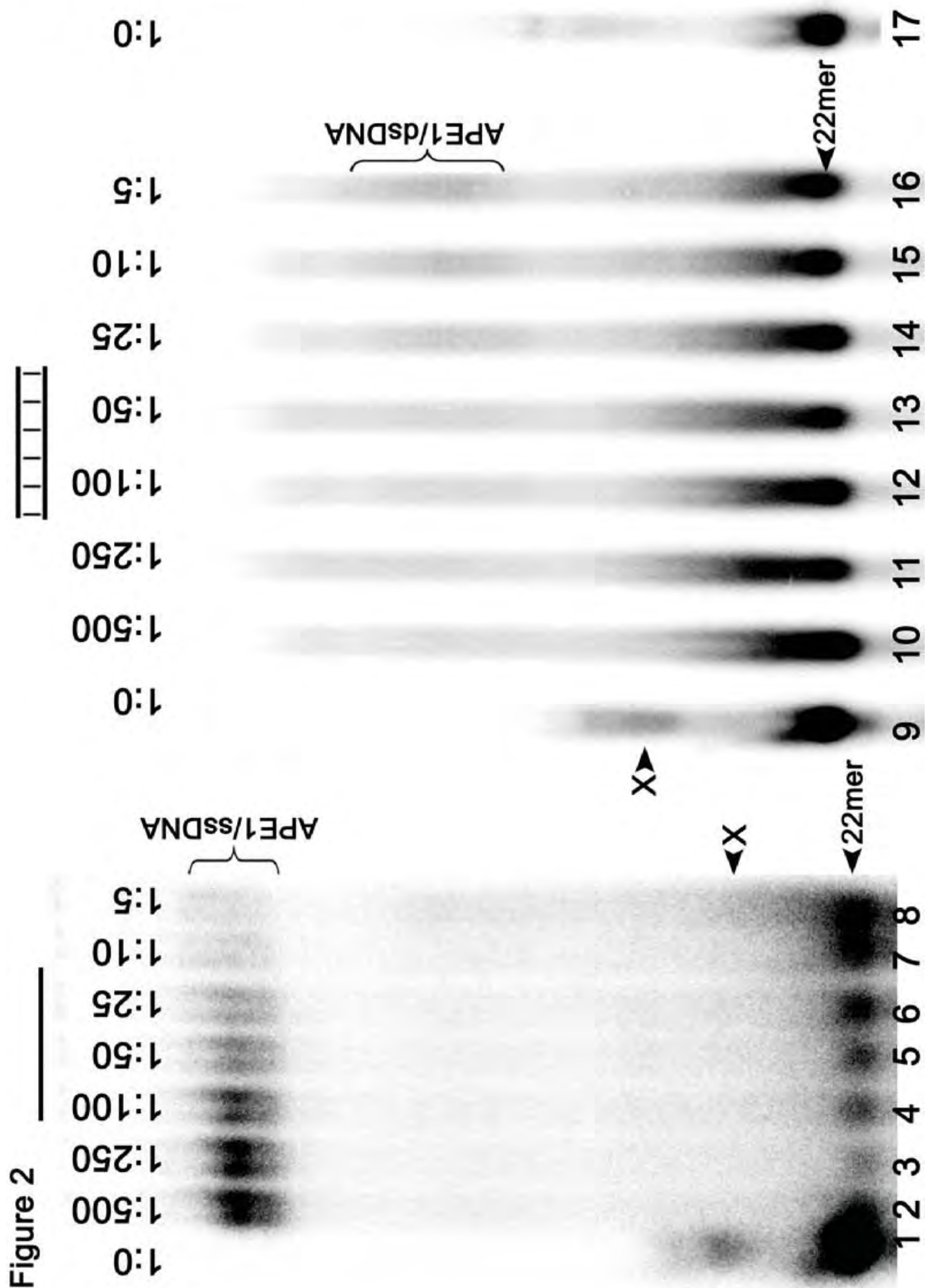




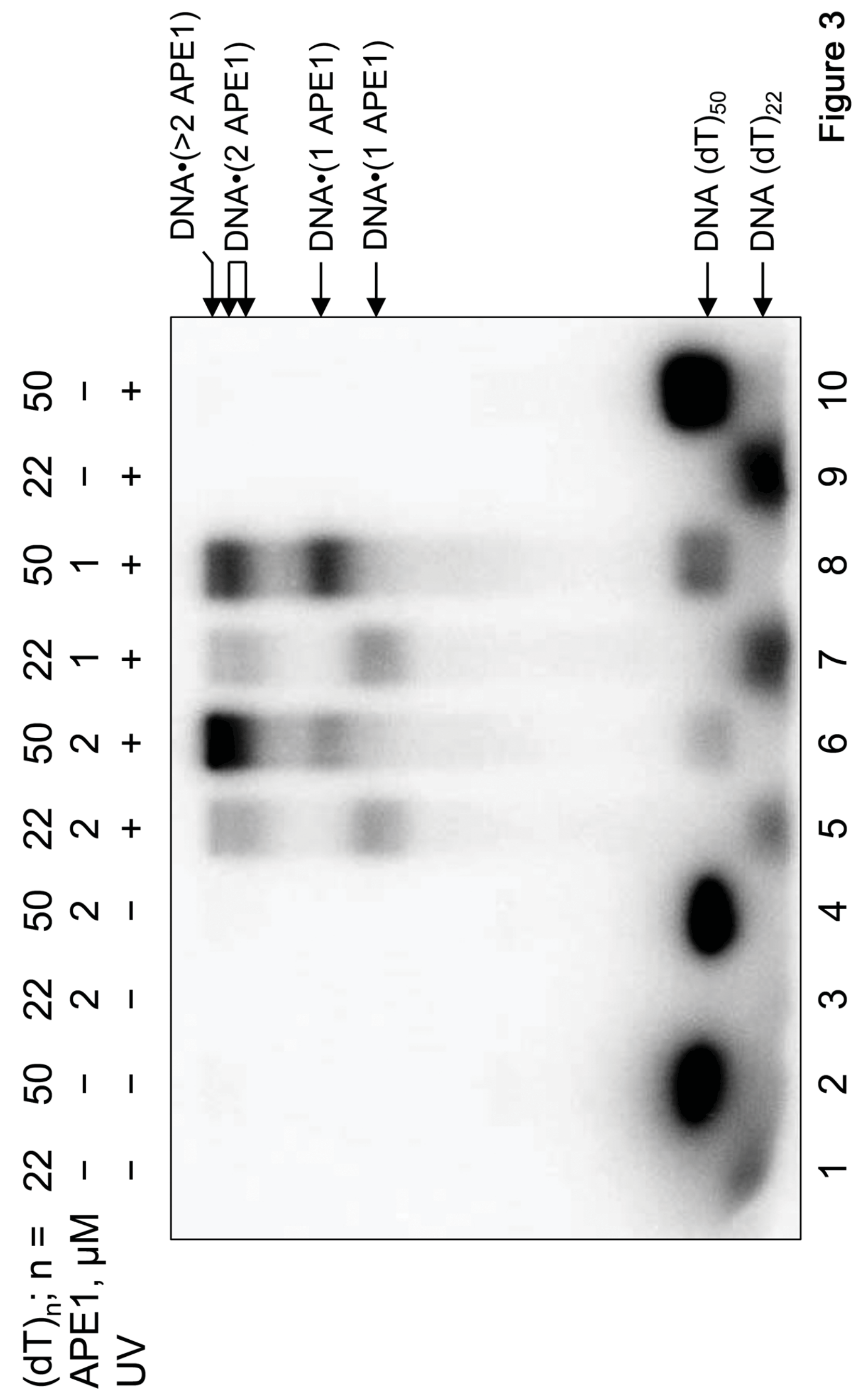


efficiency similar to the mixed-sequence 22-mer ssDNA oligonucleotide (SI Appendix, Fig. S1). This result strongly suggests that secondary structures present in ssDNA do not play a significant role in APE1 binding and the stability of APE1/DNA complexes.

As discussed above, the migration pattern of APE1/ssDNA complexes in the gel is consistent with cooperative binding of APE1 to DNA. We have studied the stoichiometry of APE1/ssDNA interactions by UV-crosslinking, taking advantage of the efficient APE1 binding to oligo (dT), in which thymine residues are prone to form covalent linkages with proteins upon UV irradiation. As expected, SDS-PAGE analysis of the protein/DNA complexes generated after irradiation of APE1/oligo mixtures with UV (254 nm) revealed efficient crosslinking of APE1 to both 22 and 50 mer oligonucleotides (Figure 3, lanes 5-8). At both $1 \mu \mathrm{M}$ and $2 \mu \mathrm{M}$, APE1 crosslinks to oligo (dT) ${ }_{22}$ predominantly as a monomer, but dimers and higher-order oligomers can be also detected (lanes 5 and 7). With a longer oligo (dT) $)_{50}$, at $2 \mu \mathrm{M}$ APE1 preferentially crosslinks as an oligomer with two and more protein molecules bound to DNA (lane 6), and even at $1 \mu \mathrm{M}$ dimers and oligomers constitute about half of the cross-linked species (lane 8). No protein/DNA complexes were detected in absence of UV irradiation or the APE1 protein (lanes 1-4 and 9-10). Taken together, these results suggest that APE1 can bind to sufficiently long ssDNA in an apparently cooperative manner.

\subsection{APE1-catalyzed repair activities on dumbbell-shaped and linear DNA duplexes containing adA and synthetic AP site}

In our earlier SPRi study, we showed that APE1 fails to stably associate with hairpin-shaped DNA duplex immobilized on the chip, but not to that of regular linear DNA duplex [29]. Also, the EMSA reveals that APE1 produces aberrant unstable complexes with dmbDNA (Figure 2). Based on these observations, we propose that DNA structure may influence APE1-catalyzed DNA repair activities. To examine this, we constructed DNA substrates with various shapes containing either single THF or $\alpha \mathrm{dA}$ residue, namely: linear 22 mer duplex with blunt ends; 51 mer dumbbell shaped DNA fragment (dmbDNA), which has a hairpin structure at both ends and composed of a long 51 mer hairpin template strand and a complementary modified 22 mer oligonucleotide; and 50 mer nicked DNA duplex composed of a long 50 mer template strand and three short 14, 14 and modified 22 mer complementary oligonucleotides (Fig. 4A and Table 1). 5'-[32P]-labelled 22 mer oligonucleotide containing single THF or $\alpha \mathrm{dA}$ residue was hybridized to complementary 22, 50 and 51 mer strands, containing either Thymine or 3-Nitropyrrole (Z) residue opposite to the lesion, to obtain 22, 50 and 51 mer duplexes containing single THF•T, $\alpha \mathrm{dA} \bullet \mathrm{T}$ or $\alpha \mathrm{dA} \bullet \mathrm{Z}$ base pair (Fig. 4B). It should be noted that APE1-catalyzed cleavage of THF•T duplex will be referred here as the BER activity, whereas the cleavage of $\alpha \mathrm{dA} \bullet T$ by APE1 will be referred here as the NIR activity. Also, to identify differences in the kinetics between various DNA shapes, we measured the NIR activity under more stringent reaction conditions in the presence of only $0.1 \mathrm{mM} \mathrm{MgCl}_{2}$. As expected, incubation of 5'-[32P]-labelled $22 \mathrm{mer}$ $\alpha \mathrm{dA} \cdot \mathrm{T}$ duplex with APE1 under the NIR conditions resulted in the efficient incision of oligonucleotide 5 ' next to $\alpha \mathrm{dA}$ residue and generation of 9 mer cleavage product (Fig. 4A, lanes 2-4 and SI Appendix, Table S2). APE1 also cleaved 50 mer nicked $\alpha \mathrm{dA} \bullet T$ duplex (6\% cleavage in $10 \mathrm{~min}$ ), though with much less efficiency as compared to $22 \mathrm{mer} \alpha \mathrm{dA} \cdot \mathrm{T}$ substrate (56\% cleavage in $5 \mathrm{~min}$ ) (SI Appendix, Table S2). In addition APE1 exhibited non-specific $3 ' \rightarrow 5^{\prime}$ exonuclease activity towards nicked $\alpha \mathrm{dA} \bullet \mathrm{T}$ duplex leading to an extensive degradation of 5'-[32P]-labelled 22 mer adA-strand (Fig. 4A, lanes 1416).

Noteworthy, APE1 failed to cleave 51 mer $\alpha \mathrm{dA} \bullet \mathrm{T}$ dmbDNA (Fig. 4A, lanes 6-8 and SI Appendix, Table S2), while it efficiently cleaved synthetic AP site in both 22 mer THF•T duplex and 51 mer THF•T dmbDNA with similar rates (SI Appendix, Fig. S2). Furthermore, the E. coli NIRproficient AP endonuclease Nfo cleaves adA-containing 22 mer duplex and 51 mer dmbDNA with a similar efficiency (SI Appendix, Fig. S3). These observations suggest that human APE1 requires a specific mechanism to recognize $\alpha \mathrm{dA}$ residues in DNA, which is different from the mechanism underlying the classic AP site cleavage activity. Also, because of conformational constraints imposed by DNA hairpin loops, the dumbbell shaped DNA structure might be more rigid as compared to linear duplex DNA fragment. Thus, the conformational rigidity of dmbDNA may inhibit APE1-catalyzed NIR activity. To examine this hypothesis, we constructed 51 mer $\alpha \mathrm{dA} \cdot \mathrm{Z}$ dmbDNA containing 3 nitropyrrole $(Z)$ residue opposite to $\alpha \mathrm{dA}$. $Z$ is an universal base that can replace any of the four normal 

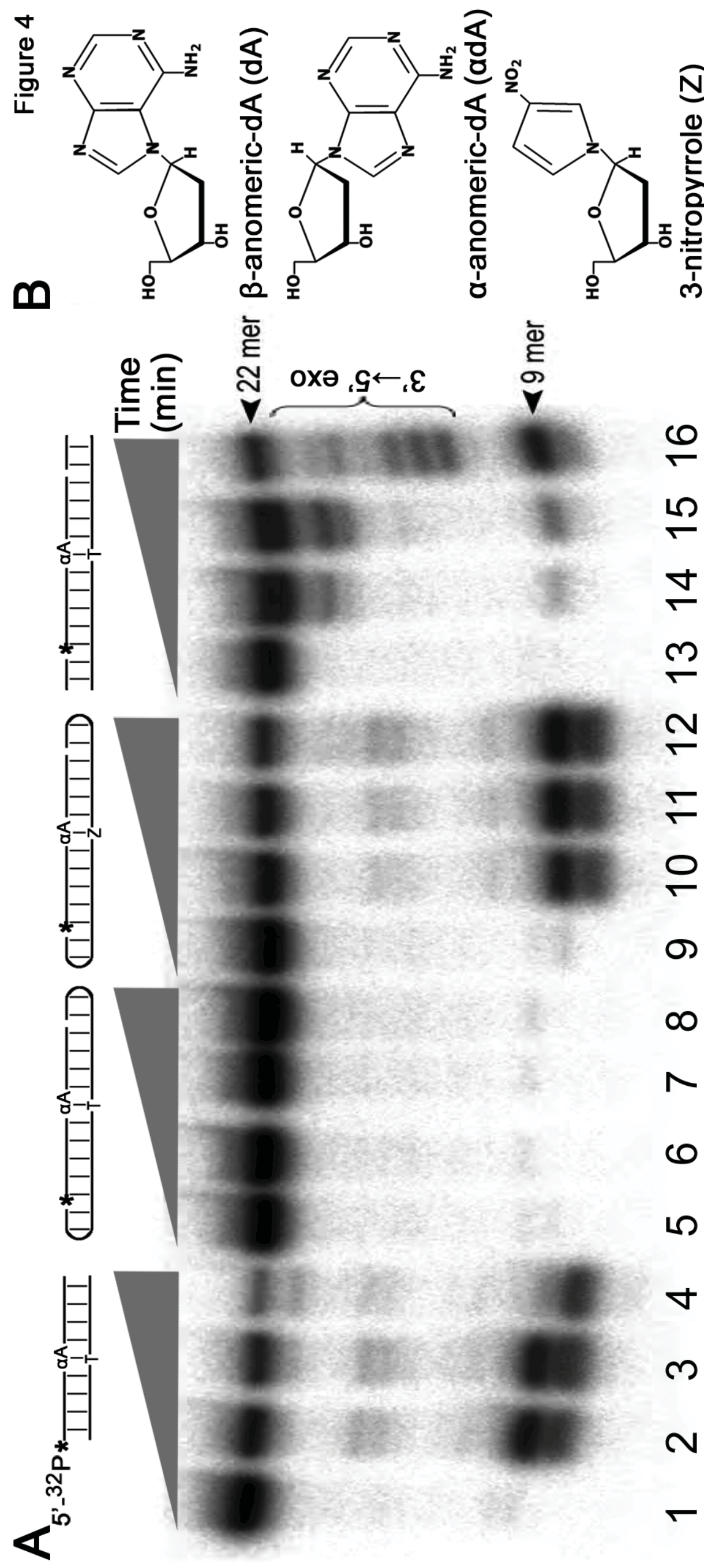
bases without significantly destabilizing neighbouring base-pair interactions. Within the DNA helix Z residue stacks well and hydrogen bonds poorly with no selectivity to the opposite base, thereby lowering the melting temperature of the duplex. Here, we expected that the presence of $\mathrm{Z}$ residue opposite to $\alpha \mathrm{dA}$ in dmbDNA would induce DNA chain flexibility and this in turn would stimulate the recognition of $\alpha \mathrm{dA}$ by APE1. Indeed, APE1 cleaves $\alpha \mathrm{dA} \cdot \mathrm{Z}$ dmbDNA with good efficiency and generates 9 mer cleavage product (Fig. 4A, lanes 10-12 and SI Appendix, Table S2), although with somewhat lower efficiency (lane 10, 43\% cleavage in $5 \mathrm{~min}$ ) as compared to $22 \mathrm{mer} \alpha \mathrm{dA} \bullet \mathrm{T}$ duplex (lane $2,56 \%$ cleavage in $5 \mathrm{~min}$ ). Based on these results we may suggest that APE1 binds $\alpha \mathrm{dA} \cdot \mathrm{Z}$ dmbDNA substrate in a stable manner which stimulates DNA bending and recognition of $\alpha \mathrm{dA}$ residue.

\subsection{APE1 differentially stimulates the binding of AP-1 to dumbbell-shaped and linear DNA duplexes.}

Next, we examined whether APE1 TF-stimulating activity depends on the DNA structure by using the standard EMSA technique described in [35]. For this we constructed three DNA substrates each containing one binding site for the AP-1 heterodimer c-Jun/c-Fos, specifically: (i) 50 mer full duplex DNA fragment composed of two complementary 50 mer strands; (ii) 51 mer dmbDNA composed of a long 79 mer hairpin template strand and a complementary 21 mer oligonucleotide; and (iii) 50 mer nicked duplex DNA fragment composed of a long 50 mer template strand and three short 14, 14 and 21 mer complementary oligonucleotides. The top 50 mer strand in full duplex and 21 mer strands in dmbDNA and nicked duplex were 5 '-[ $\left.{ }^{32} \mathrm{P}\right]$-labelled. To measure DNA binding activities the $5 \mathrm{nM} 5$ '-[ $\left.{ }^{32} \mathrm{P}\right]$-labelled DNA duplexes were incubated in the standard DNA binding buffer containing or not $250 \mathrm{nM}$ AP-1, $500 \mathrm{nM}$ APE1 and $1 \mathrm{mM}$ Glutathione (GSH) or Dithiothreitol (DTT). After incubation, the samples were placed on ice and formation of AP-1/DNA complexes was examined by the EMSA on 8\% non-denaturing PAGE. As expected, the oxidized AP-1 fails to generate stable super-shifted AP-1/DNA complex with DNA fragments containing its cognate site (Fig. 5A, lanes 3 and 11). Addition of either $1 \mathrm{mM} \mathrm{GSH}$ or $500 \mathrm{nM}$ APE1 to AP-1 generated a faint super-shifted DNA band (lanes 4-5 and 12-13), whereas addition of 1 mM DTT leads to the shift of $15-25 \%$ of DNA fragments (lanes 7 and 15). These results suggest that GSH and APE1 separately only weakly stimulate AP-1 DNA binding, in contrast to DTT, which is a stronger reducing agent as compared to GSH, efficiently stimulated the AP-1 DNA binding. Noteworthy, addition of APE1 together with GSH and DTT stimulated binding of the oxidized AP-1 to all three DNA structures in synergistic manner (Fig. 5A, lanes 6, 8, 14, 16 and Fig. 5B and SI Appendix Fig. S4). The synergistic effect of combined action of APE1 and the reducing agents in promoting AP-1 DNA binding suggests that the mechanism of APE1-catalyzed stimulation of TFs might be different from that of the reducing agents. Finally, quantitative analysis of the APE1-catalyzed stimulation of AP-1 binding to various DNA structures revealed that in the presence of reducing agents APE1 stimulates AP-1 binding to dmbDNA two-fold less efficiently as compared to the full and nicked DNA duplexes with statistically significant difference (P value < 0.05) (Fig. 5B and SI Appendix, Fig. S4). Importantly, the differences between the means of GSH- and DTT-stimulated binding of AP-1 to three distinct DNA structures were not significant $(\mathrm{P}$ value $>0.05)$, suggesting that the differences in AP-1 complex formation ability are due to APE1-mediated stimulation, and not due to the preference of AP-1 to certain DNA structures.

Intriguingly, the GSH promoted AP-1 super-shifted complexes (Fig. 5A, lanes 5 and 13) run more slowly in the gel as compared to that of DTT (lanes 7 and 15). It should be stressed, that the GSH (lanes 5 and 13) and APE1+GSH (lanes 6 and 14) promoted AP-1 super-shifted complexes run at the same position, indicating that APE1 is not associated with AP-1/DNA complex. In addition, the AP-1 super-shifted complexes promoted by DTT (lanes 7 and 15) and APE1+DTT (lanes 8 and 16) also run at the same position, again indicating that APE1 is not bound to AP-1/DNA complex. Taken together these results suggest that GSH-mediated reduction, but not that of DTT, may induce structural or conformational changes in the reduced AP-1 protein which results in different migration pattern in the non-denaturing EMSA gel. Thus GSH, contrary to DTT, may interact with reactive cysteine residues in AP-1 and generate protein-S-S-Glutathione adducts which in turn may lead to a different migration pattern of AP-1/DNA complex in the EMSA gel. 
Figure 5

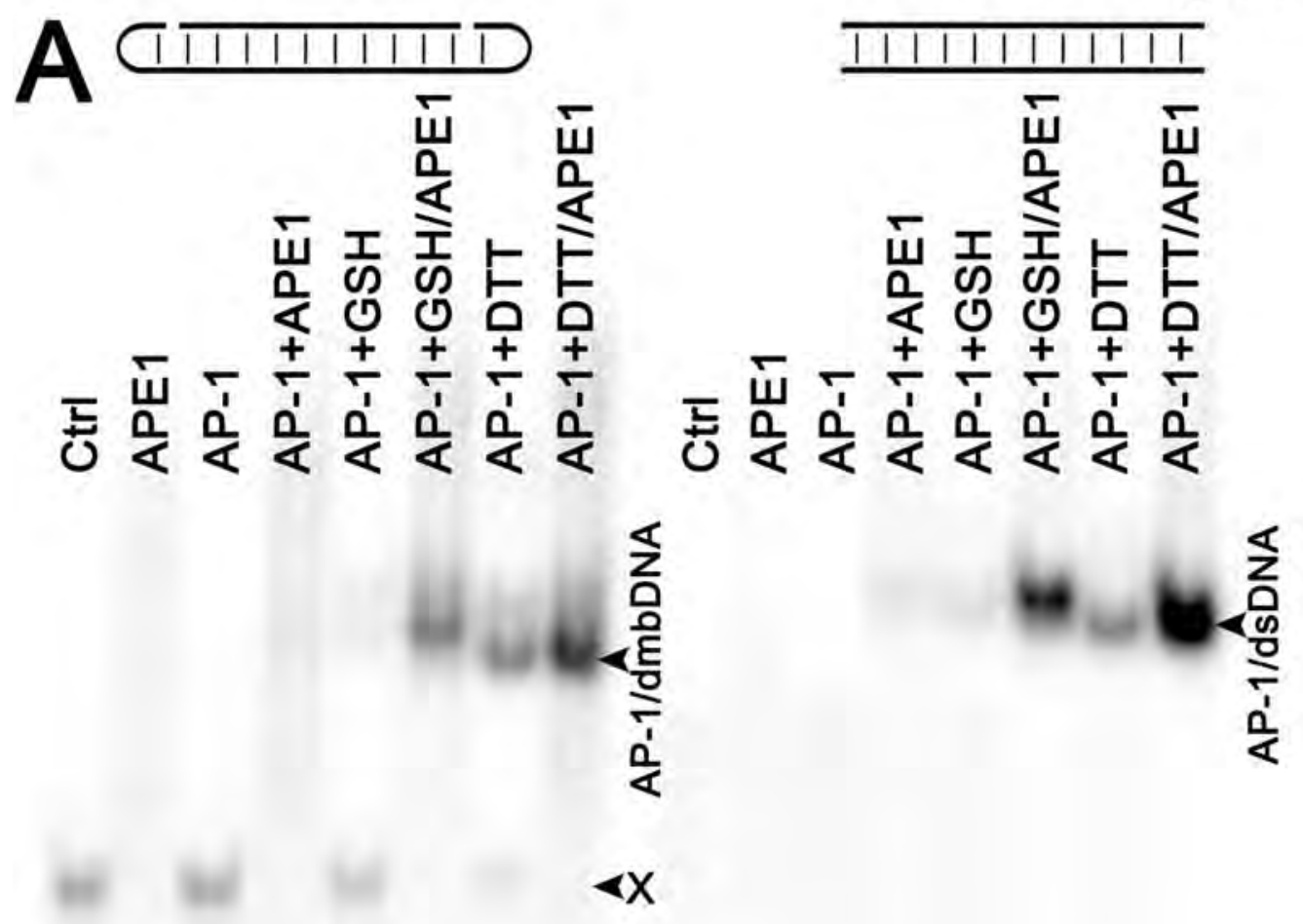

450 mer

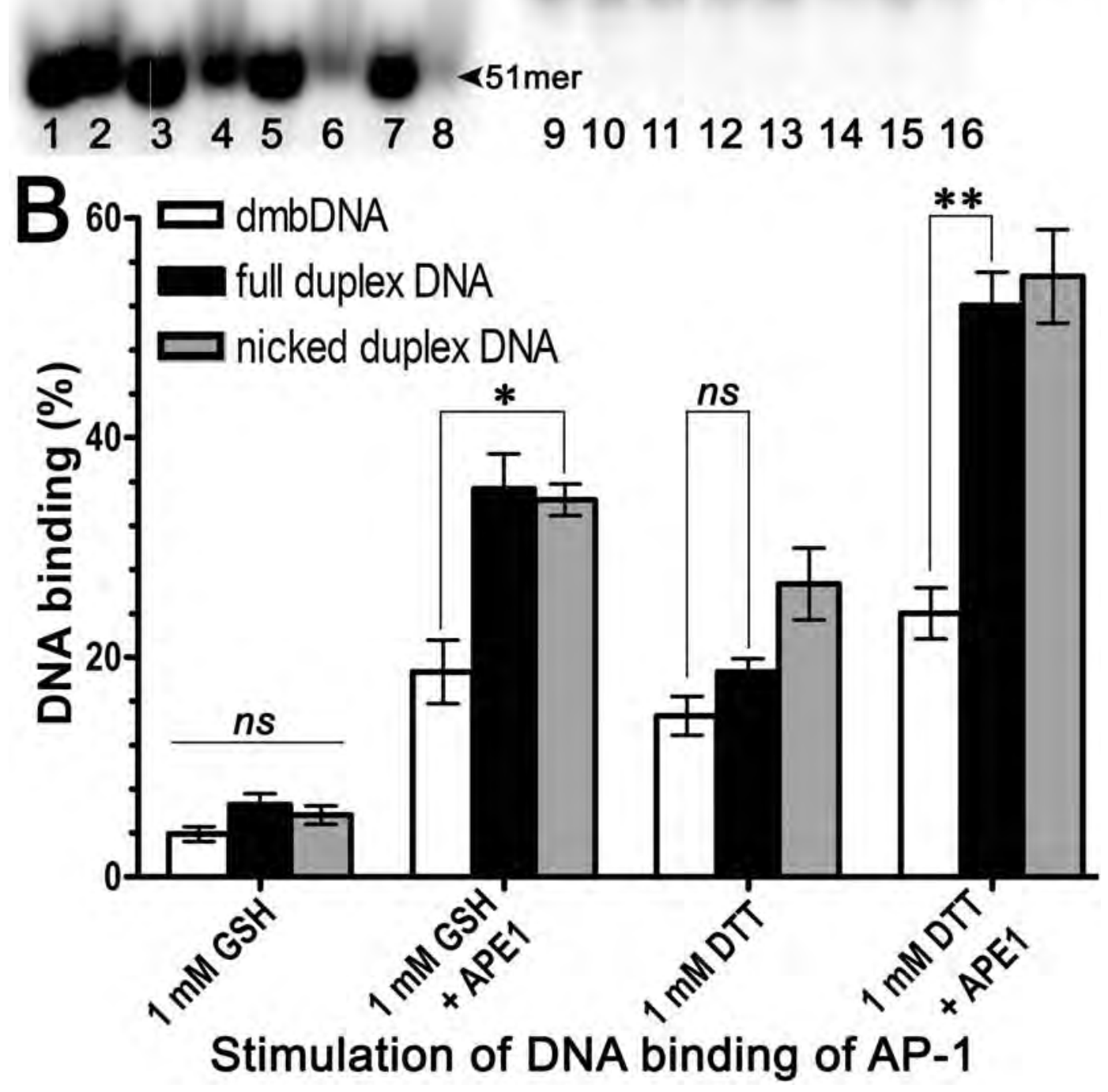




\subsection{APE1 and reducing agents stimulate binding of the NF-kB p50 subunit to 11 mer DNA duplex in a synergistic manner}

$\mathrm{NF}-\kappa \mathrm{B}$ is an ubiquitous transcription factor that regulates numerous genes involved in immune response to pathogens and inflammation. Although, NF- $\mathrm{kB}$ is structurally and functionally distinct from AP-1, both transcription factors are regulated by the APE1-catalyzed TF-stimulating activity [53]. Similar to APE1-mediated stimulation of AP-1, the stimulation of DNA binding of the NF- $\kappa B$ p50 subunit by APE1 is also well-characterized [53-54]. Therefore, we decided to examine whether APE1 can stimulate the binding of p50 to DNA in a synergistic manner with the well-characterized reducing compounds such as GSH and DTT. For this we used 11 and 26 mer oligonucleotide duplexes containing a single cognate DNA motif d(GGGACTTTCC). As expected, oxidized p50 at high concentration $(100 \mathrm{nM})$ either alone or with APE1 forms only a faint super shifted band on the gel (Fig. 6A, lanes 2-3 and 11-12, and SI Appendix Table S3). Addition of $1 \mathrm{mM} \mathrm{GSH}, 0.1$ and $1.0 \mathrm{mM}$ DTT weakly stimulated the binding of p50 to short 11 mer duplex oligonucleotide $(10 \%, 17 \%$ and $33 \%$ of complex formation, respectively) (Fig. 6A, lanes 4, 6 and 8, and SI Appendix Table S3), whereas these reducing agents strongly promoted the binding of p50 to longer 26 mer duplex (74\%, $63 \%$ and $92 \%$ of complex formation, respectively) (lanes 13, 16 and 18, and SI Appendix Table S3). These results suggest that the partially and fully reduced p50 protein binds and generates p50/DNA complexes with 26 mer duplex with higher efficiency as compared to short 11 mer duplex.

Noteworthy, APE1 together with GSH and DTT stimulated the binding of p50 to 11 mer duplex in a synergistic manner (Fig. 6A, lanes 5, 7 and 9 and Fig. 6B). Whereas, the DNA binding of p50 to long 26 mer duplex is stimulated by APE1 and the reducing agents rather in additive manner (Fig. 6A, lanes 14, 16 and 18 and Fig. 6B). Thus, the synergistic effect of the APE1-mediated stimulation of p50 binding to short 11 mer DNA fragments point to the fact that APE1 stimulates TFs independently from their redox state by an alternative mechanism.

\subsection{Plant AP endonucleases homologous to human APE1 stimulate binding of the NF-kB p50 subunit to DNA}

As we mentioned before there are a number of contradictory studies on the role of conserved cysteine residues of APE1 in the stimulation of DNA binding of TFs [11, 14-15, 17]. To resolve these conflicting studies, it has been proposed that APE1 may act as a protein chaperone which physically interacts with TFs to promote the reduction of cysteine residues by the reducing agents [15]. In the present study, to distinguish between different mechanisms of the APE1-catalyzed TF-stimulating activity, we examined plant AP endonucleases for their ability to stimulate DNA binding of the NF- $\mathrm{KB}$ p50 subunit. Previously, it was shown that the major Arabidopsis thaliana AP endonuclease, ARP, which is homologous to human APE1, can stimulate in vitro the DNA binding of AP-1 heterodimer cJun/c-Fos [16]. In addition, recently we demonstrated that both common wheat (Triticum aestivum) AP endonuclease, wARP and Arabidopsis ARP exhibit NIR activities towards $\alpha \mathrm{dA}$ residues in duplex DNA [32]. The C-terminal part of ARP and wARP proteins (residues 268-534 and 313-596 aa, respectively) exhibit homology to AP endonuclease domain of APE1 (61-318 aa), whereas the large N-terminal domains of ARP and wARP (1-268 and 1-313 aa, respectively) do not show significant sequence similarity to the N-terminal part of APE1 (1-61 aa). Importantly, the plant AP endonucleases not only lack the conserved C65 residues, but also other highly conserved C99, C138, C208, C296 and C310 which are thought to be critical for the APE1 TF-stimulating function. Plant ARP and wARP were incubated with the NF- $\mathrm{KB}$ p50 subunit and AP-1 in the presence of 5'-[ $\left.{ }^{32} \mathrm{P}\right]-$ labelled 26 mer duplex oligonucleotides containing the respective cognate sites. As shown in Fig. 7, oxidized p50 at low concentration $(10 \mathrm{nM})$ alone or in the presence of $1 \mathrm{mM}$ GSH fails to bind and generate supershifted complex with 26 mer DNA duplex (lanes 2-3). While incubation of the oxidized p50 protein with APE1, wARP and ARP resulted in the formation of super-shifted protein/DNA complexes, although with low efficiency (Fig. 7, lanes 6, 8 and 10 and SI Appendix Tables S4). Incubation of p50 together with GSH and the AP endonucleases resulted in a synergistic stimulation of p50 binding to DNA (lanes 7, 9 and 11 and SI Appendix Tables S4). Here as a control we used the TF-stimulation deficient truncated APE1 protein lacking the first $61 \mathrm{~N}$-terminal amino acid residues (APE1-N $\triangle 61$ ). As expected, the N $\triangle 61-\mathrm{APE} 1$ mutant can still stimulate the DNA binding of p50 (lanes 4-5) (14 and $28 \%$ of complex formation, respectively), but to a lesser extent as compared to wild-type APE1 and 
Figure 6

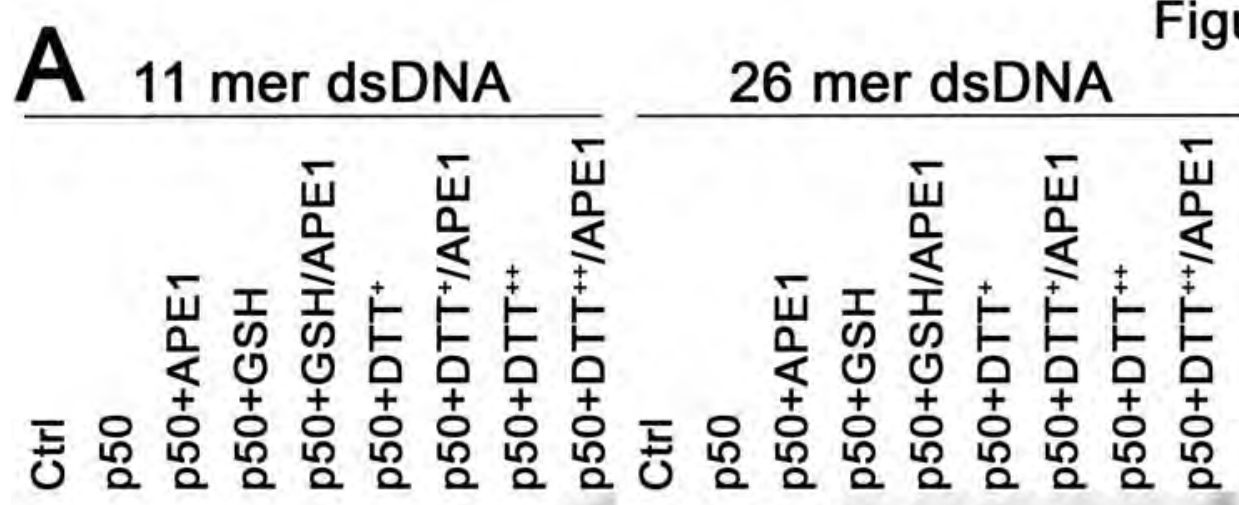

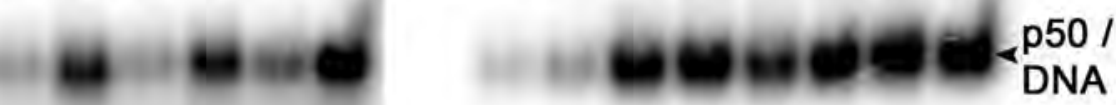

$<26 \mathrm{mer}$

$11 \mathrm{mer}$

$\begin{array}{llllllllll}12 & 34 & 5 & 6 & 7 & 8 & 9 & 101112 & 131415161718\end{array}$

B

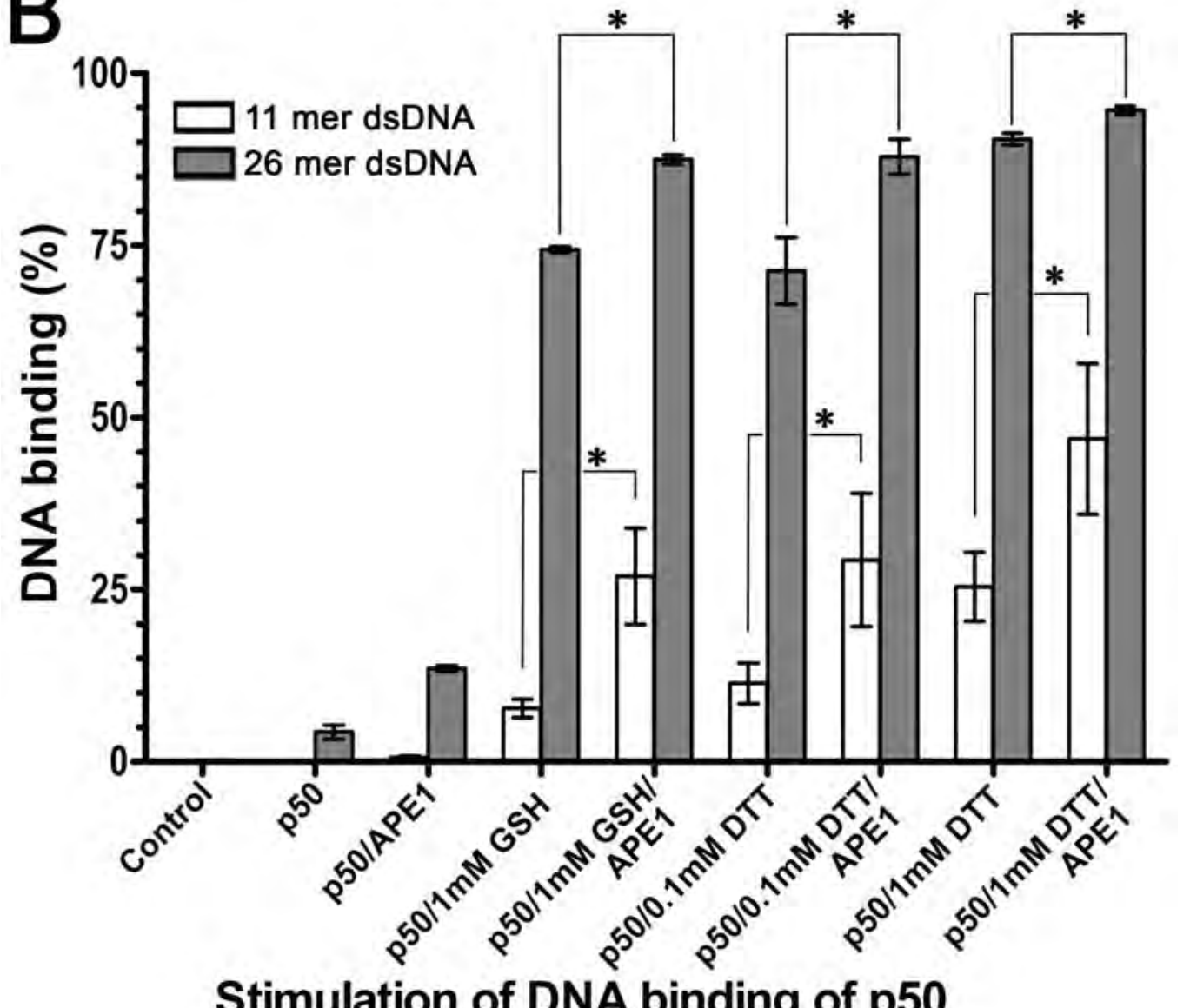

Stimulation of DNA binding of p50 
Figure 7

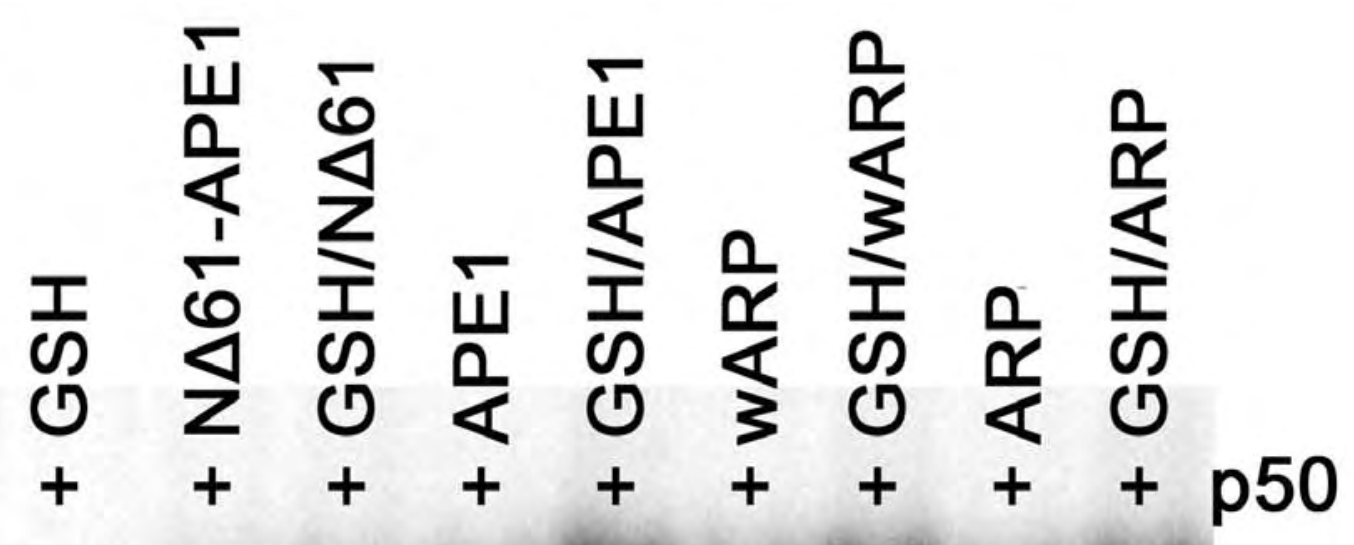

¿

$\begin{array}{lllllllllll}1 & 2 & 3 & 4 & 5 & 6 & 7 & 8 & 9 & 10 & 11\end{array}$ 
plant AP endonucleases (lanes 6-11 and SI Appendix Tables S4) (20 to 58\% of complex formation). In agreement with the previous study [16], we observed efficient stimulation of the DNA binding of the oxidized AP-1 heterodimer c-Jun/c-Fos in the presence of human and both plant AP endonucleases (SI Appendix, Fig. S5). Taken together, these results suggest that the plant AP endonucleases are able to stimulate the DNA binding of heterologous transcription factors in a manner very similar to that of human APE1. Moreover, absence of the APE1-like N-terminal domain and absolute majority of conserved cysteine residues in ARP and wARP, as well as high amino acid sequence divergence between APE1 and ARP-like proteins, suggest that the plant proteins stimulate the DNA binding of p50 in the redox- and chaperon-independent manner.

\subsection{Human APE1 stimulates binding of the redox-insensitive NF- $\mathrm{BB}$ p50-C62S mutant to DNA.}

Previous studies demonstrated that Cysteine at position 62 (C62) in the highly-conserved Rel homology DNA-binding domain (RHD) of p50 has to be in a reduced state for the efficient DNA binding $[2,4,55]$. Consistent with this observation, the amino acid substitution Cysteine $\rightarrow$ Serine at position 62 in p50-C62S mutant resulted in its strong DNA binding even under oxidized conditions, which moreover was not affected by the presence of reducing agents [54]. Biochemical data obtained in this study suggest that APE1 stimulates DNA binding of the transcription factors without reducing the conserved cysteine residues in the both AP-1 and NF- $\mathrm{kB}$ proteins. To further substantiate our findings, we decided to examine whether APE1 can stimulate the DNA binding of redox-insensitive p50-C62S mutant. In agreement with the previous observations [15], we demonstrate that utilization of high concentrations of p50-C62S mutant $(50-100 \mathrm{nM})$ resulted in saturation of DNA binding and masked the stimulatory effect of APE1 (SI Appendix, Fig. S6). Therefore, we measured the formation of super-shifted p50/DNA band after incubation of the 5'-[32P]-labelled 11 mer and 26 mer duplex oligonucleotides with limited amount of the p50-C62S protein (10 nM), APE1 (500 nM) and either diamide, a disulfide generating agent, or varying concentration of the reducing agents (Fig. 8 and SI Appendix, Fig. S7). Under these limiting conditions, the p50-C62S mutant generated a weak supershifted band with 26 mer on the EMSA gel (Fig. 8, lane 3), but not with 11 mer DNA duplex (SI Appendix, Fig. S7) (for quantification see SI Appendix Table S5). As expected, incubation of the p50C62S mutant with $70 \mu \mathrm{M}$ diamide, 1 and $5 \mathrm{mM}$ DTT, and $1 \mathrm{mM} \mathrm{GSH}$, did not significantly inhibit or stimulate formation of the p50-C62S/DNA complex (Fig. 8, lanes 4, 6-7 and 10, and SI Appendix, Fig. $\mathrm{S} 6$ and Table S5). On the other hand, addition of APE1 alone stimulated the DNA binding of p50C62S mutant (Fig. 8, lane 5 and SI Appendix, Fig. S7 and Table S5), suggesting that APE1 can stimulate the transcription factors without affecting the redox state of cysteine residues.

Noteworthy, GSH and DTT at high $5 \mathrm{mM}$ concentrations, but not at $1 \mathrm{mM}$, interfered with DNA binding of p50-C62S and APE1-mediated stimulation. Addition of $5 \mathrm{mM} \mathrm{GSH}$, but not $1 \mathrm{mM}$ GSH, strongly inhibited p50-C62S binding to 26 mer DNA duplex (Fig. 8, lane 11) and 11 mer DNA duplex (SI Appendix, Fig. S7), as compared to p50-C62S incubated without reducing agents (Fig. 8, lanes 3-4 and SI Appendix, Fig. S7). Furthermore, the presence of $5 \mathrm{mM}$ GSH strongly inhibits the APE1-mediated stimulation of DNA binding of p50-C62S (Fig. 8, lane 13 and SI Appendix, Fig. S7 and Table S5). These results suggest that high concentration of GSH, but not that of DTT, inhibits DNA binding of p50-C62S mutant and consequently the APE1-mediated stimulation. We may propose that GSH when used at high concentrations induce S-glutathionylation of cysteine residues in p50-C62S mutant which inhibits its DNA binding. Addition of 1 or $5 \mathrm{mM}$ DTT alone does not significantly influence DNA binding of p50-C62S (Fig. 8, lanes 6-7 and SI Appendix, Fig. S7 and Table S5), however, in the presence of APE1, 5 mM DTT strongly stimulates DNA binding of p50C62S (Fig. 8, lane 9) as compared to APE1 only (Fig. 8, lane 5). We suggest that an increase in the APE1-mediated stimulation of DNA binding of p50-C62S by $5 \mathrm{mM}$ DTT is due to interaction of this reducing agent with APE1 and not due to interaction with the p50-C62S protein.

\subsection{Electron microscopy analysis of DNA complexes with the APE1 protein.}

Previously, transmission electron microscopy (TEM) and Atomic Force Microscopy (AFM) imaging of protein/DNA complexes showed that APE1 binds to regular DNA duplex as multi-protein oligomers [30]. In the present study, the results obtained with EMSA suggest that the APE1 oligomers 
Figure 8

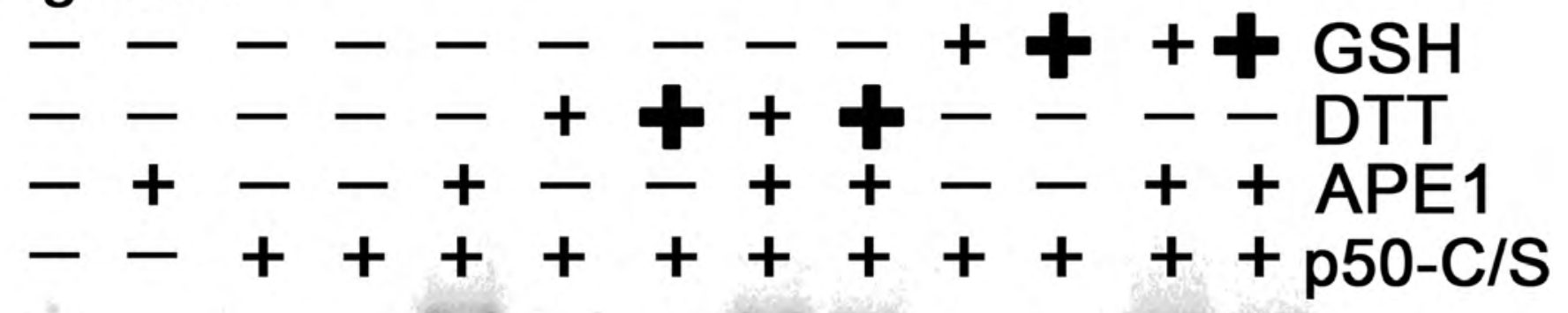

$<\frac{\pi}{z}$

$\begin{array}{lllllllllllll}1 & 2 & 3 & 4 & 5 & 6 & 7 & 8 & 9 & 10 & 11 & 12 & 13\end{array}$ 
on DNA could be involved in the stimulation of TFs. To get insight into the mechanism of APE1mediated stimulation, we examined the interactions between APE1 and DNA using TEM. In addition to wild-type (WT) full-length APE1, we used truncated C-terminal deletion variant APE1-C $\Delta 128$ which contains first N-terminal 190 amino acids. It was shown that the APE1-C $\Delta 128$ protein stimulates DNA binding of TFs, but completely lacks DNA repair activities [9]. For TEM imaging, we incubated $5 \mathrm{nM}$ of undamaged negatively supercoiled (sc) pUC19 plasmid DNA with $2.5 \mu \mathrm{M}$ fulllength APE1-WT (1 APE1 per 5 bp) or $5 \mu \mathrm{M}$ C-terminal deletion variant APE1-C $\Delta 128$ which contains first $\mathrm{N}$-terminal 190 amino acids (1 APE1 molecule per $2.5 \mathrm{bp}$ ) in binding buffer $(10 \mathrm{mM}$ Tris- $\mathrm{HCl} \mathrm{pH} \mathrm{8,50} \mathrm{mM} \mathrm{NaCl}$ ) for $10 \mathrm{~min}$ at $4^{\circ} \mathrm{C}$. The resulting APE1/DNA complexes were visualized using TEM in dark-field mode. The dark field electron images showed that both APE1 proteins efficiently bind scDNA molecules (91\% of protein/DNA complexes were formed) (Fig. 9, panels B-C). We could note that both full-length and truncated APE1 proteins favor DNA strands crossing each other, apparently involving (DNA/protein)-(protein/DNA) interactions. Previously. we have shown that the presence of APE1-WT on undamaged linear dsDNA increased the intra-molecular folding of DNA fragments and can further induce inter-molecular bridging among several linear dsDNA molecules [30]. Consistent with these observation here, the APE1-WT and APE1-C $\Delta 128$ proteins bind and bridge negative supercoiled DNA.

\subsection{APE1-WT and APE1-C $\triangle 128$ are multimerized at areas containing sSDNA-dsDNA junctions}

Since our EMSA data show that APE1 can stably bind single-stranded DNA fragments which might adopt secondary structures, we examined the binding of APE1-WT and APE1-C $\Delta 128$ to the singlestranded region within linear DNA duplex using TEM imaging. For this, the hybrid DNA molecules containing a large $440 \mathrm{nt}$ ssDNA gap between two dsDNA segments referred as 1440gapDNA have been constructed. The differential behavior of APE-WT and APE1-C $\Delta 128$ proteins on the ss and ds DNA was analyzed by TEM using $5 \mathrm{nM}$ 1440gapDNA and $500 \mathrm{nM}$ APE-WT and APE1-C $\Delta 128$ proteins incubated in the binding buffer $(10 \mathrm{mM}$ Tris- $\mathrm{HCl} \mathrm{pH} 8,50 \mathrm{mM} \mathrm{NaCl})$ for $10 \mathrm{~min}$ at $4^{\circ} \mathrm{C}$ (Fig. 10). Both the APE1-WT and APE1-C $\Delta 128$ proteins were accumulated on the ds-ssDNA junction of the gapped molecules. The APE1-C $\Delta 128 / \mathrm{DNA}$ complexes seem to be more stable than that of the APE1-WT/DNA. The ds-ssDNA junction mimics a specific DNA structure area comparable to a fourway Holliday junction or to an abasic site. This result is consistent with the previously published data where we have shown that APE1-WT polymerizes along linear DNA fragment to recognize and accumulate on AP site [30].

\subsection{APE1-WT and APE1-C $\triangle 128$ search and distort the DNA areas containing intrinsic curvature and anisotropic flexibility.}

APE1 affinity to DNA structures exhibiting increased flexibility such as ssDNA oligonucleotides and ssDNA-dsDNA junctions implies that the APE1-mediated multimerization on DNA depends on the presence of anisotropic flexibility in the DNA conformation. The sequence-dependent intrinsic curvature of DNA, which is characterized by the presence of A-tracts with the adjacent 5' or 3' CA or TA dinucleotides and anisotropic flexibility, can promote the stabilization of DNA binding proteins which are searching for the particular sites on DNA and in turn these proteins are able to distort the curved DNA areas [56-57]. The A-tracts appear to be structurally rigid [58], whereas adjacent CA/TA dinucleotides exhibit the anisotropic flexibility due to their well-known low base pair stacking energy [59-60]. Thus, such structure (flexible dinucleotide / rigid segment) appears optimal to curve or to kink DNA by specific proteins as it was shown previously for the LrpC protein [37] and for the H-NS protein which both induce structurally similar DNA distortions [61]. Bacterial DNA binding proteins such as LrpC and $\mathrm{H}-\mathrm{NS}$ are able to oligomerize in a non-specific manner along DNA duplex and be stabilized in areas exhibiting increased DNA bendability and distortions. To explore the human AP endonuclease behavior on curved DNA, the APE1 protein was incubated with a linear pBR322 C7 dsDNA fragment which has a region of curvature containing the A tracts (CAAAA and AAAAC) (Fig. 11A). Five nM of linear C7 dsDNA (Fig. 11B) was mixed with either $500 \mathrm{nM}$ APE1-WT (Fig. 11, panels $\mathrm{C} 1-\mathrm{C} 5)$ or APE1-C $\Delta 128$ (Fig. 11, panels D1-D5) and incubated in the binding buffer $(10 \mathrm{mM}$ Tris- $\mathrm{HCl} \mathrm{pH} \mathrm{8,50} \mathrm{mM} \mathrm{NaCl}$ ) for $10 \mathrm{~min}$ at $4^{\circ} \mathrm{C}$. The results of TEM imaging revealed the capacity of 


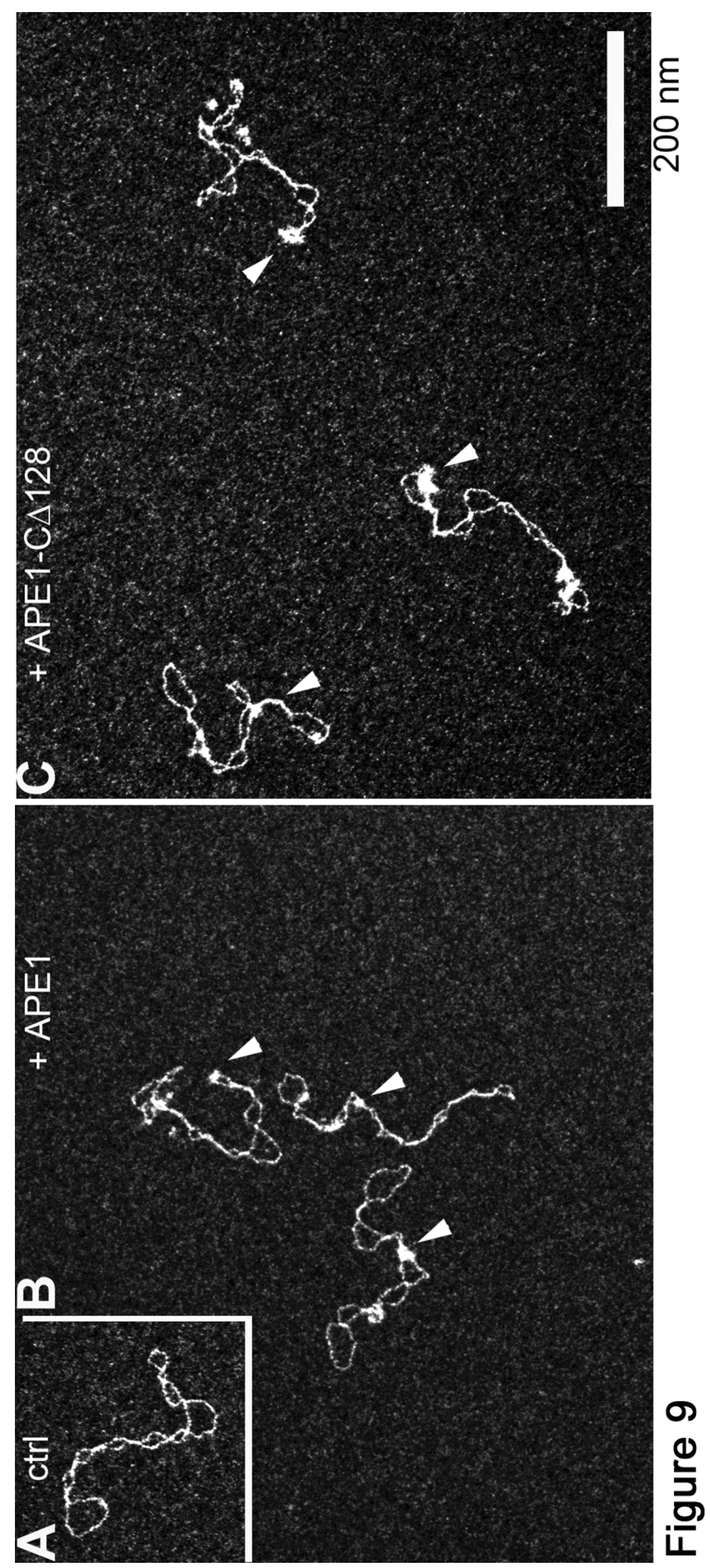




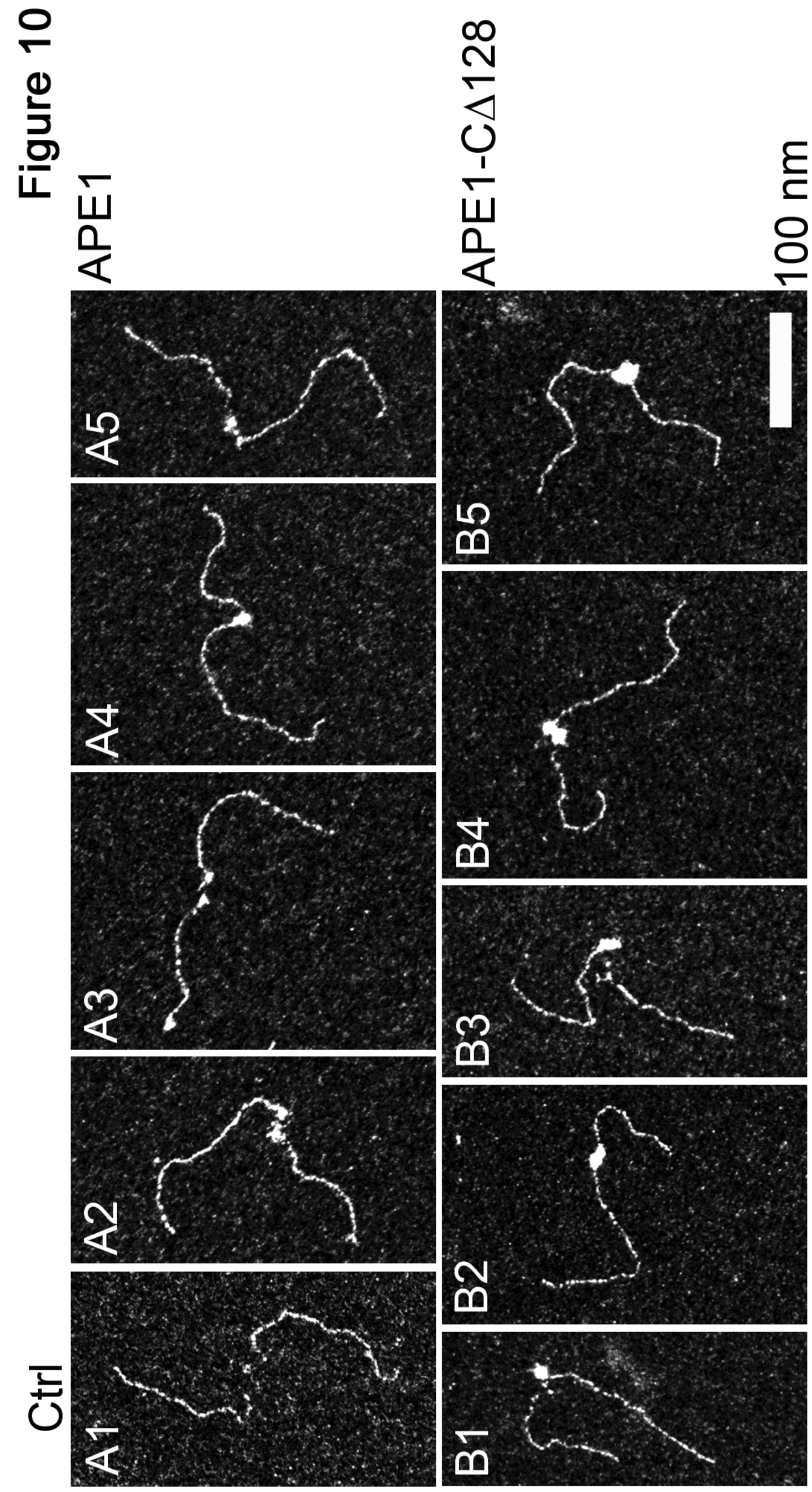




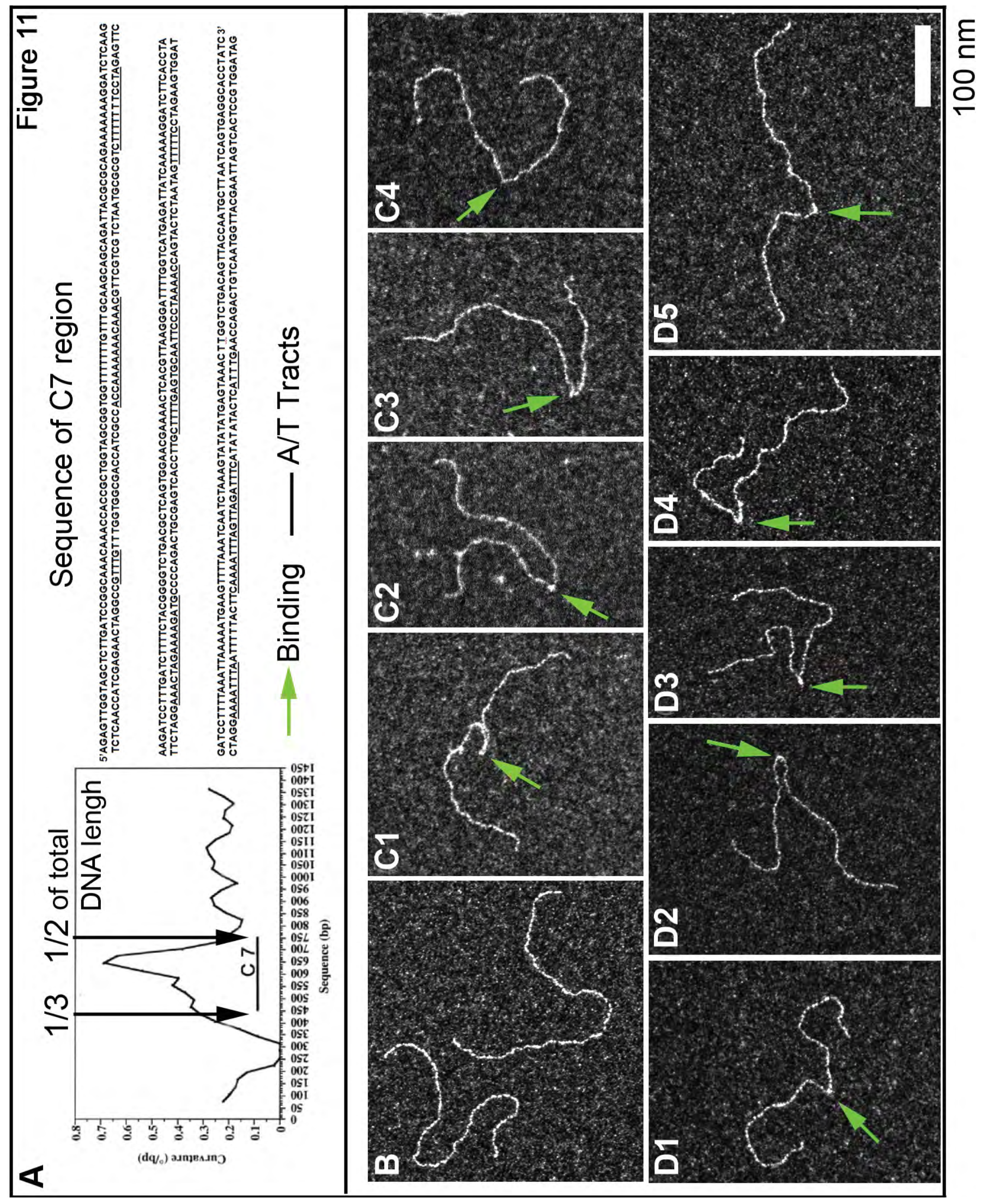


both APE1-WT and APE1-C $\triangle 128$ proteins to generate site-specific distortions in the $\mathrm{C} 7$ region of DNA molecules (Fig. 10C-D). Noteworthy, the APE1-WT and APE1-C $\Delta 128$ proteins bound to the A tract - enriched region induce a kink in $14 \%$ of DNA molecules (total molecules analyzed: $\mathrm{n}=346$ and $n=286$, respectively).

\subsection{Computer modeling of the APE1-DNA interactions.}

To rationalize the findings related to the experimental data from the structural point of view, we first attempted to reconstruct the full-length APE1 molecule, since all available structures of human APE1 have truncations of 36 to 44 amino acid residues from the N-terminus [12, 17, 45, 62-68]. In the structures, residues Met37-Lys52 form an extended chain running along one side of the main protein globule. We performed elastic network analysis of available APE1 structures, which showed that vibrational movements in this $\mathrm{N}$-terminal region are only loosely coupled with the rest of the protein (SI Appendix, Fig. S8A). Thus, both the structural data and elastic network analysis indicate that forty to fifty residues in the N-terminal region of APE1 likely behave independently of the rest of the protein in terms of their folding and movement.

We then combined $a b$ initio folding and protein-protein docking to obtain the shape of the $\mathrm{N}$ terminal fragment. To this aim, we have first employed replica-exchange_Monte Carlo simulation of protein folding to generate models of the Met1-Glu46 fragment from APE1 (APE ${ }_{1-46}$ ). Ten bestscoring models were then subjected to rigid-body protein-protein docking with the APE1 structure artificially truncated to start from Asp47 ( $\left.\mathrm{APE}_{47-318}\right)$; ten pairs of chains were generated for every folding model, resulting in a total of 100 models. When they were ranked based on the distance between the $\mathrm{C}$-terminus of the $\mathrm{N}$-terminal fragment and the $\mathrm{N}$-terminus of the protein body, a single model stood out with $3.82 \AA$ separating C[Glu46] and N[Asp47] and allowing their re-connection with minimal structural changes (SI Appendix, Fig. S9A). Two other docked pairs, coming from the same

folding model, had the C[Glu46]-N[Asp47] distances of 5.02 $\AA$ and 5.69 $\AA$, and were essentially less favorable rotations of the folded fragment at the same docking spot (SI Appendix, Fig. S9A). All other models produced the C[Glu46]-N[Asp47] distance > $9.3 \AA$ (SI Appendix, Fig. S9B) and thus were unsuitable candidates for correct folding and docking. In the best model, the peptide backbone was restored, and the structure was energy-minimized to produce the full-length APE1 model, APE $1_{\text {full }}$ (Fig. 12A). Similarly to what was observed in the truncated protein forms, the vibrational modes in the $\mathrm{APE}_{1-46}$ fragment were weakly correlated with the rest of the protein (SI Appendix, Fig. S8B), suggesting that it likely functions as an independent structural module.

To reveal possible reasons for the multimerization of APE1 on DNA observed by TEM, we have docked APE $1_{\text {full }}$ on itself, restricting the output to asymmetric models with the docking interface involving the N-terminal fragment and the DNA-binding groove not obscured. A single model that satisfied these criteria also displayed roto-translational symmetry with four monomers docked as rigid bodies until clashes started to appear. Energy minimization to relieve these clashes produced a tetramer model in which DNA can be wrapped around the protein core, which is extendable by adding more APE1 molecules (Fig. 12B).

Based on the biochemical data, we have proposed that APE1 can bind ends of double-stranded DNA. APE1 belongs to the Exonuclease-Endonuclease-Phosphatase structural superfamily, which also includes tyrosyl DNA phosphodiesterase 2 (TDP2), an enzyme that specifically processes doublestranded DNA breaks with covalently trapped topoisomerase II molecules [69]. Superposition of the structure of TDP2 bound at an end of double-stranded DNA with that of APE1 (both experimental structures and homology models on the TDP2 templates) showed that APE1, with minimal structural readjustment, could bind a DNA end in a similar manner (Fig. 12C and SI Appendix, Fig. S10).

\section{DISCUSSION}

The multi-functional human APE1 protein participates in the repair of oxidative DNA damage, transcriptional regulation of redox-dependent factors and cellular proliferation. Suppression of APE1 results in embryonic lethality in mice [70], inhibits human cell proliferation and induces apoptosis [5]. 


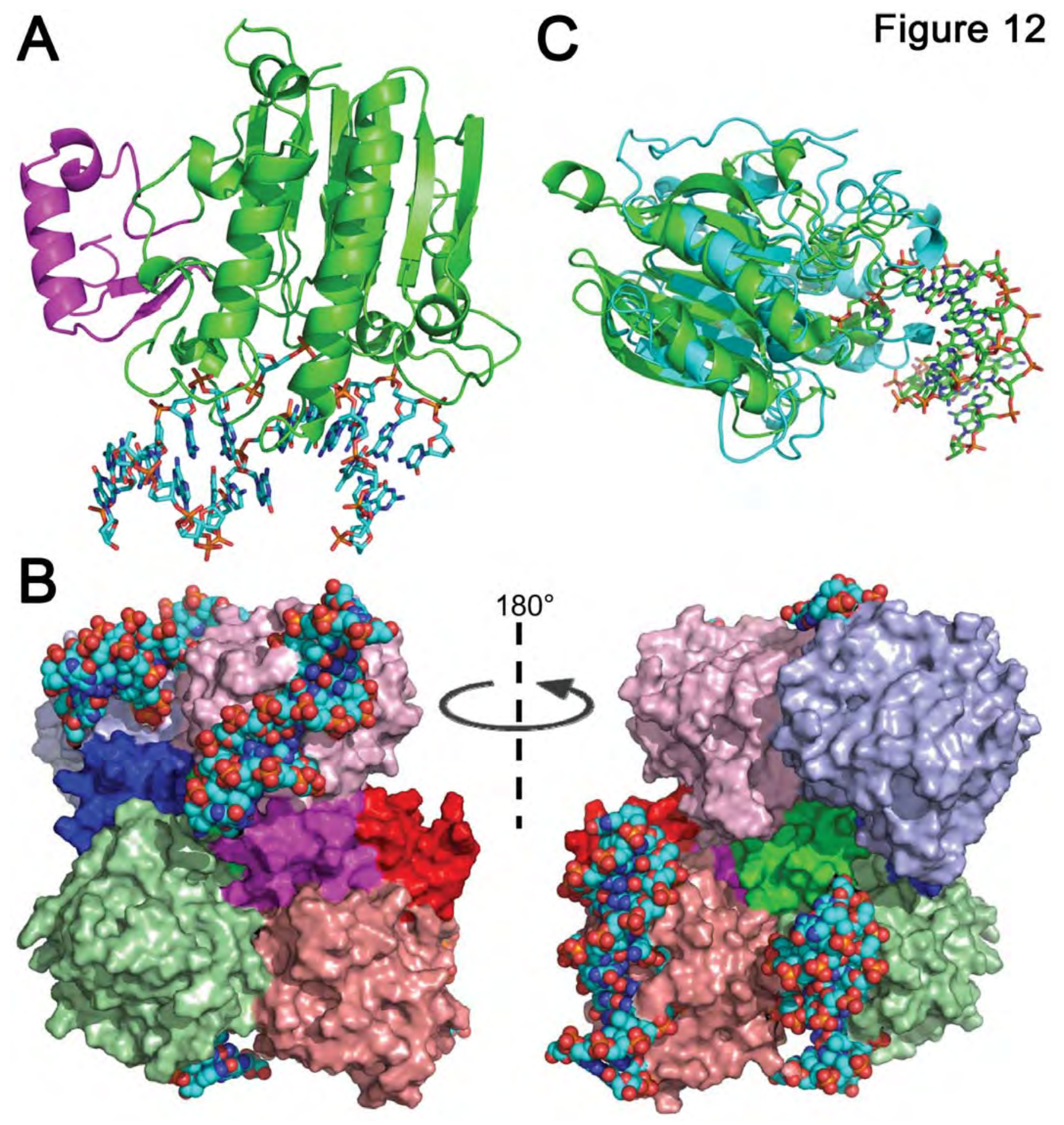


At present, it remains unknown which of the APE1-catalyzed functions are essential for cell viability, since the lack of comprehensive understanding of the molecular mechanisms which link the DNA repair and non-DNA repair functions of APE1 in human cells. In the present study, we investigated the molecular mechanisms of APE1-catalyzed TF-stimulating function and NIR activity, by using several different techniques: EMSA, DNA repair assay, electron microscopy and molecular modeling.

\subsection{APE1 binds to ssDNA in an apparently cooperative manner to form stable protein/DNA complexes.}

We demonstrated that APE1 can generate super-shifted protein/DNA complexes in the EMSA gel with 22-64-mer oligonucleotides (Fig. 1). Analysis of the migration pattern of super-shifted DNA fragments points to a cooperative binding of APE1 to DNA, which may be required to generate stable APE1/DNA bound complexes. Indeed, APE1 fails to bind very short 11-15-mer ssDNA fragments implying that the stable DNA binding of APE1 requires sufficiently long DNA fragments to position more than one molecule of protein (Fig. 1). By using oligo (dT) primers we showed that stable binding of APE1 to ssDNA does not require the presence of secondary structures (SI Appendix Fig. S1). Contrary to ssDNA, APE1 does not generate stable bound complexes with dsDNA, instead we observed smeared DNA bands in the EMSA gel (Fig. 2). Based on our previous electron and atomic force microscopy imaging of APE1-DNA complexes [30], we may propose that APE1 oligomers on dsDNA induce intermolecular bridging among several DNA molecules thus generating small and large DNA condensates possibly either via protein-protein interactions across distant APE1-oligomers or protein-DNA interactions between APE1 oligomer and free DNA. Therefore, the smearing pattern of dsDNA migration in the gel in the presence of APE1 may be due to intermolecular bridging between two duplex DNA molecules mediated by APE1 oligomers. Alternatively, the affinity of bound APE1 mono- and oligomers may be simply not sufficient to stabilize the complex enough to be detected by EMSA, which is a non-equilibrium assay where even highly stable complexes may fall apart quickly and fail to re-form while moving in an electric field.

We have also investigated the stoichiometry of APE1 binding to ssDNA by using UVcrosslinking to 22 and 50 mer oligo (dT) primers. The data showed that APE1 is capable to bind ssDNA in apparently cooperative manner to form dimers and higher-order oligomers on sufficiently long DNA fragments (Fig. 3). Based on these results, we hypothesize that cooperative DNA binding by APE1 may play a role in the NIR and redox functions.

\subsection{APE1-catalyzed repair and TF-stimulating activities depend on DNA duplex structure.}

Here we demonstrated that under reaction conditions used APE1 is unable to cleave the dumbbell-shaped DNA duplex (dmbDNA) containing single adA residue, whereas it cleaves with a high efficiency dmbDNA with a synthetic AP site and linear DNA duplex with $\alpha \mathrm{dA} \bullet \mathrm{T}$ (Fig. 4 and SI Appendix Fig. S2). These results indicate that APE1 utilizes different mechanisms of DNA damage recognition when acting upon AP site and $\alpha \mathrm{dA}$ nucleotide. Interestingly, the bacterial AP endonuclease Nfo was not sensitive to DNA structures and was able to cleave with high efficiency both duplex and dmbDNA substrates containing AP site and $\alpha \mathrm{dA}$ residue implying that Nfo utilizes the same mechanism to recognize structurally different DNA lesions. Inclusion of the non-coding residue $\mathrm{Z}$ opposite to $\alpha \mathrm{dA}$ in dmbDNA enables APE1 to cleave this particular DNA substrate. Here, we propose that the APE1-catalyzed NIR activity towards $\alpha \mathrm{dA} \bullet T$ requires more drastic DNA bending than BER on THF•T. It is tempting to speculate that APE1 bends $\alpha \mathrm{dA} \bullet T$ DNA similarly to that observed in two crystal structures of $E$. coli Nfo bound to a cleaved synthetic AP site and to a nicked duplex DNA which reveal that the bacterial enzyme sharply kinks the DNA helix by $\sim 90^{\circ}$ and flips the $\mathrm{AP}$ site and the $\mathrm{dC}$ nucleotide, respectively, and also the opposite base partner out of the DNA base stack [71-73]. Intriguingly, APE1 can recognize $\alpha \mathrm{dA} \cdot Z$ base pair when present in dmbDNA, suggesting that the presence of $Z$ residue may increase the flexibility of dmbDNA enabling APE1 to bend the dmbDNA in more pronounced manner and to form catalytically proficient complex with the DNA substrate. In the previous study, we have demonstrated that APE1 can bind to dsDNA in a cooperative manner and generate oligomers on DNA [30]. Based on this, we hypothesize that the tight binding of APE1 to $\alpha \mathrm{dA} \cdot \mathrm{T}$ DNA duplex under NIR conditions is due to cooperative assembly of several enzyme molecules into oligomers on the DNA which enables APE1 to recognize $\alpha \mathrm{dA}$ and cleave DNA substrate. Thus, in the case of dmbDNA substrate, APE1 fails to bind dmbDNA 
containing $\alpha \mathrm{dA}$ in a cooperative manner and to form stable oligomers, suggesting that APE1 acts on these dmbDNA substrates as a monomer and requires additional means to destabilize DNA, such as the presence of $\mathrm{Z}$ residue, in order to catalyze the cleavage of phosphodiester bond 5 ' next to the lesion.

In agreement with above observations, the APE1-mediated AP-1 stimulation on dmbDNA was less efficient as compared to linear DNA duplexes (Fig. 5 and SI Appendix, Fig. S4). Taken together, these observations suggest that the APE1 protein assembling on DNA, required for NIR and TFstimulation, strongly depends on structural properties of the helix.

\subsection{APE1 acts synergistically with reducing agents and stimulates DNA binding of p50-C62S redox mutant.}

Previously, it was shown that the reduction of cysteine in TFs requires high concentration of APE1, which cannot be replaced with BSA [74] suggesting that the stimulation of DNA binding of AP-1 and NF-kB is very specific for APE1. Nevertheless, addition of BSA can enhance the effect of DTT on AP-1 implying a possible non-specific crowding effect $[3,9]$. To further substantiate a possible mechanistic link between DNA repair and TF-stimulating function, we characterized APE1 and plant AP endonuclease catalyzed stimulation of DNA binding of AP-1 and NF- $\kappa$ B using EMSA and high molar concentration of the repair proteins. First, we compared APE1-mediated stimulation of DNA binding of the AP-1 heterodimer c-Jun/c-Fos to dmbDNA, intact and nicked DNA duplexes each containing a recognition site for AP-1. Results revealed that in the presence of reducing agents APE1 stimulates AP-1 binding to dmbDNA two-fold less efficiently as compared to intact and nicked DNA duplexes (Fig. 5B), suggesting that APE1-catalyzed stimulation of DNA binding of AP-1 depends on DNA structures. This result is in agreement with very low APE1 NIR activity on dmbDNA substrate described above. Furthermore, we showed that when acting together APE1 and the reducing agents stimulate the DNA binding of the oxidized AP-1 and NF- $\mathrm{kB}$ p50 subunit in a synergistic manner implying that APE1 does not reduce the cysteine residues in TFs, but employs a different mechanism (Figs. 5 and 6). Previously, Ando and colleagues proposed that APE1 employs redox-chaperone function to induce conformational changes in TFs and facilitate reduction of cysteine residues by the reducing agents [15]. However, we showed that the plant AP endonucleases, which are far diverged from the human counterpart and lack many conserved cysteine residues, stimulate the DNA binding of p50 subunit of NF- $\mathrm{kB}$ similarly to human APE1 (Fig. 7). This result together with the previous observation of the ARP-mediated stimulation of DNA binding of AP-1 [16] strongly suggests that the plant AP endonucleases stimulate mammalian TFs in the redox- and chaperon-independent manner.

To further substantiate the alternative mechanism of APE1-catalyzed stimulation of TFs, we characterized the DNA binding of the redox-insensitive p50-C62S mutant. Previously, Ando and colleagues demonstrated that APE1 did not stimulate DNA binding of p50-C62S mutant [15].

However, the authors used high concentration of the mutant protein $(50 \mathrm{nM})$, under this conditions more than $50 \%$ of the DNA probe was stably bound to protein in the EMSA gel (SI Appendix Fig. S6). Here, to avoid saturation of DNA binding we used limited concentration of the p50-C62S mutant protein $(10 \mathrm{nM})$. The EMSA showed that APE1, but not the reducing agents, stimulates the DNA binding of p50-C62S (Fig. 8). This result further supports the alternative mechanism in which APE1 stimulates the DNA binding of transcription factors without affecting the redox state of their conserved cysteine residues. In addition, we observed that high concentration of GSH and DTT can modulate the APE1-mediated stimulation of p50-C62S (Fig. 8 and SI Appendix Fig. S7).

\subsection{APE1 multimerizes on curved DNA and promotes binding of the transcription factors.}

In our previous work using TEM and AFM imaging, we showed that APE1 can dynamically multimerize on linear DNA fragments in apparently sequence-independent manner [30]. In the present work, we further investigated APE1 oligomerization on the covalently closed circular plasmid DNA (scDNA), gapped linear duplex DNA and duplex DNA fragment containing a region of curvature with A-tracts. TEM imaging revealed that both the full-length APE1 and TF-stimulation active truncated APE1-C $\triangle 128$ efficiently oligomerize along scDNA and generate mainly intra-molecular DNA folding of the circular molecules which give rise to bridging and small condensates (Fig. 9). Noteworthy, both the APE1-WT and APE1-C $\triangle 128$ proteins preferentially bind and multimerize onto ssDNA in the gapped DNA fragment and are stabilized at the ss-dsDNA junctions due to the increased flexibility of 
these areas in DNA (Fig. 10). As we have shown previously, the presence of AP site in duplex DNA also creates anisotropic flexibility, which facilitates the lesion recognition by APE1 after the protein oligomerization to search the lesion [30]. In agreement with the above observations, we showed that the site-specific oligomerization of APE1 on DNA occurs on intrinsically curved DNA containing the C7 region with the A-tracts rich motifs (Fig. 11). The oligomerization of APE1-WT and APE1-C 128 on DNA areas with anisotropic flexibility promotes the site-specific distortions of DNA molecules offering a possible mechanism by which APE1 may regulate transcription (Fig. 11C-D).

Protein polymerization along DNA sequences enables mechanical scanning or sensing of the structural properties of DNA for the presence of intrinsic curvature or flexibility due to DNA lesions (strand breaks, abasic sites, mismatches, thymine dimers, etc). Stable association of the proteins at specific DNA sites may be correlated with DNA bending they induce. Such DNA bending also induces distortions at the level of adjacent sequences, thus promoting the binding of other proteins, such as transcription factors, as it was shown for the p53 protein binding to its DNA cognate which is favored by the DNA curvature induced by HMG1B [75]. Generally, the proteins which induce DNA bending exhibit better affinity when their recognition sites are located in curved or flexible regions, so called DNA bendable regions. Indeed, intrinsically curved DNA regions play important role in transcription regulation [76-78]. Our results suggest similar mechanisms since NF- $\kappa B$ and Fos-Jun have been described as the DNA bending factors [79-80], even if the DNA bending by Fos-Jun was argued [81].

Previously, using nuclear cell extracts it was shown that APE1 binds to two negative calcium responsive elements (nCaRE-A and nCaRE-B) in the promoters of $\mathrm{Ca}^{2+}$-dependent repressor of the parathyroid hormone (PTH) gene [82] and also APE1 itself [83]. Furthermore, using EMSA it has been demonstrated that the purified APE1 protein can stably bind to the duplex oligonucleotide containing nCaRE-B sequences [28]. Strikingly, sequence analysis of $\mathrm{nCaRE}$ reveals the presence of A-tracts (dTTTTTG)/(dCAAAAA) flanking the recognition site for nCaRE-binding proteins. It was shown that the negative transcriptional regulatory elements such as $\mathrm{nCaRE}$ in PTH gene are created during retransposition of 7SL RNA to Alu repeat [84]. Alu elements contain the 3' poly-A tail which is prerequisite for retro-transposition, and in turn gives rise to the formation of intrinsic DNA curvature observed in the promoters containing the $\mathrm{nCaRE}$ regulatory sequence. Besides, intrinsically curved DNA structures are often found within or next to transcription regulatory regions (TRRs) in eukaryotic genomes. Based on our data, we propose that APE1 specifically binds and oligomerizes on curved DNA regions and promotes site specific distortion which in turn stimulates binding of various transcription factors to their cognate sites. The available crystal structures $[12,64,66]$ indicate that APE1 binds DNA in the minor groove and widens the major groove; since both AP-1 and NF-kB p50 bind in the major groove [85-86], APE1 could assist these TFs in a binding-dependent, redoxindependent manner, acting essentially as a molecular matchmaker. It should be noted that in oligonucleotide substrates, the collective affinity of bound APE1 oligomers is likely sufficient to facilitate TF binding but not sufficient to stabilize the complex enough to be detected by EMSA. In long DNA, the oligomers could cooperatively grow to much longer, more stable filaments, allowing their microscopic detection.

\subsection{Functionally relevant structural features of APE1 revealed by computer modeling.}

The "redox domain" was first identified in the literature by deletion mapping as a part of APE1 that spans the region between amino acid positions 35 and 127 and regulates the sequencespecific DNA binding of various transcription factors $[9,17]$. However, the available crystal structures, our APE $1_{\text {full }}$ model, and sequence conservation do not support the existence of a structural domain there in the strict sense as a distinctly folded and independently evolving protein fragment. Rather, it spans a part of the conserved catalytic core and the end of the N-terminal fragment of human APE1. Notably, the postulated redox-active C65 residue is not conserved even within vertebrates, which mostly contain S/T at this position (SI Appendix, Supplemental File S1), and seems to be a unique mammalian feature [17]. Structurally, C65 lies in the $\beta 1$ strand buried inside the protein globule. Interestingly, in the elastic network model, the short stretch I64-W67 shows cross-correlated vibrational movements with almost all $\beta$-strands that make up the central core of the APE1 structure (SI Appendix, Fig. S8). Moreover, in low-frequency modes, the APE1 molecule has C65 at one of global hinge centers, which often mark functionally important sites in enzymes [87]. These 
observations suggest that, despite being buried, C65 is located in a quite dynamic region of the APE1 globule.

The structure of the N-terminal fragment ( 40 residues) of APE1 is not solved experimentally and may be disordered (SI Appendix, Fig. S11). However, even disordered protein regions are often satisfactorily described by an ensemble of conformations, some of which can be more stable despite a relatively flat energy landscape [88-90]. Thus, we have attempted to generate a plausible structure of full APE1 by folding the N-terminal fragment $a b$ initio and docking it to the existing structure of the catalytic core (Fig. 12). Although the resulting model is by no means definitive, two observations give hope of its resemblance of an actual structure, or at least one of the structures in the conformational ensemble. First, there was clearly the best solution (SI Appendix, Fig. S9), which came from the highest-scoring folded structure and the bin of ten highest-scoring docked models; two next best solutions also came from the same model at nearly the same docking spot. Second, the model produced a reliable APE1 oligomerization interface that could explain the TEM observations. Additionally, our model is consistent with the observed post-translational modifications of several lysine residues in the N-terminal fragment [91]. We hypothesize that the folded state of the N-terminal fragment could be more stable in the isolated protein or in APE1 oligomers, and that binding DNA could induce partial unfolding of this tail, highly enriched in positively charged Lys and Arg residues, which can be engaged in electrostatic interactions with DNA phosphates, effectively serving as an accessory DNA-binding site. Several lines of evidence show that the N-terminal fragment of APE1 participates in DNA binding during NIR activity [23] and in interaction of the protein with RNA and nCaRE sequence in certain gene promoters [27-28, 92]. The deletion, mutation, and acetylation of Lys residues within the $\mathrm{N}$-terminal fragment lead to increased AP site cleavage activity [27, 91]. More speculatively, the intrinsic dynamics of the $\mathrm{N}$-terminal fragment could induce transient unfolding of the adjacent core domain, exposing C65 to interactions with the proteins regulated by APE1.

Earlier, 3'-terminal phosphodiesterase activity of APE1 at double-stranded breaks had been reported [93], and we have also observed distinct dependence of APE1 action on the nature of ends of double-stranded oligonucleotide substrates. The ability of APE1 to bind the ends of the duplex may be due to its structural similarity to TDP2, an enzyme evolved for repair of topoisomerase irreversibly stalled at double-strand breaks. In the cell, double-strand breaks are often parts of clustered DNA damage, with other base or sugar lesions located nearby. Thus, the affinity of the ends for APE1 could provide a fast entry route for removing such lesions and cleaning the ends for the subsequent break repair.

\subsection{Possible biological role of APE1-catalyzed stimulation of TFs.}

Here, we demonstrate that APE1 can specifically oligomerize on curved DNA structures and exacerbate further the existing helix distortion. Based on the data obtained in present study, we may propose that the nucleosome-free transcription regulatory regions (TRRs) containing intrinsically bend DNA structures would be prone to APE1-mediated stimulation of DNA binding of certain TFs. Similarly, DNA curvature may enhance the removal of oxidized bases in these TRRs via BER pathway. Noteworthy, it has been shown that activation of the expression of immune- and stressresponsive genes, such as THF $\alpha$ and interleukins depends on 8-oxoguanine-DNA glycosylase, OGG1, which excises oxidized guanines in promoter regions of NF- $\mathrm{BB}$-regulated genes [94-95]. In our previous study and in the present work, we showed that APE1 greatly stimulates OGG1-catalyzed excision of 8oxoG residues and DNA binding of NF- $\kappa B$ by the same mechanism [30]. Under oxidative stress conditions caused by inflammation or hypoxia, increased level of ROS will oxidize DNA bases in the genome in essentially random manner. The APE1-mediated stimulation of oxidized TFs and the DNA glycosylases would recruit TFs and in the presence of 8oxoG would introduce single-strand breaks, respectively, in the nucleosome-free TRRs containing an intrinsic curvature. The APE1promoted DNA strand breaks in TRRs would be recognized by PARP1 which in turn might regulate the transcription of the genes under the control of these TRRs. Whereas, APE1-mediated TFstimulation may in addition promote interactions between distantly located enhancer/insulator elements with their promoters and lead to the formation of new DNA interactions within topologically associated domains (TADs). Transcription factors, chromatin organizers and other nuclear proteins bind to their recognition sites on DNA to regulate transcription, replication and chromatin structure. These lead to genome compaction into chromatin domains which in turn provides a major framework 
for a coordinated modulation of gene expression and DNA replication. TADs represent one of the higher levels of DNA organization; they may also be related to spatial organization of DNA replication and gene expression [96]. Here, we hypothesize that APE1 is involved in chromatin organization via stimulation of the DNA binding of certain TFs and possibly chromatin organizers such as the CCCTC-binding factor (CTCF). Importantly, down-regulation of APE1 strongly inhibits human cell proliferation and induces apoptosis $[5,97]$ suggesting that APE1 could be involved in the regulation of essential cellular processes such as DNA transcription and replication possibly via chromatin organization.

\section{Conclusions.}

In this study, we attempted to elucidate the molecular mechanism underlying APE1-catalyzed NIR and TF-stimulating activities. We demonstrated that APE1 binds to DNA in transient and cooperative manner to generate oligomer-like structures, which in turn induce conformational changes in the helix and increase the affinity of transcription factors for cognate DNA sequences. APE1 multimerization on DNA can be considered as a substitute for diffusion along the DNA contour to probe the helix for the presence of anisotropic flexibility in form of a DNA lesion or intrinsic curvature. Indeed, APE1 specifically binds to intrinsically curved DNA structures and promotes further helix distortion. We suggest that the APE1-mediated site-specific DNA helix distortions within or near TRRs recruits various DNA binding factors which in turn stimulate the organization of multiprotein regulatory complexes. During evolution the eukaryotic homologues of bacterial AP endonuclease Xth acquired the N-terminal non-catalytic redox domain which provided additional biological functions including TF-stimulating and NIR activities. In the process of natural evolution, these additional functions of APE1 have become essential for cellular proliferation and embryonic development in mammals.

\section{Conflict of interest.}

The authors declare no conflict of interest.

Acknowledgements. We are grateful to and Hiroshi Handa, Yamaguchi Yuki and Tom Curran for the expression vectors of p50 and AP-1. This work was supported by grants to Murat Saparbaev from la Ligue National Contre le Cancer "Equipe Labellisee", Electricité de France (RB 2017) and French National Center for Scientific Research (PRC CNRS/RFBR n1074 REDOBER); to Alexander Ishchenko from French National Research Agency, ANR-18-CE44-0008, Fondation ARC (PJA20181208015); to Bakhyt T. Matkarimov from Nazarbayev University ORAU grant and MES RK grants AP05135073, AP05134722 program BR05236508; to Dmitry O. Zharkov from the Russian Ministry of Science and Education (6.5773.2017/6.7 and VI.62.1.5 0309-2019-0003) and Russian Science Foundation (17-14-01190, molecular modeling); to Amangeldy K. Bissenbaev from the Science Committee of the Ministry of Education and Science of the Republic of Kazakhstan [grant No. AP05131478]; to Eric Le Cam from la Ligue National Contre le Cancer, Plan Cancer Inserm, and Paris Sud University (MRM); and to Barbara Tudek from National Science Centre grant UMO2014/15/B/NZ5/01444. M.B-K. was supported by the fellowship Bourse Gouvernement Français "Doctorat en cotutelle" from France. P.P. was supported by a fellowship from International PhD Projects Programme of Foundation for Polish Science, "Studies of nucleic acids and proteins from basic to applied research", the project is co-financed by the European Union Regional Development Fund. The funders had no role in study design, data collection and analysis, decision to publish, or preparation of the manuscript.

\section{Appendix A. Supplementary data}

Supplementary material related to this article can be found, in the online version. 


\section{Bibliography.}

[1] C. Abate, L. Patel, F.J. Rauscher, 3rd, T. Curran, Redox regulation of fos and jun DNA-binding activity in vitro, Science, 249 (1990) 1157-1161.

[2] J.R. Matthews, W. Kaszubska, G. Turcatti, T.N. Wells, R.T. Hay, Role of cysteine62 in DNA recognition by the P50 subunit of NF-kappa B, Nucleic Acids Res., 21 (1993) 1727-1734.

[3] S. Xanthoudakis, G. Miao, F. Wang, Y.C. Pan, T. Curran, Redox activation of Fos-Jun DNA binding activity is mediated by a DNA repair enzyme, Embo J., 11 (1992) 3323-3335.

[4] K. Mitomo, K. Nakayama, K. Fujimoto, X. Sun, S. Seki, K. Yamamoto, Two different cellular redox systems regulate the DNA-binding activity of the p50 subunit of NF-kappa B in vitro, Gene, 145 (1994) 197-203.

[5] B. Demple, J.S. Sung, Molecular and biological roles of Ape1 protein in mammalian base excision repair, DNA Repair (Amst), 4 (2005) 1442-1449.

[6] G. Tell, D.M. Wilson, 3rd, C.H. Lee, Intrusion of a DNA repair protein in the RNome world: is this the beginning of a new era?, Mol. Cell. Biol., 30 (2010) 366-371.

[7] B. Demple, T. Herman, D.S. Chen, Cloning and expression of APE, the cDNA encoding the major human apurinic endonuclease: definition of a family of DNA repair enzymes, Proc. Natl. Acad. Sci. U. S. A., 88 (1991) $11450-11454$.

[8] C.N. Robson, A.M. Milne, D.J. Pappin, I.D. Hickson, Isolation of cDNA clones encoding an enzyme from bovine cells that repairs oxidative DNA damage in vitro: homology with bacterial repair enzymes, Nucleic Acids Res., 19 (1991) 1087-1092.

[9] S. Xanthoudakis, G.G. Miao, T. Curran, The redox and DNA-repair activities of Ref-1 are encoded by nonoverlapping domains, Proc. Natl. Acad. Sci. U. S. A., 91 (1994) 23-27.

[10] T. Izumi, S. Mitra, Deletion analysis of human AP-endonuclease: minimum sequence required for the endonuclease activity, Carcinogenesis, 19 (1998) 525-527.

[11] L.J. Walker, C.N. Robson, E. Black, D. Gillespie, I.D. Hickson, Identification of residues in the human DNA repair enzyme HAP1 (Ref-1) that are essential for redox regulation of Jun DNA binding, Mol. Cell. Biol., 13 (1993) 5370-5376.

[12] C.D. Mol, T. Izumi, S. Mitra, J.A. Tainer, DNA-bound structures and mutants reveal abasic DNA binding by APE1 and DNA repair coordination [corrected], Nature, 403 (2000) 451-456.

[13] M. Li, D.M. Wilson, 3rd, Human apurinic/apyrimidinic endonuclease 1, Antioxid Redox Signal, 20 (2014) 678-707.

[14] J.M. Ordway, D. Eberhart, T. Curran, Cysteine 64 of Ref-1 is not essential for redox regulation of AP-1 DNA binding, Mol. Cell. Biol., 23 (2003) 4257-4266.

[15] K. Ando, S. Hirao, Y. Kabe, Y. Ogura, I. Sato, Y. Yamaguchi, T. Wada, H. Handa, A new APE1/Ref-1dependent pathway leading to reduction of NF-kappaB and AP-1, and activation of their DNA-binding activity, Nucleic Acids Res, 36 (2008) 4327-4336.

[16] E. Babiychuk, S. Kushnir, M. Van Montagu, D. Inze, The Arabidopsis thaliana apurinic endonuclease Arp reduces human transcription factors Fos and Jun, Proc Natl Acad Sci U S A, 91 (1994) 3299-3303.

[17] M.M. Georgiadis, M. Luo, R.K. Gaur, S. Delaplane, X. Li, M.R. Kelley, Evolution of the redox function in mammalian apurinic/apyrimidinic endonuclease, Mutat. Res., 643 (2008) 54-63.

[18] M. Luo, J. Zhang, H. He, D. Su, Q. Chen, M.L. Gross, M.R. Kelley, M.M. Georgiadis, Characterization of the redox activity and disulfide bond formation in apurinic/apyrimidinic endonuclease, Biochemistry, 51 (2012) 695-705.

[19] D.E. Barnes, T. Lindahl, Repair and genetic consequences of endogenous DNA base damage in mammalian cells, Annu. Rev. Genet., 38 (2004) 445-476.

[20] H.E. Krokan, M. Bjoras, Base excision repair, Cold Spring Harb. Perspect. Biol., 5 (2013) a012583.

[21] A. Yasui, Alternative excision repair pathways, Cold Spring Harb. Perspect. Biol., 5 (2013) 1-8.

[22] A.A. Ischenko, M.K. Saparbaev, Alternative nucleotide incision repair pathway for oxidative DNA damage, Nature, 415 (2002) 183-187.

[23] L. Gros, A.A. Ishchenko, H. Ide, R.H. Elder, M.K. Saparbaev, The major human AP endonuclease (Ape1) is involved in the nucleotide incision repair pathway, Nucleic Acids Res., 32 (2004) 73-81.

[24] M. Redrejo-Rodriguez, C. Saint-Pierre, S. Couve, A. Mazouzi, A.A. Ishchenko, D. Gasparutto, M.

Saparbaev, New insights in the removal of the hydantoins, oxidation product of pyrimidines, via the base excision and nucleotide incision repair pathways, PLoS One, 6 (2011) e21039.

[25] E. Yu, S.P. Gaucher, M.Z. Hadi, Probing conformational changes in Ape1 during the progression of base excision repair, Biochemistry, 49 (2010) 3786-3796.

[26] S. Daviet, S. Couve-Privat, L. Gros, K. Shinozuka, H. Ide, M. Saparbaev, A.A. Ishchenko, Major oxidative products of cytosine are substrates for the nucleotide incision repair pathway, DNA Repair (Amst), 6 (2007) 818. 
[27] D. Fantini, C. Vascotto, D. Marasco, C. D'Ambrosio, M. Romanello, L. Vitagliano, C. Pedone, M. Poletto, L. Cesaratto, F. Quadrifoglio, A. Scaloni, J.P. Radicella, G. Tell, Critical lysine residues within the overlooked N-terminal domain of human APE1 regulate its biological functions, Nucleic Acids Res, 38 (2010) 8239-8256. [28] G. Antoniali, L. Lirussi, C. D'Ambrosio, F. Dal Piaz, C. Vascotto, E. Casarano, D. Marasco, A. Scaloni, F. Fogolari, G. Tell, SIRT1 gene expression upon genotoxic damage is regulated by APE1 through nCaREpromoter elements, Mol Biol Cell, 25 (2014) 532-547.

[29] P. Prorok, C. Saint-Pierre, D. Gasparutto, O.S. Fedorova, A.A. Ishchenko, H. Leh, M. Buckle, B. Tudek, M. Saparbaev, Highly mutagenic exocyclic DNA adducts are substrates for the human nucleotide incision repair pathway, PLoS One, 7 (2012) e51776.

[30] O.A. Kladova, M. Bazlekowa-Karaban, S. Baconnais, O. Piétrement, A.A. Ishchenko, B.T. Matkarimov, D.A. Iakovlev, A. Vasenko, O.S. Fedorova, E. Le Cam, B. Tudek, N.A. Kuznetsov, M. Saparbaev, The role of the N-terminal domain of human apurinic/apyrimidinic endonuclease 1, APE1, in DNA glycosylase stimulation, DNA Repair, 64 (2018) 10-25.

[31] A.A. Ishchenko, E. Deprez, A. Maksimenko, J.C. Brochon, P. Tauc, M.K. Saparbaev, Uncoupling of the base excision and nucleotide incision repair pathways reveals their respective biological roles, Proc. Natl. Acad. Sci. U. S. A., 103 (2006) 2564-2569.

[32] Z. Akishev, S. Taipakova, B. Joldybayeva, C. Zutterling, I. Smekenov, A.A. Ishchenko, D.O. Zharkov, A.K. Bissenbaev, M. Saparbaev, The major Arabidopsis thaliana apurinic/apyrimidinic endonuclease, ARP is involved in the plant nucleotide incision repair pathway, DNA Repair (Amst), 48 (2016) 30-42.

[33] C. Abate, D. Luk, R. Gentz, F.J. Rauscher, 3rd, T. Curran, Expression and purification of the leucine zipper and DNA-binding domains of Fos and Jun: both Fos and Jun contact DNA directly, Proc. Natl. Acad. Sci. U. S. A., 87 (1990) 1032-1036.

[34] N. Shimizu, K. Sugimoto, J. Tang, T. Nishi, I. Sato, M. Hiramoto, S. Aizawa, M. Hatakeyama, R. Ohba, H. Hatori, T. Yoshikawa, F. Suzuki, A. Oomori, H. Tanaka, H. Kawaguchi, H. Watanabe, H. Handa, Highperformance affinity beads for identifying drug receptors, Nat Biotechnol, 18 (2000) 877-881.

[35] S. Xanthoudakis, T. Curran, Analysis of c-Fos and c-Jun redox-dependent DNA binding activity, Methods Enzymol, 234 (1994) 163-174.

[36] L.A. Chodosh, UV crosslinking of proteins to nucleic acids, Curr Protoc Mol Biol, Chapter 12 (2001) Unit 1215.

[37] C. Beloin, J. Jeusset, B. Revet, G. Mirambeau, F. Le Hegarat, E. Le Cam, Contribution of DNA

conformation and topology in right-handed DNA wrapping by the Bacillus subtilis LrpC protein, J. Biol. Chem., 278 (2003) 5333-5342.

[38] G. Muzard, B. Theveny, B. Revet, Electron microscopy mapping of pBR322 DNA curvature. Comparison with theoretical models, Embo J., 9 (1990) 1289-1298.

[39] P. Doruker, A.R. Atilgan, I. Bahar, Dynamics of proteins predicted by molecular dynamics simulations and analytical approaches: application to alpha-amylase inhibitor, Proteins, 40 (2000) 512-524.

[40] A.R. Atilgan, S.R. Durell, R.L. Jernigan, M.C. Demirel, O. Keskin, I. Bahar, Anisotropy of fluctuation dynamics of proteins with an elastic network model, Biophys J, 80 (2001) 505-515.

[41] E. Eyal, L.W. Yang, I. Bahar, Anisotropic network model: systematic evaluation and a new web interface, Bioinformatics, 22 (2006) 2619-2627.

[42] E. Eyal, G. Lum, I. Bahar, The anisotropic network model web server at 2015 (ANM 2.0), Bioinformatics, 31 (2015) 1487-1489.

[43] D. Xu, Y. Zhang, Ab initio protein structure assembly using continuous structure fragments and optimized knowledge-based force field, Proteins, 80 (2012) 1715-1735.

[44] D. Xu, Y. Zhang, Toward optimal fragment generations for ab initio protein structure assembly, Proteins, 81 (2013) 229-239.

[45] M.A. Gorman, S. Morera, D.G. Rothwell, E. de La Fortelle, C.D. Mol, J.A. Tainer, I.D. Hickson, P.S. Freemont, The crystal structure of the human DNA repair endonuclease HAP1 suggests the recognition of extrahelical deoxyribose at DNA abasic sites, Embo J., 16 (1997) 6548-6558.

[46] A. Tovchigrechko, I.A. Vakser, Development and testing of an automated approach to protein docking, Proteins, 60 (2005) 296-301.

[47] A. Tovchigrechko, I.A. Vakser, GRAMM-X public web server for protein-protein docking, Nucleic Acids Res, 34 (2006) W310-314.

[48] A. Waterhouse, M. Bertoni, S. Bienert, G. Studer, G. Tauriello, R. Gumienny, F.T. Heer, T.A.P. de Beer, C. Rempfer, L. Bordoli, R. Lepore, T. Schwede, SWISS-MODEL: homology modelling of protein structures and complexes, Nucleic Acids Res, 46 (2018) W296-W303.

[49] M.J. Schellenberg, L. Perera, C.N. Strom, C.A. Waters, B. Monian, C.D. Appel, C.K. Vilas, J.G. Williams, D.A. Ramsden, R.S. Williams, Reversal of DNA damage induced Topoisomerase 2 DNA-protein crosslinks by Tdp2, Nucleic Acids Res, 44 (2016) 3829-3844. 
[50] W. Kabsch, A solution for the best rotation to relate two sets of vectors, Acta Crystallographica Section A, 32 (1976) 922-923.

[51] D.M. Wilson, 3rd, Ape1 Abasic Endonuclease Activity is Regulated by Magnesium and Potassium Concentrations and is Robust on Alternative DNA Structures, J. Mol. Biol., 345 (2005) 1003-1014.

[52] J. Fan, Y. Matsumoto, D.M. Wilson, 3rd, Nucleotide sequence and DNA secondary structure, as well as replication protein A, modulate the single-stranded abasic endonuclease activity of APE1, J Biol Chem, 281 (2006) 3889-3898.

[53] Y. Kabe, K. Ando, S. Hirao, M. Yoshida, H. Handa, Redox regulation of NF-kappaB activation: distinct redox regulation between the cytoplasm and the nucleus, Antioxid Redox Signal, 7 (2005) 395-403.

[54] T. Nishi, N. Shimizu, M. Hiramoto, I. Sato, Y. Yamaguchi, M. Hasegawa, S. Aizawa, H. Tanaka, K.

Kataoka, H. Watanabe, H. Handa, Spatial redox regulation of a critical cysteine residue of NF-kappa B in vivo, J Biol Chem, 277 (2002) 44548-44556.

[55] M.B. Toledano, D. Ghosh, F. Trinh, W.J. Leonard, N-terminal DNA-binding domains contribute to differential DNA-binding specificities of NF-kappa B p50 and p65, Mol. Cell. Biol., 13 (1993) 852-860.

[56] A. Minsky, Information content and complexity in the high-order organization of DNA, Annu Rev Biophys Biomol Struct, 33 (2004) 317-342.

[57] T.E. Haran, U. Mohanty, The unique structure of A-tracts and intrinsic DNA bending, Q Rev Biophys, 42 (2009) 41-81.

[58] T. Drsata, N. Spackova, P. Jurecka, M. Zgarbova, J. Sponer, F. Lankas, Mechanical properties of symmetric and asymmetric DNA A-tracts: implications for looping and nucleosome positioning, Nucleic Acids Res, 42 (2014) 7383-7394.

[59] P. Yakovchuk, E. Protozanova, M.D. Frank-Kamenetskii, Base-stacking and base-pairing contributions into thermal stability of the DNA double helix, Nucleic Acids Res, 34 (2006) 564-574.

[60] R.E. Dickerson, DNA bending: the prevalence of kinkiness and the virtues of normality, Nucleic Acids Res, 26 (1998) 1906-1926.

[61] R.T. Dame, C. Wyman, N. Goosen, Structural basis for preferential binding of H-NS to curved DNA, Biochimie, 83 (2001) 231-234.

[62] P.T. Beernink, B.W. Segelke, M.Z. Hadi, J.P. Erzberger, D.M. Wilson, 3rd, B. Rupp, Two divalent metal ions in the active site of a new crystal form of human apurinic/apyrimidinic endonuclease, Ape1: implications for the catalytic mechanism, J. Mol. Biol., 307 (2001) 1023-1034.

[63] B.A. Manvilla, E. Pozharski, E.A. Toth, A.C. Drohat, Structure of human apurinic/apyrimidinic endonuclease 1 with the essential Mg2+ cofactor, Acta Crystallogr D Biol Crystallogr, 69 (2013) 2555-2562. [64] S.E. Tsutakawa, D.S. Shin, C.D. Mol, T. Izumi, A.S. Arvai, A.K. Mantha, B. Szczesny, I.N. Ivanov, D.J. Hosfield, B. Maiti, M.E. Pique, K.A. Frankel, K. Hitomi, R.P. Cunningham, S. Mitra, J.A. Tainer, Conserved structural chemistry for incision activity in structurally non-homologous apurinic/apyrimidinic endonuclease APE1 and endonuclease IV DNA repair enzymes, J Biol Chem, 288 (2013) 8445-8455.

[65] H. He, Q. Chen, M.M. Georgiadis, High-resolution crystal structures reveal plasticity in the metal binding site of apurinic/apyrimidinic endonuclease I, Biochemistry, 53 (2014) 6520-6529.

[66] B.D. Freudenthal, W.A. Beard, M.J. Cuneo, N.S. Dyrkheeva, S.H. Wilson, Capturing snapshots of APE1 processing DNA damage, Nat Struct Mol Biol, 22 (2015) 924-931.

[67] A.M. Whitaker, T.S. Flynn, B.D. Freudenthal, Molecular snapshots of APE1 proofreading mismatches and removing DNA damage, Nat Commun, 9 (2018) 399.

[68] M. Redrejo-Rodriguez, A. Vigouroux, A. Mursalimov, I. Grin, D. Alili, Z. Koshenov, Z. Akishev, A. Maksimenko, A.K. Bissenbaev, B.T. Matkarimov, M. Saparbaev, A.A. Ishchenko, S. Morera, Structural comparison of AP endonucleases from the exonuclease III family reveals new amino acid residues in human AP endonuclease 1 that are involved in incision of damaged DNA, Biochimie, 128-129 (2016) 20-33.

[69] F. Cortes Ledesma, S.F. El Khamisy, M.C. Zuma, K. Osborn, K.W. Caldecott, A human 5'-tyrosyl DNA phosphodiesterase that repairs topoisomerase-mediated DNA damage, Nature, 461 (2009) 674-678.

[70] S. Xanthoudakis, R.J. Smeyne, J.D. Wallace, T. Curran, The redox/DNA repair protein, Ref-1, is essential for early embryonic development in mice, Proc. Natl. Acad. Sci. U. S. A., 93 (1996) 8919-8923.

[71] D.J. Hosfield, Y. Guan, B.J. Haas, R.P. Cunningham, J.A. Tainer, Structure of the DNA repair enzyme endonuclease IV and its DNA complex: double-nucleotide flipping at abasic sites and three-metal-ion catalysis, Cell, 98 (1999) 397-408.

[72] E.D. Garcin, D.J. Hosfield, S.A. Desai, B.J. Haas, M. Bjoras, R.P. Cunningham, J.A. Tainer, DNA apurinicapyrimidinic site binding and excision by endonuclease IV, Nat. Struct. Mol. Biol., 15 (2008) 515-522.

[73] A. Mazouzi, A. Vigouroux, B. Aikeshev, P.J. Brooks, M.K. Saparbaev, S. Morera, A.A. Ishchenko, Insight into mechanisms of 3'-5' exonuclease activity and removal of bulky 8,5'-cyclopurine adducts by apurinic/apyrimidinic endonucleases, Proc. Natl. Acad. Sci. U. S. A., 110 (2013) E3071-3080.

[74] C. Abate, D. Luk, T. Curran, A ubiquitous nuclear protein stimulates the DNA-binding activity of fos and jun indirectly, Cell Growth Differ, 1 (1990) 455-462. 
[75] M. Stros, M. Kucirek, S.A. Sani, E. Polanska, HMGB1-mediated DNA bending: Distinct roles in increasing p53 binding to DNA and the transactivation of p53-responsive gene promoters, Biochim Biophys Acta Gene Regul Mech, 1861 (2018) 200-210.

[76] J. Perez-Martin, F. Rojo, V. de Lorenzo, Promoters responsive to DNA bending: a common theme in prokaryotic gene expression, Microbiol Rev, 58 (1994) 268-290.

[77] J.V. Falvo, D. Thanos, T. Maniatis, Reversal of intrinsic DNA bends in the IFN beta gene enhancer by transcription factors and the architectural protein HMG I(Y), Cell, 83 (1995) 1101-1111.

[78] T. Ohyama, Intrinsic DNA bends: an organizer of local chromatin structure for transcription, Bioessays, 23 (2001) 708-715.

[79] R. Schreck, H. Zorbas, E.L. Winnacker, P.A. Baeuerle, The NF-kappa B transcription factor induces DNA bending which is modulated by its 65-kD subunit, Nucleic Acids Res, 18 (1990) 6497-6502.

[80] D.A. Leonard, T.K. Kerppola, DNA bending determines Fos-Jun heterodimer orientation, Nat. Struct. Biol., 5 (1998) 877-881.

[81] G. McGill, D.E. Fisher, DNA bending and the curious case of Fos/Jun, Chem Biol, 5 (1998) R29-38.

[82] T. Okazaki, U. Chung, T. Nishishita, S. Ebisu, S. Usuda, S. Mishiro, S. Xanthoudakis, T. Igarashi, E. Ogata, A redox factor protein, ref1, is involved in negative gene regulation by extracellular calcium, J Biol Chem, 269 (1994) 27855-27862.

[83] T. Izumi, W.D. Henner, S. Mitra, Negative regulation of the major human AP-endonuclease, a multifunctional protein, Biochemistry, 35 (1996) 14679-14683.

[84] G.S. McHaffie, S.H. Ralston, Origin of a negative calcium response element in an ALU-repeat: implications for regulation of gene expression by extracellular calcium, Bone, 17 (1995) 11-14.

[85] C.W. Muller, F.A. Rey, M. Sodeoka, G.L. Verdine, S.C. Harrison, Structure of the NF-kappa B p50 homodimer bound to DNA, Nature, 373 (1995) 311-317.

[86] L. Chen, J.N. Glover, P.G. Hogan, A. Rao, S.C. Harrison, Structure of the DNA-binding domains from NFAT, Fos and Jun bound specifically to DNA, Nature, 392 (1998) 42-48.

[87] C. Chennubhotla, A.J. Rader, L.W. Yang, I. Bahar, Elastic network models for understanding biomolecular machinery: from enzymes to supramolecular assemblies, Phys Biol, 2 (2005) S173-180.

[88] T. Mittag, J.D. Forman-Kay, Atomic-level characterization of disordered protein ensembles, Curr Opin Struct Biol, 17 (2007) 3-14.

[89] C.J. Oldfield, A.K. Dunker, Intrinsically disordered proteins and intrinsically disordered protein regions, Annu Rev Biochem, 83 (2014) 553-584.

[90] R. van der Lee, M. Buljan, B. Lang, R.J. Weatheritt, G.W. Daughdrill, A.K. Dunker, M. Fuxreiter, J. Gough, J. Gsponer, D.T. Jones, P.M. Kim, R.W. Kriwacki, C.J. Oldfield, R.V. Pappu, P. Tompa, V.N. Uversky, P.E. Wright, M.M. Babu, Classification of intrinsically disordered regions and proteins, Chem Rev, 114 (2014) 65896631

[91] L. Lirussi, G. Antoniali, C. Vascotto, C. D'Ambrosio, M. Poletto, M. Romanello, D. Marasco, M. Leone, F. Quadrifoglio, K.K. Bhakat, A. Scaloni, G. Tell, Nucleolar accumulation of APE1 depends on charged lysine residues that undergo acetylation upon genotoxic stress and modulate its BER activity in cells, Mol Biol Cell, 23 (2012) 4079-4096.

[92] K.K. Bhakat, T. Izumi, S.H. Yang, T.K. Hazra, S. Mitra, Role of acetylated human AP-endonuclease (APE1/Ref-1) in regulation of the parathyroid hormone gene, Embo J, 22 (2003) 6299-6309.

[93] D. Suh, D.M. Wilson, 3rd, L.F. Povirk, 3'-phosphodiesterase activity of human apurinic/apyrimidinic endonuclease at DNA double-strand break ends, Nucleic Acids Res., 25 (1997) 2495-2500.

[94] L. Pan, B. Zhu, W. Hao, X. Zeng, S.A. Vlahopoulos, T.K. Hazra, M.L. Hegde, Z. Radak, A. Bacsi, A.R. Brasier, X. Ba, I. Boldogh, Oxidized Guanine Base Lesions Function in 8-Oxoguanine DNA Glycosylase-1mediated Epigenetic Regulation of Nuclear Factor kappaB-driven Gene Expression, J Biol Chem, 291 (2016) $25553-25566$.

[95] X. Ba, I. Boldogh, 8-Oxoguanine DNA glycosylase 1: Beyond repair of the oxidatively modified base lesions, Redox Biol, 14 (2018) 669-678.

[96] S.V. Razin, Y.S. Vassetzky, 3D genomics imposes evolution of the domain model of eukaryotic genome organization, Chromosoma, 126 (2017) 59-69.

[97] T. Izumi, D.B. Brown, C.V. Naidu, K.K. Bhakat, M.A. Macinnes, H. Saito, D.J. Chen, S. Mitra, Two essential but distinct functions of the mammalian abasic endonuclease, Proc. Natl. Acad. Sci. U. S. A., 102 (2005) 5739-5743.

[98] I. Walsh, A.J. Martin, T. Di Domenico, S.C. Tosatto, ESpritz: accurate and fast prediction of protein disorder, Bioinformatics, 28 (2012) 503-509.

[99] F. Sievers, A. Wilm, D. Dineen, T.J. Gibson, K. Karplus, W. Li, R. Lopez, H. McWilliam, M. Remmert, J. Soding, J.D. Thompson, D.G. Higgins, Fast, scalable generation of high-quality protein multiple sequence alignments using Clustal Omega, Mol Syst Biol, 7 (2011) 539. 


\section{FIGURE LEGENDS}

Figure 1. EMSA analysis of the APE1 binding to single-stranded DNA oligonucleotides of varying length. The standard binding reaction mixture $(20 \mu \mathrm{l})$ contained $2 \mathrm{nM}$ of 5'-[ $\left.{ }^{32} \mathrm{P}\right]$-labelled ssDNA oligonucleotide and $500 \mathrm{nM}$ APE1. The mixture was incubated for $30 \mathrm{~min}$ at $6^{\circ} \mathrm{C}$, after which an aliquot was analyzed by EMSA. Lane 1, 11 mer ssDNA; lane 2, as 1, but with APE1; lanes 3, 5, 7, 9, 11, 13 and 15, 15 mer, 22 mer, 28 mer, 36 mer, 40 mer, 38 mer and 63 mer ssDNA, respectively; lanes 4, 6, 8,10,12, 14 and 16, as 3, 5, 7, 9, 11, 13 and 15, but with APE1. The positions of migration of APE1/DNA complexes and free DNA probes are indicated to the right of the gel. "X" denotes contaminating DNA band. For details see Materials and Methods.

Figure 2. EMSA analysis of the APE1 binding to DNA oligonucleotides with varying structures. The standard binding reaction mixture $(20 \mu \mathrm{l})$ contained 1-100 $\mathrm{nM} \mathrm{5'}-\left[{ }^{32} \mathrm{P}\right]-$ labelled single-stranded and duplex oligonucleotides and $500 \mathrm{nM}$ APE1. The mixtures were incubated for $20 \mathrm{~min}$ at room $\mathrm{T}^{\circ} \mathrm{C}$, after which an aliquot was analyzed by EMSA. Lane 1, control free $1 \mathrm{nM} 22$ mer ssDNA; lanes 2-8, 1, 2, 5, 10, 20, 50 and $100 \mathrm{nM} 22$ mer ssDNA incubated with $500 \mathrm{nM}$ APE1; lane 9, control free $1 \mathrm{nM}$ 22 mer dsDNA; lanes 10-16, 1, 2, 5, 10, 20, 50 and $100 \mathrm{nM} 22$ mer dsDNA incubated with $500 \mathrm{nM}$ APE1; lane 17, control free $1 \mathrm{nM} 50$ mer dumbbell-shaped duplex DNA (dmbDNA); lanes 18-23, 1, 5, 10, 20, 50 and $100 \mathrm{nM} 50$ mer dmbDNA incubated with $500 \mathrm{nM}$ APE1. Schematic drawings of three DNA structures used are shown at the top of the gel. The positions of migration of APE1/DNA complexes and free DNA probes are indicated to the right of the gel. "X" denotes contaminating DNA band. For details see Materials and Methods.

Figure 3. UV cross-linking of APE1 to single-stranded DNA. Odd lanes, $(\mathrm{dT})_{22}$, even lanes, $(\mathrm{dT})_{50}$. Lanes 1 and 2, no UV and no APE1; lanes 3 and 4, no UV, $2 \mu \mathrm{M}$ APE1; lanes 5 and 6, 30 min UV, $2 \mu \mathrm{M}$ APE1; lanes 7 and 8, $30 \mathrm{~min} \mathrm{UV}, 1 \mu \mathrm{M}$ APE1; lanes 9 and 10, $30 \mathrm{~min} \mathrm{UV}$, no APE1. Arrows indicate the bands presumably corresponding to 1,2 and more than 2 molecules of APE1 cross-linked to single-stranded oligo-dT. For details see Materials and Methods.

Figure 4. APE1-catalyzed NIR activity towards dumbbell-shaped DNA sructure. $(A)$ Denaturing PAGE analysis of the cleavage products. Briefly, $10 \mathrm{nM} 5^{\prime}-{ }^{32} \mathrm{P}-$ labeled $\alpha \mathrm{dA} \cdot \mathrm{T}$ and $\alpha \mathrm{dA} \cdot \mathrm{Z}$ duplex oligonucleotides were incubated in the NIR reaction buffer $(20 \mu \mathrm{l})$ for $0-60 \mathrm{~min}$ at $37^{\circ} \mathrm{C}$ in the presence of $5 \mathrm{nM}$ APE1. Lane 1, control $22 \mathrm{mer} \alpha \mathrm{dA} \bullet \mathrm{T}$ duplex; lanes 2-4, as 1, but APE1 for 5, 10 and $60 \mathrm{~min}$; lane 5, control $51 \mathrm{mer}$ adA $\bullet$ T dumbbell oligonucleotide duplex (dmbDNA); lanes 6-8, as 5, but APE1 for 5, 10 and $60 \mathrm{~min}$; lane 9, control 51 mer $\alpha \mathrm{dA} \cdot \mathrm{Z}$ dmbDNA; lanes 10-12, as 9, but APE1 for 5, 10 and $60 \mathrm{~min}$; lane 13, control 50 mer $\alpha \mathrm{dA} \bullet$ T nicked oligonucleotide duplex; lanes 14-16, as 13, but APE1 for 5, 10 and $60 \mathrm{~min}$. Schematic drawings of four oligonucleotide DNA duplexes used are shown at the top of the gel. Substrate and cleavage product sizes and $3^{\prime} \rightarrow 5^{\prime}$ exonuclease degraded fragments are indicated to the right of the gel. $(B)$ Chemical structures of modified DNA bases used in the assay. For details, see Materials and Methods.

Figure 5. APE1-stimulated binding of AP-1 to regular and dumbbell-shaped DNA duplexes. $(A)$

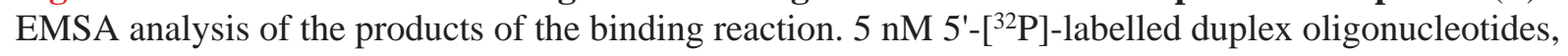
51 mer dmbDNA (dumbbell) and 50 mer dsDNA (full duplex) were incubated in the standard EMSA buffer $(20 \mu \mathrm{l})$ containing $500 \mathrm{nM}$ APE1, $250 \mathrm{nM}$ AP-1 and $1 \mathrm{mM}$ of the reducing agents GSH or DTT. After incubation for $30 \mathrm{~min}$ at room $\mathrm{T}^{\circ} \mathrm{C}$, the products were analyzed by gel shift assay. Lane 1 , control free 51 mer dmbDNA probe; lane 2, dmbDNA + APE1; lane 3, dmbDNA + AP-1; lane 4, dmbDNA + AP-1/APE1; lane 5, dmbDNA + AP-1/GSH; lane 6, dmbDNA + AP-1/GSH/APE1; lane 7, dmbDNA + AP-1/DTT; lane 8, dmbDNA + AP-1/DTT/APE1; lanes 9-16, same as 1-8 but with 50 mer dsDNA probe. Schematic drawings of dmbDNA and dsDNA oligonucleotide probes used are 
shown at the top of the gel. The positions of migration of AP-1/DNA complex and free DNA probe are indicated to the right of the gel. "X" denotes contaminating DNA band. (B) Graphical representation of the APE1-mediated stimulation of AP-1 DNA binding to dmbDNA, dsDNA (full duplex) and nicked duplex DNA. Asterisks indicate statistically significant, whereas "ns" indicates not significant differences between the means. For details see Materials and Methods.

Figure 6. APE1 together with reducing agents stimulate DNA binding of the NF-кB p50 subunit

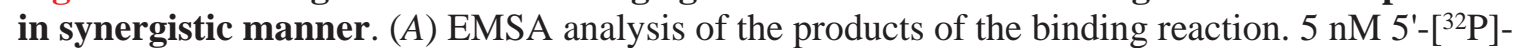
labelled 11 and 26 mer oligonucleotide duplexes were incubated in the EMSA buffer for p50 $(20 \mu \mathrm{l})$ containing $500 \mathrm{nM}$ APE1, $100 \mathrm{nM} \mathrm{p} 50$ and varying concentration of the reducing agents GSH and DTT. After incubation for $30 \mathrm{~min}$ at room $\mathrm{T}^{\circ} \mathrm{C}$, the samples were analyzed by EMSA. Lanes 1 and 10, control free 11 and 26 mer DNA; lanes 2 and 11, as 1 and 10, but p50; lanes 3 and 12, as 1 and 10, but p50 and APE1; lanes 4 and 13, as 1 and 10, but p50 and $1 \mathrm{mM} \mathrm{GSH}$; lanes 5 and 14, as 1 and 10, but p50, $1 \mathrm{mM} \mathrm{GSH}$ and APE1; lanes 6 and 15, as 1 and 10, but p50 and 0.1 mM DTT; lanes 7 and 16, as 1 and 10, but p50, $0.1 \mathrm{mM}$ DTT and APE1; lanes 8 and 17, as 1 and 10, but p50 and $1 \mathrm{mM}$ DTT; lanes 9 and 18, as 1 and 10, but p50, $1 \mathrm{mM}$ DTT and APE1. The positions of migration of p50/DNA complex and free DNA probe are indicated to the right of the gel. (B) Graphical representation of the APE1-mediated stimulation of p50 DNA binding to 11 and 26 mer oligonucleotide duplexes. Asterisks indicate statistically significant, whereas "ns" indicates not significant differences between the means. For details see Materials and Methods.

Figure 7. Plant AP endonucleases stimulate DNA binding of the NF-אB p50 subunit to 26 mer DNA duplex. $5 \mathrm{nM} 5$ '-[ $\left.{ }^{32} \mathrm{P}\right]$-labelled 26 mer duplex oligonucleotide was incubated in the EMSA buffer for p50 (20 $\mu \mathrm{l})$ containing $10 \mathrm{nM}$ p50, $500 \mathrm{nM}$ AP endonuclease (APE1, N $\Delta 61$-APE1, ARP or wARP), and $1 \mathrm{mM} \mathrm{GSH}$. After incubation for $30 \mathrm{~min}$ at room $\mathrm{T}^{\circ} \mathrm{C}$, the samples were analyzed by EMSA. Lane 1, control free 26 mer oligonucleotide duplex; lane 2, as 1, but p50; lane 3, as 1, but p50 and GSH; lane 4, as 1, but p50 and N $\triangle 61-\mathrm{APE} 1$; lane 5, as 1, but p50, GSH and N $\triangle 61-\mathrm{APE} 1$; lane 6, as 1, but p50 and APE1; lane 7, as 1, but p50, GSH and APE1; lane 8, as 1, but p50 and wARP; lane 9, as 1, but p50, GSH and wARP; lane 10, as 1, but p50 and ARP; lane 5, as 1, but p50, GSH and ARP. The positions of migration of p50/DNA complex and free DNA probe are indicated to the right of the gel. For details see Materials and Methods.

Figure 8. APE1 stimulates binding of the NF-kB p50-C62S redox insensitive mutant to 26 mer DNA duplex. $5 \mathrm{nM}$ of 5'-[ ${ }^{32} \mathrm{P}$-labelled 26 mer duplex oligonucleotide was incubated in the EMSA buffer for p50 (20 $\mu \mathrm{l})$ containing $10 \mathrm{nM}$ p50-C62S, $500 \mathrm{nM}$ APE1, and varying concentrations of GSH and DTT. After incubation for $30 \mathrm{~min}$ at room $\mathrm{T}^{\circ} \mathrm{C}$, the products of the binding reaction were analyzed by EMSA. Lane 1, control free 26 mer duplex DNA; lane 2, as 1, but with APE1; lane 3, as 1, but with p50-C62S; lane 4, as 1, but with p50-C62S treated by $70 \mu \mathrm{M}$ diamide; lane 5, as 1, but with p50-C62S and APE1; lanes 6-7, as 3, but with 1 and 5 mM DTT; lanes 8-9, as 6-7, but with APE1; lanes 10-11, as 3, but with 1 and $5 \mathrm{mM}$ GSH; lanes 12-13, as 10-11, but with APE1. The positions of migration of AP-1/DNA complex and free DNA probe are indicated to the right of the gel. For details see Materials and Methods.

Figure 9. Interactions of the APE1 and APE1-C $\Delta 128$ proteins with covalently closed circular negatively supercoiled DNA. Filtered dark-field electron microscopy images of $5 \mathrm{nM}$ supercoiled pUC19 plasmids in binding buffer containing $10 \mathrm{mM}$ Tris-HCl pH 8 and $50 \mathrm{mM} \mathrm{NaCl}$. $(A)$ DNA alone. $(B)$ DNA was incubated in the presence of $2,5 \mu \mathrm{M}$ of APE1-WT or $(C) 5 \mu \mathrm{M}$ APE1-C $\Delta 128$. The full-length APE1 and APE1-C $\Delta 128$ proteins bind (91\% of plasmid DNA) and bridge negatively supercoiled DNA. Scale Bar $=200 \mathrm{~nm}$. For details see Materials and Methods. 
Figure 10. Interactions of the APE1 and APE1-C $\triangle 128$ proteins with gapped DNA fragment. Filtered dark-field electron microscopy images of $5 \mathrm{nM} 1440 \mathrm{bp}$ gapped DNA fragment (1440gapDNA) incubated in binding buffer containing $10 \mathrm{mM}$ Tris- $\mathrm{HCl} \mathrm{pH} 8,50 \mathrm{mM} \mathrm{NaCl}$. (Al) 1440gapDNA alone. (A2-A5) 1440gapDNA $500 \mathrm{nM}$ of APE1, or (B1-B5) with APE1-C 128 proteins. APE1 and APE1-C $\Delta 128$ proteins recognize and stably bind to DNA areas which have an anisotropic flexibility. For details see Materials and Methods.

Figure 11. Interactions of the APE1 and APE1-C $\triangle 128$ proteins with linear plasmid DNA fragment containing curvature. Linear pBR322 DNA fragment was incubated with $500 \mathrm{nM}$ APE1 or APE1-C $\Delta 128$ proteins in the binding buffer containing $10 \mathrm{mM}$ Tris- $\mathrm{HCl} \mathrm{pH} 8$ and $50 \mathrm{mM} \mathrm{NaCl}$. The products of the binding reaction were analyzed by TEM. (A) Schematic representation of the DNA fragment containing $\mathrm{C} 7$ region with intrinsic curvature using the DNA ReSCue. (B) Filtered dark-field electron micrograph of control $5 \mathrm{nM}$ linear pBR322 dsDNA containing $\mathrm{C} 7$ curved region. The APE1 (C1-C4) and APE1-CA128 (D1-D5) proteins induce kink in DNA when they bind A-tract enriched region. Arrows indicate position of APE1 oligomers. The underlined DNA sequences show A/T tracts. Scale Bar $=100 \mathrm{~nm}$. For details see Materials and Methods.

Figure 12. Computer aided three-dimensional reconstruction and modeling of the full-length APE1 molecule. (A) Structure of the full-length APE1 model. The modeled and docked APE $1-46$ fragment is shown in magenta. Coordinates of the bound DNA are from PDB structure 1DE8 (APE1 bound to THF-containing 11-mer, [12]. (B) Model of an APE1 tetramer with bound DNA. Four $\mathrm{APE} 1_{\text {full }}$ molecules shown as surface representation (salmon, olive, pink, and lavender) with their folded $\mathrm{APE}_{1-46}$ fragments shown in brighter colors (red, green, magenta, and blue, respectively). Four DNA molecules are shown as sphere models. (C) Superposition of APE1 (cyan, PDB ID 1BIX [45] and TDP2 bound at the end of a DNA duplex with one hanging nucleotide (green, PDB ID 5INQ [49]. 


\title{
Appendix A. Supplementary data
}

\author{
Supporting Information Figure Legends
}

\begin{abstract}
SI Appendix, Figure S1. EMSA analysis of the APE1 binding to 22 mer oligo (dT) primer. $(A)$ EMSA analysis of the products of the binding reaction. $2 \mathrm{nM} 5^{5}-\left[{ }^{32} \mathrm{P}\right]$-labelled 22 mer regular oligonucleotide (ssDNA), oligo (dT) 22 primer, and 22 mer oligonucleotide duplex (dsDNA) were incubated in the EMSA buffer for APE1 binding $(20 \mu \mathrm{l})$ containing $500 \mathrm{nM}$ APE1, and varying amount of poly(dI:dC) $\bullet$ poly $(\mathrm{dI}: \mathrm{dC})(0-100 \mathrm{ng})$. After incubation for $30 \mathrm{~min}$ at $+6^{\circ} \mathrm{C}$, the samples were analyzed by EMSA. Lanes 1, 4 and 7, control free 22 mer ssDNA, oligo (dT) and dsDNA; lane 8, as 7 but with APE1; lanes 2, 5 and 9, as 1, 4 and 7, but with APE1 + $50 \mathrm{ng}$ poly(dI:dC)•poly(dI:dC); lanes 3, 6 and 10, as 1, 4 and 7, but with APE1 + $100 \mathrm{ng}$ poly(dI:dC)•poly(dI:dC). Schematic drawings of three DNA substrates used are shown at the top of the gel. The positions of migration of APE1/DNA complex and free DNA probe are indicated to the right of the gel. (B) Graphical representation of the APE1/DNA complex formation with different DNA substrates. For details see Materials and Methods.
\end{abstract}

SI Appendix, Figure S2. APE1-catalyzed AP site cleavage activity towards dumbbell-shaped DNA sructure. $10 \mathrm{nM} 5{ }^{\prime}-{ }^{32} \mathrm{P}$-labeled THF$\bullet T$ duplex oligonucleotides were incubated in the BER reaction buffer $(20 \mu \mathrm{l})$ for $0-60 \mathrm{~min}$ at $37^{\circ} \mathrm{C}$ in the presence of $0.1 \mathrm{nM}$ APE1. Lane 1, control $22 \mathrm{mer}$ $\mathrm{THF} \bullet \mathrm{T}$ duplex; lanes 2-8, as 1 but APE1 for 0.5, 1, 5, 10, 15, 30 and $60 \mathrm{~min}$; lane 9, control $51 \mathrm{THF} \bullet \mathrm{T}$ mer dumbbell oligonucleotide duplex (dmbDNA); lanes 10-16, as 9, but APE1 for 0.5, 1, 5, 10, 15, 30 and $60 \mathrm{~min}$; lane 17, control $51 \mathrm{mer} \mathrm{THF} \cdot \mathrm{Z}$ dumbbell oligonucleotide duplex (dmbDNA); lanes 18-24, as 17, but APE1 for $0.5,1,5,10,15,30$ and $60 \mathrm{~min}$. Schematic drawings of three DNA substrates used are shown at the top of the gel. Substrate and cleavage product sizes are indicated to the right of the gel. For details, see Materials and Methods.

SI Appendix, Figure S3. E. coli Nfo-catalyzed NIR activity towards dumbbell-shaped DNA

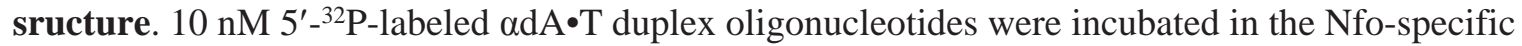
reaction buffer $(20 \mu \mathrm{l})$ for $0-120 \mathrm{~min}$ at $37^{\circ} \mathrm{C}$ in the presence of $1 \mathrm{nM} \mathrm{Nfo}$. Lane 1, control $22 \mathrm{mer}$ $\alpha \mathrm{dA} \cdot \mathrm{T}$ duplex; lanes 2-7, as 1 but Nfo for 1, 5, 10, 30, 60 and $120 \mathrm{~min}$; lane 8, control 51 mer $\alpha \mathrm{dA} \bullet \mathrm{T}$ dumbbell oligonucleotide duplex (dmbDNA); lanes 9-14, as 9, but APE1 for 1, 5, 10, 30, 60 and 120 min. Schematic drawings of two DNA substrates used are shown at the top of the gel. Substrate and cleavage product sizes are indicated to the right of the gel. For details, see Materials and Methods.

SI Appendix, Figure S4. EMSA analysis of the APE1-stimulated binding of AP-1 to nicked oligonucleotide duplex. $5 \mathrm{nM}$ 5'-[ $\left.{ }^{32} \mathrm{P}\right]$-labelled 50 mer nicked DNA duplex was incubated in the standard EMSA buffer $(20 \mu \mathrm{l})$ containing $500 \mathrm{nM}$ APE1, $250 \mathrm{nM}$ AP-1 and $1 \mathrm{mM}$ of the reducing agents GSH or DTT. After incubation for $30 \mathrm{~min}$ at room $\mathrm{T}^{\circ} \mathrm{C}$, the DNA bound products were analyzed by EMSA. Lane 1, control free DNA probe; lane 2, as 1, but with APE1; lane 3, as 1, but with oxidized AP-1; lane 4, as 1, but with APE1 and AP-1; lane 5, as 1, but with AP-1 and GSH; lane 6, as 1, but with AP-1, APE1 and GSH; lane 7, as 1, but with AP-1 and DTT; lane 8, as 1, but with AP-1, APE1 and DTT. Schematic drawing of nicked oligonucleotide DNA duplex used is shown at the top of the gel. The positions of migration of AP-1/DNA complex and free DNA probe are indicated to the right of the gel. For details see Materials and Methods.

SI Appendix, Figure S5. Arabidopsis and wheat AP endonucleases stimulate DNA binding of AP-1. 5 nM 50 mer 5'-[32P]-labelled full duplex oligonucleotide (dsDNA) was incubated in the standard EMSA buffer (20 $\mu \mathrm{l})$ containing $250 \mathrm{nM}$ AP-1, $1 \mathrm{mM} \mathrm{GSH}$ and 0.5-2.0 $\mu \mathrm{M}$ A. thaliana ARP or T. aestivum wARP. After incubation for $30 \mathrm{~min}$ at room $\mathrm{T}^{\circ} \mathrm{C}$, the products of the binding reaction were analysed by EMSA. Lane 1, control free 50 mer dsDNA probe; lane 2, as 1, but with AP-1; lane 3 , as 1, but with AP-1 and GSH; lanes 4-6, as 2, but with 0.5, 1.0 and 2.0 $\mu \mathrm{M}$ ARP, respectively; lanes 
7-9, as 3, but with $0.5,1.0$ and $2.0 \mu \mathrm{M}$ ARP, respectively; lanes 10-12, as 2, but with $0.5,1.0$ and 2.0 $\mu \mathrm{M}$ wARP, respectively; lanes $13-15$, as 3 , but with $0.5,1.0$ and $2.0 \mu \mathrm{M}$ wARP, respectively; lane 16 , same as 2; lane 17, as 2, but with $0.5 \mu \mathrm{M}$ APE1. The positions of migration of AP-1/DNA complex and free DNA probe are indicated to the right of the gel. For details see Materials and Methods.

SI Appendix, Figure S6. Binding of the NF-кB p50-C62S redox insensitive mutant to 11 and 26 mer DNA duplexes in the presence of APE1 and reducing agents. $5 \mathrm{nM} 5$ 5'-[ $\left.^{32} \mathrm{P}\right]$-labelled $11 \mathrm{mer}$ and 26 mer oligonucleotide duplex was incubated in the EMSA buffer for p50 $(20 \mu \mathrm{l})$ containing 50 and $100 \mathrm{nM}$ p50-C62S, $500 \mathrm{nM}$ APE1, and varying concentrations of GSH and DTT. After incubation for $30 \mathrm{~min}$ at room $\mathrm{T}^{\circ} \mathrm{C}$, the products of the binding reaction were analyzed by EMSA. (A) Binding of NF- $\kappa B$ p50-C62S to 11 mer DNA duplex. Lane 1, control free 11 mer duplex DNA; lane 2, as 1, but with p50-C62S; lane 3, as 1, but with p50-C62S treated by $70 \mu \mathrm{M}$ diamide; lane 4 , as 2, but with 1 mM DTT; lane 5, as 2, but with $1 \mathrm{mM}$ GSH; lane 6, as 2, but with APE1; lane 7, as 6, but with $1 \mathrm{mM}$ GSH. (B) Binding of NF- $\kappa B$ p50-C62S to 26 mer DNA duplex. Lane 1, control free 26 mer duplex DNA; lane 2, as 1, but with $50 \mathrm{nM}$ p50-C62S; lane 3, as 1, but with $50 \mathrm{nM} \mathrm{p50-C62S} \mathrm{treated} \mathrm{by} 70$ $\mu \mathrm{M}$ diamide; lane 4, as 2, but with $1 \mathrm{mM}$ DTT; lane 5, as 2, but with $1 \mathrm{mM} \mathrm{GSH}$; lane 6, as 2, but with APE1; lane 7, as 6, but with $1 \mathrm{mM} \mathrm{GSH}$. lane 8, as 1, but with $100 \mathrm{nM} \mathrm{p50-C62S;} \mathrm{lane} \mathrm{9,} \mathrm{as} \mathrm{1,} \mathrm{but}$ with $100 \mathrm{nM}$ p50-C62S treated by $70 \mu \mathrm{M}$ diamide; lane 10, as 8, but with $1 \mathrm{mM}$ DTT; lane 11, as 8 , but with $1 \mathrm{mM}$ GSH; lane 12, as 8, but with APE1. The positions of migration of p50-C62S/DNA complex and free DNA probe are indicated to the right of the gel. For details see Materials and Methods.

SI Appendix, Figure S7. APE1 stimulates binding of the NF-кB p50-C62S redox insensitive mutant to 11 mer DNA duplex. $5 \mathrm{nM} 5$ '-[ $\left.{ }^{32} \mathrm{P}\right]$-labelled 11 mer oligonucleotide duplex was incubated in the EMSA buffer for p50 (20 $\mu \mathrm{l})$ containing $10 \mathrm{nM}$ p50-C62S, $500 \mathrm{nM}$ APE1, and varying concentrations of GSH and DTT. After incubation for $30 \mathrm{~min}$ at room $\mathrm{T}^{\circ} \mathrm{C}$, the products of the binding reaction were analyzed by EMSA. Lane 1, control free 11 mer duplex DNA; lane 2, as 1, but with APE1; lane 3, as 1, but with p50-C62S; lane 4, as 1, but with p50-C62S treated by $70 \mu \mathrm{M}$ diamide; lane 5, as 1, but with p50-C62S and APE1; lanes 6-7, as 3, but with 1 and $5 \mathrm{mM}$ DTT; lanes 8-9, as 67, but with APE1; lanes 10-11, as 3, but with 1 and $5 \mathrm{mM} \mathrm{GSH}$; lanes 12-13, as 10-11, but with APE1. The positions of migration of p50-C62S/DNA complex and free DNA probe are indicated to the right of the gel. For details see Materials and Methods.

SI Appendix, Figure S8. Matrix of correlations in fluctuation between APE1 residues in $(A)$ structure 2O3H [17]; starting at Met37, this is the longest available human APE1 structure) and (B) $\mathrm{APE} 1_{\text {full }}$ model. Co-variation was calculated over the first 20 normal modes. Blue to red heat scale is for the cross correlation between different residues. The $\mathrm{N}$-terminal $\mathrm{APE}_{1-46}$ fragment as present in the structures is boxed.

SI Appendix, Figure S9. The shapes of the N-terminal fragment of APE1 obtained by ab initio folding and protein-protein docking. $(A)$ Three best models after docking the folded $\mathrm{APE}_{1-46}$ fragment on the $\mathrm{APE}_{47-318}$ structure. $\mathrm{APE}_{47-318}$ and the best model of $\mathrm{APE}_{1-46}(\mathrm{C}[\mathrm{Glu} 46]-$ $\mathrm{N}[$ Asp47] = $3.82 \AA$ ) are shown in green, the second-best model $(5.02 \AA)$, in cyan, the third (5.69 $\AA$ ), in magenta. (B) Distribution of C[Glu46]-N[Asp47] in 100 docked pairs of $\mathrm{APE}_{1-46}$ model with $\mathrm{APE}_{47-}$ 318 structure.

SI Appendix, Figure S10. Superimposition of the X-ray structures. Structure of APE1 (PDB ID 1BIX, colored salmon) superimposed over the homology models of the APE1 catalytic domain built on TDP2 templates (PDB IDs 5INL, green, 5INO, cyan, 5INP, magenta, 5INQ, yellow [49]. The DNA-binding groove is facing the viewer. Note that the most pronounced structural differences between the models are around the $\alpha 9$ helix of 1BIX (left) away from the DNA-binding groove.

SI Appendix, Figure S11. Disorder prediction in the sequence of APE1. The prediction was performed by ESpritz bi-directional recursive neural network trained on a DisProt set [98]. The 
checkered pattern marks the catalytic domain of APE1 (Leu62-Leu316). The dashed line marks the position of C65.

SI Appendix, Supplemental File S1. Alignment of several metazoan APE1 sequences, limited to one per taxonomic class. Vertebrate sequences are shown in bold; the position corresponding to C65 of human APE1 is marked. The alignment was produced by Clustal Omega v1.2.4 [99]. 


\title{
Appendix A. Supplementary data
}

\section{Mechanism of stimulation of DNA binding of the transcription factors by human apurinic/apyrimidinic endonuclease 1, APE1}

\author{
Milena BAZLEKOWA-KARABAN ${ }^{a, b, c, 1}$, Paulina PROROK ${ }^{a, b, d, 1}$, Sonia BACONNAIS ${ }^{e}$, Sabira \\ TAIPAKOVA ${ }^{f}$, Zhiger AKISHEV ${ }^{f}$, Dominika ZEMBRZUSKA ${ }^{c}$, Alexander V. POPOV ${ }^{g, h}$, Anton V. \\ ENDUTKIN $^{g, h}$, Regina GROISMAN ${ }^{a}$, Alexander A. ISHCHENKO ${ }^{a}$, Bakhyt T. MATKARIMOV ${ }^{i}$, \\ Amangeldy BISSENBAEV $V^{f}$ Eric LE CAM ${ }^{e}$, Dmitry O. ZHARKOV ${ }^{g, h}$, Barbara TUDEK ${ }^{b, c, *}$, and Murat \\ SAPARBAEV ${ }^{a, *}$ \\ ${ }^{a}$ Groupe «Réparation de l'ADN», Equipe Labellisée par la Ligue Nationale Contre le Cancer, CNRS \\ UMR8200, Université Paris-Sud, Gustave Roussy Cancer Campus, F-94805 Villejuif Cedex, France. \\ ${ }^{b}$ Institute of Biochemistry and Biophysics, Polish Academy of Sciences, 02-106 Warsaw, Poland. \\ ${ }^{c}$ Institute of Genetics and Biotechnology, University of Warsaw, Warsaw, Poland. \\ ${ }^{d}$ Institute of Human Genetics, UMR 9002, CNRS and the University of Montpellier, Replication and \\ Genome Dynamics, 141 rue de la Cardonille, 34396, Montpellier, France; \\ ${ }^{e}$ CNRS UMR8126, Université Paris-Sud, Université Paris-Saclay, Gustave Roussy Cancer Campus, \\ F-94805 Villejuif Cedex, France. \\ ${ }^{f}$ Department of Molecular Biology and Genetics, Faculty of Biology, al-Farabi Kazakh National \\ University, 0530040, Almaty, Kazakhstan. \\ ${ }^{g}$ Institute of Chemical Biology and Fundamental Medicine, SB RAS, Novosibirsk 630090, Russia. \\ ${ }^{h}$ Novosibirsk State University, Novosibirsk 630090, Russia. \\ ${ }^{i}$ National laboratory Astana, Nazarbayev University, Astana 010000, Kazakhstan.
}


Supporting Information SI Appendix Figures S1-S11 


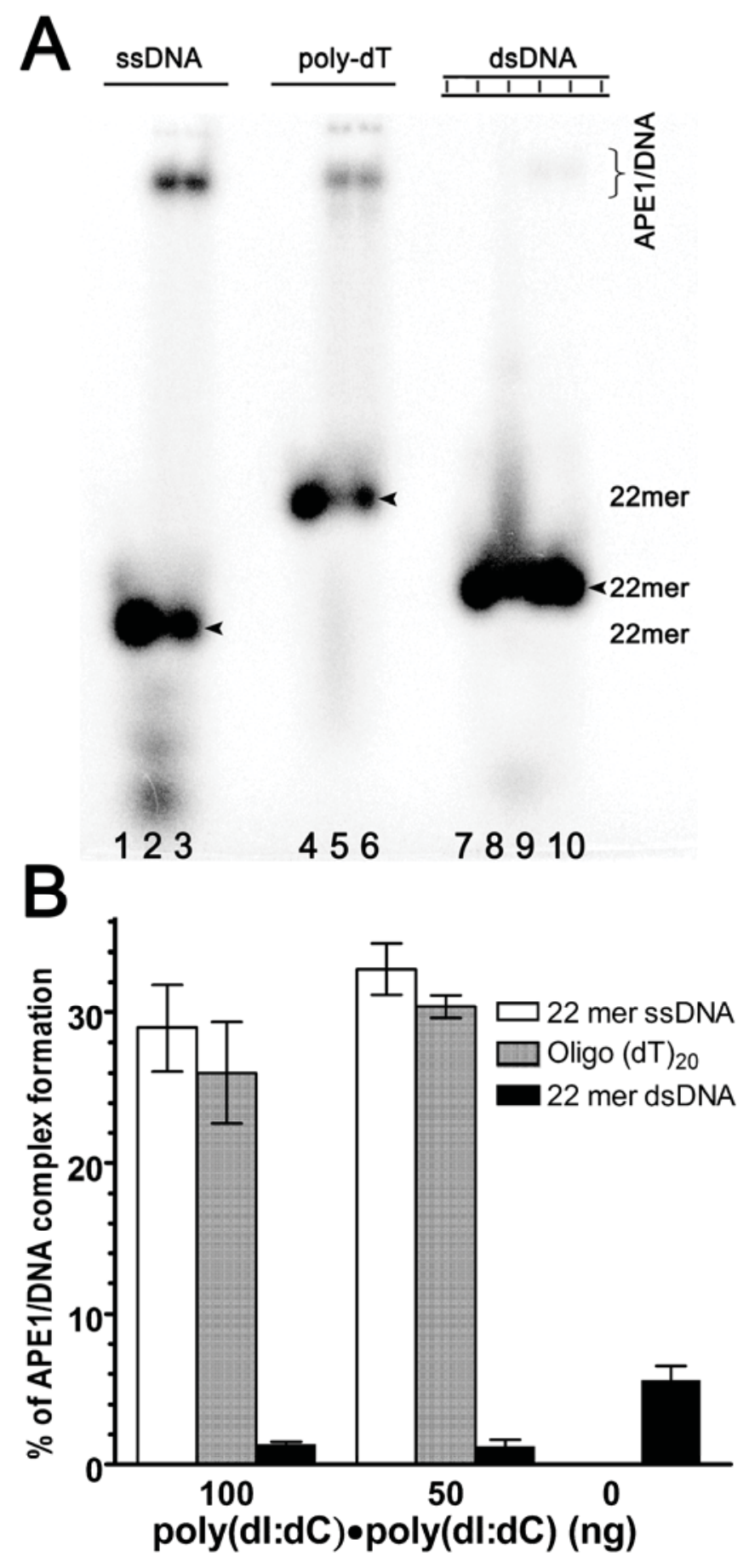

SI Appendix, Figure S1. EMSA analysis of the APE1 binding to 22 mer oligo (dT) primer. (A)

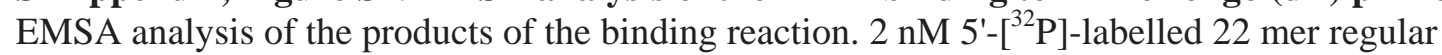
oligonucleotide (ssDNA), oligo (dT) 22 primer, and 22 mer oligonucleotide duplex (dsDNA) were incubated in the EMSA buffer for APE1 binding $(20 \mu \mathrm{l})$ containing $500 \mathrm{nM}$ APE1, and varying amount of poly $(\mathrm{dI}: \mathrm{dC}) \bullet \operatorname{poly}(\mathrm{dI}: \mathrm{dC})(0-100 \mathrm{ng})$. After incubation for $30 \mathrm{~min}$ at $+6^{\circ} \mathrm{C}$, the samples were analyzed by EMSA. Lanes 1, 4 and 7, control free 22 mer ssDNA, oligo (dT) and dsDNA; lane 8, as 7 but with APE1; lanes 2, 5 and 9, as 1, 4 and 7, but with APE1 + $50 \mathrm{ng}$ poly(dI:dC)•poly(dI:dC); lanes 3, 6 and 10, as 1, 4 and 7, but with APE1 + $100 \mathrm{ng}$ poly(dI:dC)•poly(dI:dC). Schematic drawings of three DNA substrates used are shown at the top of the gel. The positions of migration of APE1/DNA complex and free DNA probe are indicated to the right of the gel. (B) Graphical representation of the APE1/DNA complex formation with different DNA substrates. For details see Materials and Methods. 


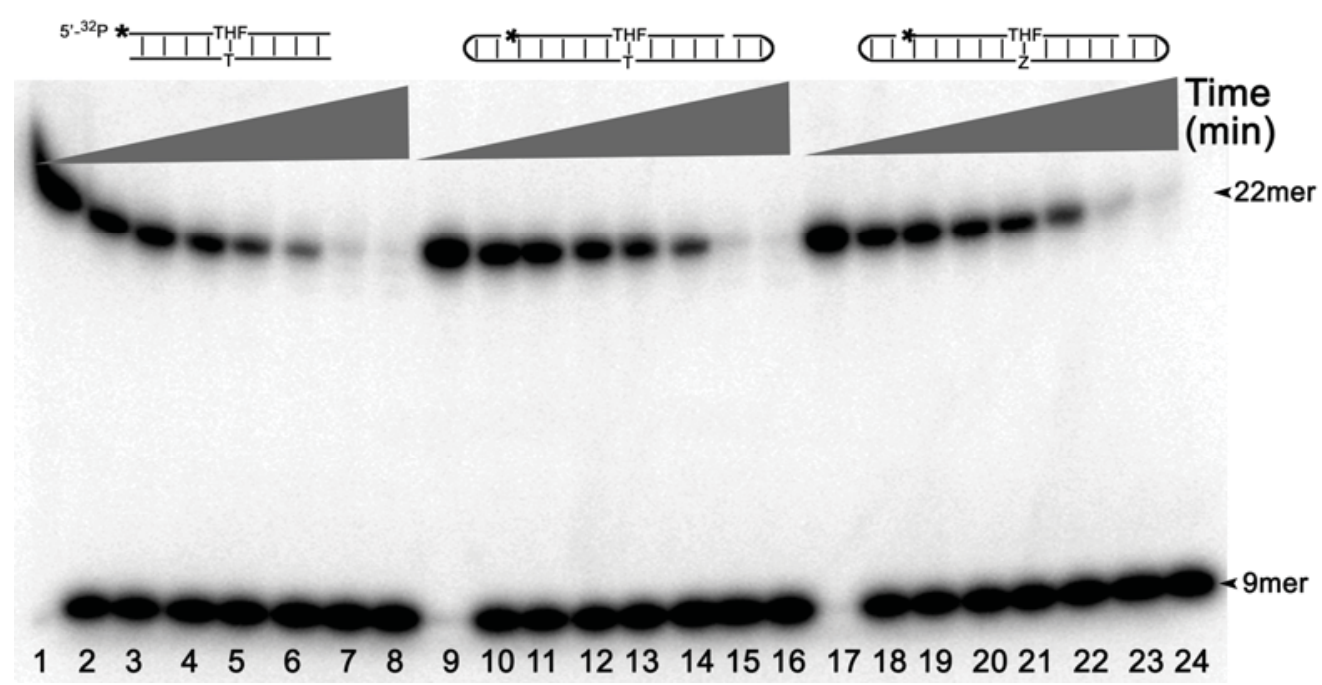

SI Appendix, Figure S2. APE1-catalyzed AP site cleavage activity towards dumbbell-shaped DNA sructure. $10 \mathrm{nM} 5^{\prime}{ }_{-}^{32} \mathrm{P}$-labeled THF $\bullet$ T duplex oligonucleotides were incubated in the BER reaction buffer $(20 \mu \mathrm{l})$ for $0-60 \mathrm{~min}$ at $37^{\circ} \mathrm{C}$ in the presence of $0.1 \mathrm{nM}$ APE1. Lane 1, control $22 \mathrm{mer}$ $\mathrm{THF} \bullet \mathrm{T}$ duplex; lanes 2-8, as 1 but APE1 for 0.5, 1, 5, 10, 15, 30 and $60 \mathrm{~min}$; lane 9, control $51 \mathrm{THF} \bullet \mathrm{T}$ mer dumbbell oligonucleotide duplex (dmbDNA); lanes 10-16, as 9, but APE1 for 0.5, 1, 5, 10, 15, 30 and $60 \mathrm{~min}$; lane 17, control $51 \mathrm{mer} \mathrm{THF} \bullet \mathrm{Z}$ dumbbell oligonucleotide duplex (dmbDNA); lanes 18-24, as 17, but APE1 for $0.5,1,5,10,15,30$ and 60 min. Schematic drawings of three DNA substrates used are shown at the top of the gel. Substrate and cleavage product sizes are indicated to the right of the gel. For details, see Materials and Methods.
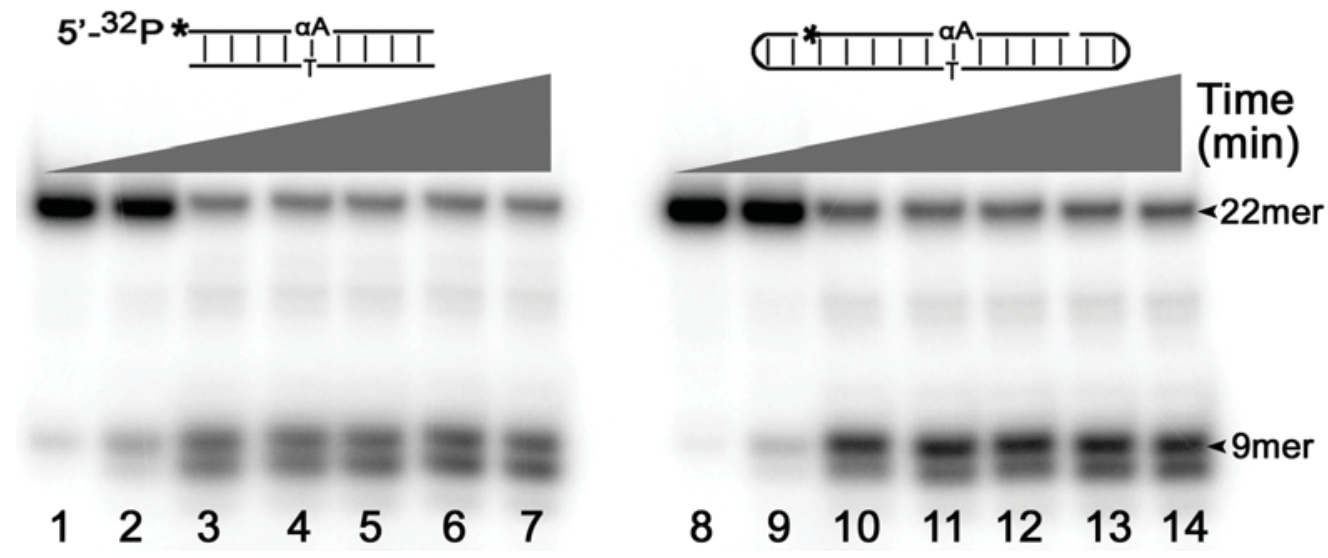

SI Appendix, Figure S3. E. coli Nfo-catalyzed NIR activity towards dumbbell-shaped DNA sructure. $10 \mathrm{nM} 5^{\prime}-{ }^{32} \mathrm{P}$-labeled $\alpha \mathrm{dA} \cdot \mathrm{T}$ duplex oligonucleotides were incubated in the Nfo-specific reaction buffer $(20 \mu \mathrm{l})$ for $0-120 \mathrm{~min}$ at $37^{\circ} \mathrm{C}$ in the presence of $1 \mathrm{nM} \mathrm{Nfo}$. Lane 1, control $22 \mathrm{mer}$ $\alpha \mathrm{dA} \bullet \mathrm{T}$ duplex; lanes 2-7, as 1 but Nfo for 1, 5, 10, 30, 60 and $120 \mathrm{~min}$; lane 8, control 51 mer $\alpha \mathrm{dA} \bullet \mathrm{T}$ dumbbell oligonucleotide duplex (dmbDNA); lanes 9-14, as 9, but APE1 for 1, 5, 10, 30, 60 and 120 min. Schematic drawings of two DNA substrates used are shown at the top of the gel. Substrate and cleavage product sizes are indicated to the right of the gel. For details, see Materials and Methods. 


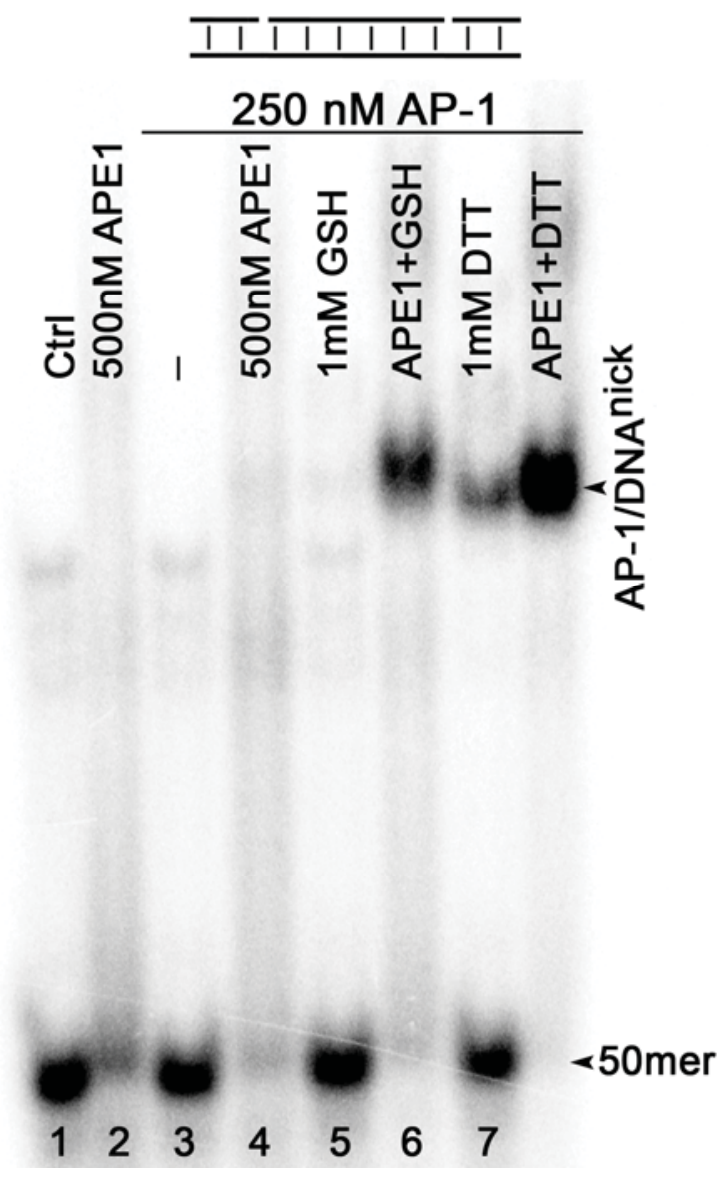

SI Appendix, Figure S4. EMSA analysis of the APE1-stimulated binding of AP-1 to nicked

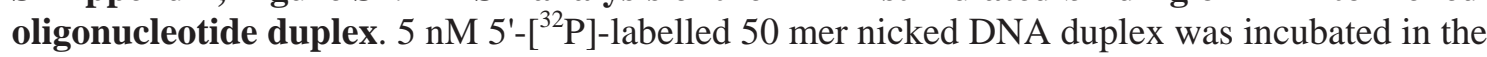
standard EMSA buffer $(20 \mu \mathrm{l})$ containing $500 \mathrm{nM}$ APE1, $250 \mathrm{nM}$ AP-1 and $1 \mathrm{mM}$ of the reducing agents GSH or DTT. After incubation for $30 \mathrm{~min}$ at room $\mathrm{T}^{\circ} \mathrm{C}$, the DNA bound products were analyzed by EMSA. Lane 1, control free DNA probe; lane 2, as 1, but with APE1; lane 3, as 1, but with oxidized AP-1; lane 4, as 1, but with APE1 and AP-1; lane 5, as 1, but with AP-1 and GSH; lane 6, as 1, but with AP-1, APE1 and GSH; lane 7, as 1, but with AP-1 and DTT; lane 8, as 1, but with AP-1, APE1 and DTT. Schematic drawing of nicked oligonucleotide DNA duplex used is shown at the top of the gel. The positions of migration of AP-1/DNA complex and free DNA probe are indicated to the right of the gel. For details see Materials and Methods. 


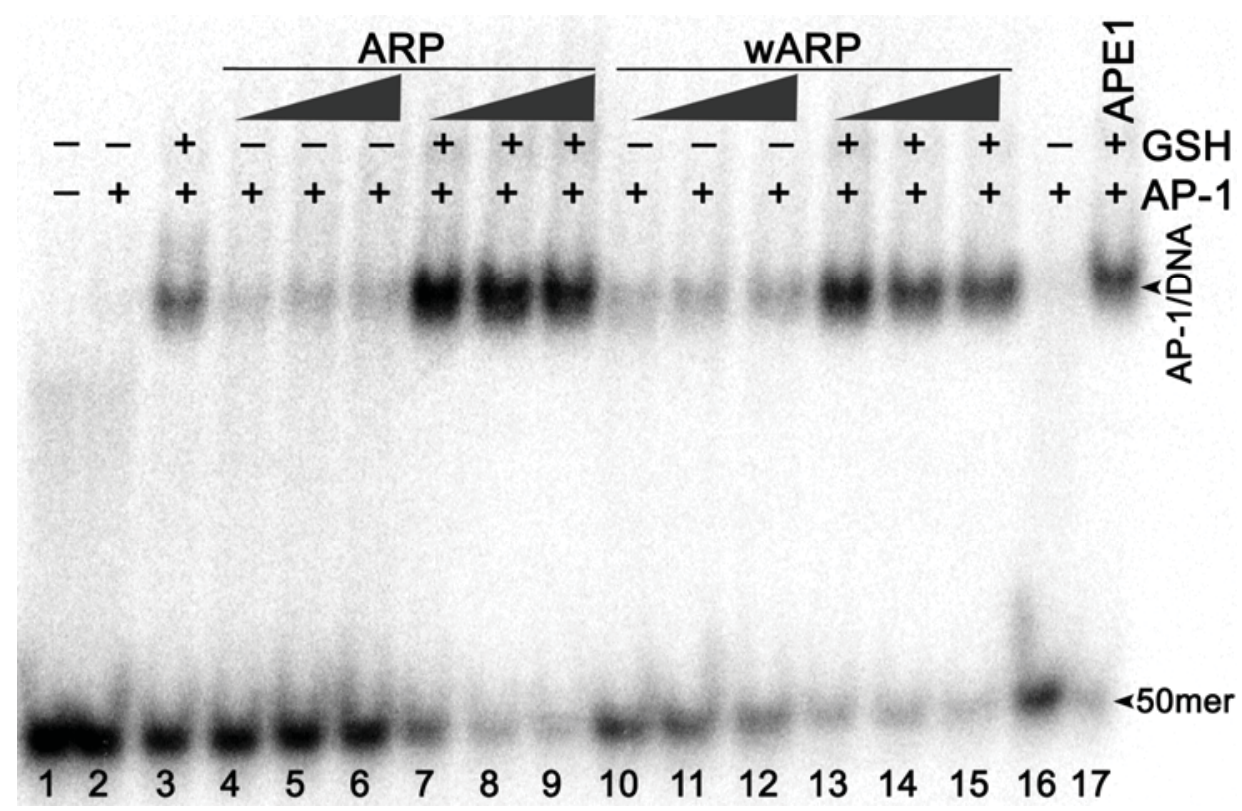

SI Appendix, Figure S5. Arabidopsis and wheat AP endonucleases stimulate DNA binding of AP-1. $5 \mathrm{nM} 50$ mer 5'-[ $\left.{ }^{32} \mathrm{P}\right]$-labelled full duplex oligonucleotide (dsDNA) was incubated in the standard EMSA buffer $(20 \mu \mathrm{l})$ containing $250 \mathrm{nM}$ AP-1, $1 \mathrm{mM} \mathrm{GSH}$ and 0.5-2.0 $\mu \mathrm{M}$ A. thaliana ARP or T. aestivum wARP. After incubation for $30 \mathrm{~min}$ at room $\mathrm{T}^{\circ} \mathrm{C}$, the products of the binding reaction were analysed by EMSA. Lane 1, control free 50 mer dsDNA probe; lane 2, as 1, but with AP-1; lane 3, as 1, but with AP-1 and GSH; lanes 4-6, as 2, but with 0.5, 1.0 and $2.0 \mu \mathrm{M}$ ARP, respectively; lanes 7-9, as 3, but with $0.5,1.0$ and $2.0 \mu \mathrm{M}$ ARP, respectively; lanes 10-12, as 2 , but with $0.5,1.0$ and 2.0 $\mu \mathrm{M}$ wARP, respectively; lanes 13-15, as 3, but with $0.5,1.0$ and $2.0 \mu \mathrm{M}$ wARP, respectively; lane 16 , same as 2; lane 17, as 2, but with $0.5 \mu \mathrm{M}$ APE1. The positions of migration of AP-1/DNA complex and free DNA probe are indicated to the right of the gel. For details see Materials and Methods. 


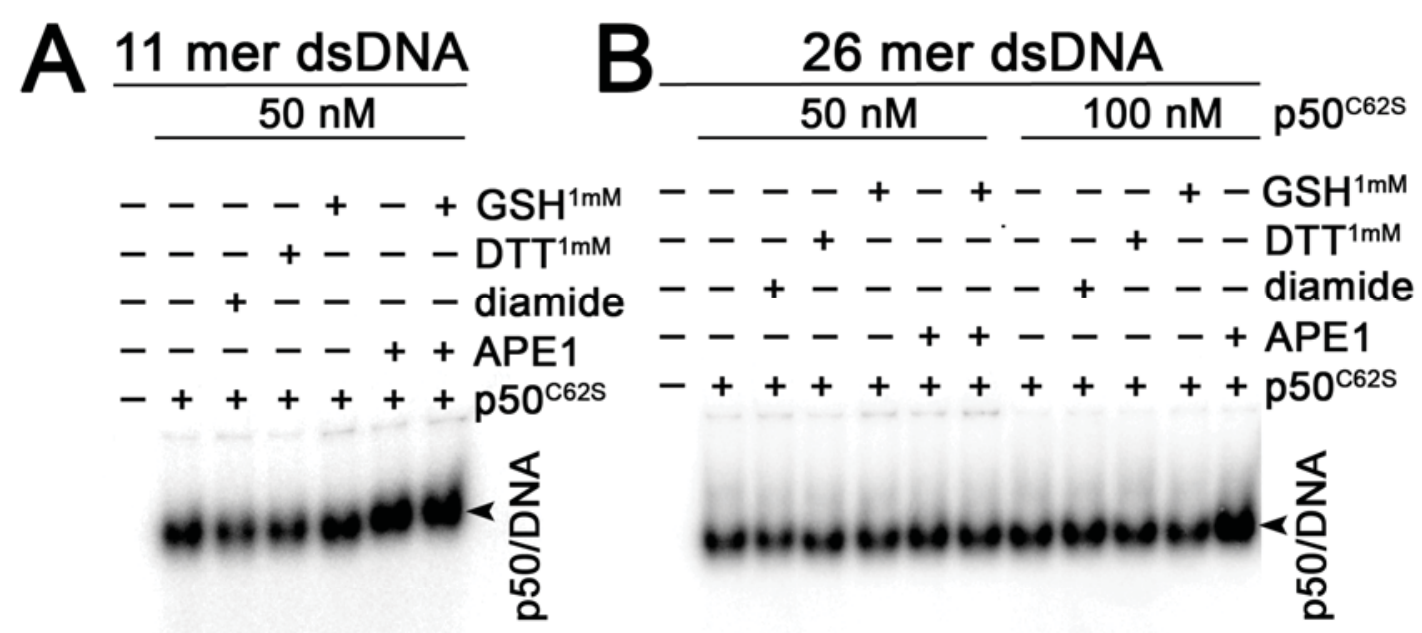

$<26$ mer

\section{2}

\section{7}

SI Appendix, Figure S6. Binding of the NF-кB p50-C62S redox insensitive mutant to 11 and 26 mer DNA duplexes in the presence of APE1 and reducing agents. $5 \mathrm{nM} 5^{2}-\left[{ }^{32} \mathrm{P}\right]-$ labelled 11 mer and 26 mer oligonucleotide duplex was incubated in the EMSA buffer for p50 $(20 \mu \mathrm{l})$ containing 50 and $100 \mathrm{nM}$ p50-C62S, $500 \mathrm{nM}$ APE1, and varying concentrations of $\mathrm{GSH}$ and DTT. After incubation for $30 \mathrm{~min}$ at room $\mathrm{T}^{\circ} \mathrm{C}$, the products of the binding reaction were analyzed by EMSA. (A) Binding of the NF- $\mathrm{B}$ p50-C62S redox insensitive mutant to 11 mer DNA duplex. Lane 1, control free 11 mer duplex DNA; lane 2, as 1, but with p50-C62S; lane 3, as 1 , but with p50-C62S treated by $70 \mu \mathrm{M}$ diamide; lane 4 , as 2 , but with $1 \mathrm{mM}$ DTT; lane 5, as 2, but with $1 \mathrm{mM} \mathrm{GSH}$; lane 6, as 2, but with APE1; lane 7, as 6, but with $1 \mathrm{mM}$ GSH. (B) Binding of the NF- $\mathrm{BB}$ p50-C62S redox insensitive mutant to 26 mer DNA duplex.

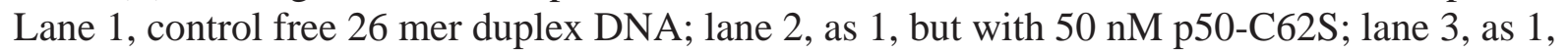
but with $50 \mathrm{nM}$ p50-C62S treated by $70 \mu \mathrm{M}$ diamide; lane 4, as 2, but with $1 \mathrm{mM}$ DTT; lane 5, as 2, but with $1 \mathrm{mM} \mathrm{GSH}$; lane 6, as 2, but with APE1; lane 7, as 6, but with $1 \mathrm{mM} \mathrm{GSH}$. lane 8, as 1 , but with $100 \mathrm{nM}$ p50-C62S; lane 9, as 1, but with $100 \mathrm{nM}$ p50-C62S treated by $70 \mu \mathrm{M}$ diamide; lane 10, as 8 , but with $1 \mathrm{mM}$ DTT; lane 11 , as 8 , but with $1 \mathrm{mM} \mathrm{GSH}$; lane 12 , as 8 , but with APE1. The positions of migration of p50-C62S/DNA complex and free DNA probe are indicated to the right of the gel. For details see Materials and Methods. 


$$
\begin{aligned}
& ------\overline{-}++++\mathrm{GSH} \\
& -----++++---t \mathrm{DTT} \\
& -+--+-\frac{1}{++}+-++\mathrm{APE} 1 \\
& --+++++++++++\mathrm{p} 50-\mathrm{C} / \mathrm{S}
\end{aligned}
$$

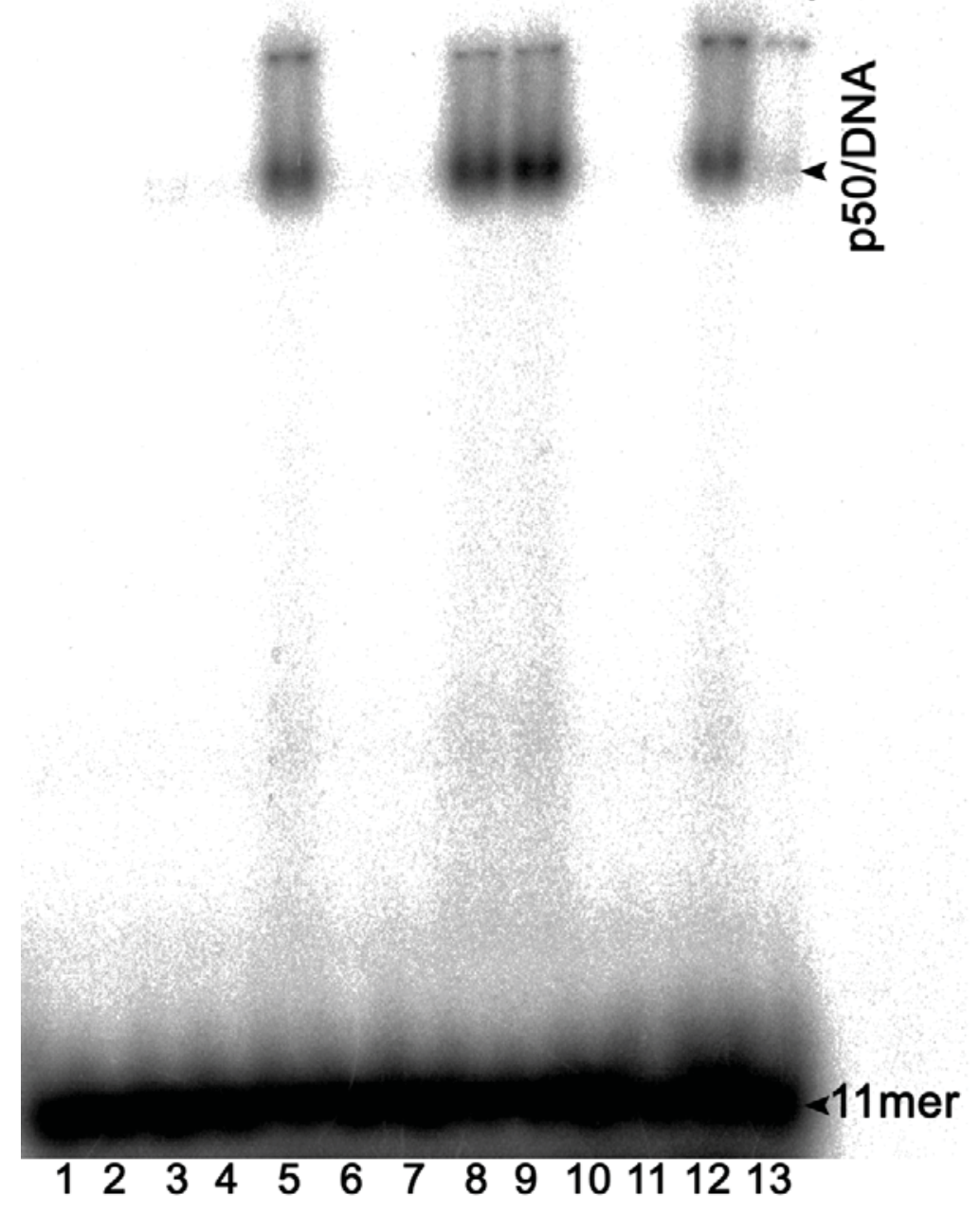

SI Appendix, Figure S7. APE1 stimulates binding of the NF- $\kappa B$ p50-C62S redox insensitive mutant to 11 mer DNA duplex. $5 \mathrm{nM} 5$ '-[ $\left.{ }^{32} \mathrm{P}\right]$-labelled 11 mer oligonucleotide duplex was incubated in the EMSA buffer for p50 $(20 \mu \mathrm{l})$ containing $10 \mathrm{nM}$ p50-C62S, $500 \mathrm{nM}$ APE1, and varying concentrations of GSH and DTT. After incubation for $30 \mathrm{~min}$ at room $\mathrm{T}^{\circ} \mathrm{C}$, the products of the binding reaction were analyzed by EMSA. Lane 1, control free 11 mer duplex DNA; lane 2, as 1, but with APE1; lane 3, as 1, but with p50-C62S; lane 4, as 1, but with p50-C62S treated by $70 \mu \mathrm{M}$ diamide; lane 5 , as 1 , but with p50-C62S and APE1; lanes 6-7, as 3, but with 1 and 5 mM DTT; lanes 8-9, as 6-7, but with APE1; lanes 10-11, as 3, but with 1 and $5 \mathrm{mM} \mathrm{GSH}$; lanes 12-13, as 10-11, but with APE1. The positions of migration of p50-C62S/DNA complex and free DNA probe are indicated to the right of the gel. For details see Materials and Methods. 


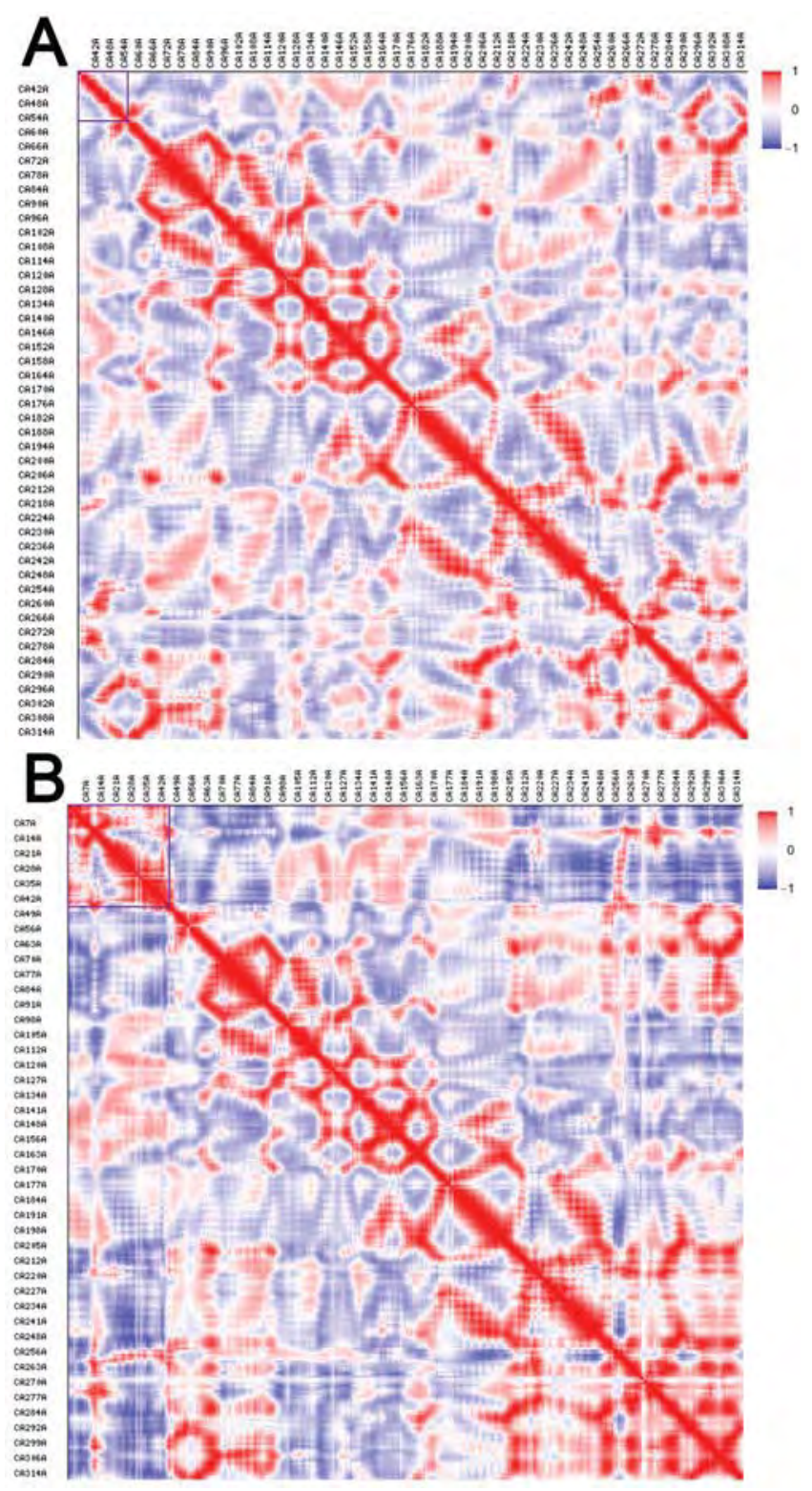

SI Appendix, Figure S8. Matrix of correlations in fluctuation between APE1 residues in $(A)$ structure 2O3H [16]; starting at Met37, this is the longest available human APE1 structure) and (B) $\mathrm{APE} 1_{\text {full }}$ model. Co-variation was calculated over the first 20 normal modes. Blue to red heat scale is for the cross correlation between different residues. The N-terminal $\mathrm{APE}_{1-46}$ fragment as present in the structures is boxed. 


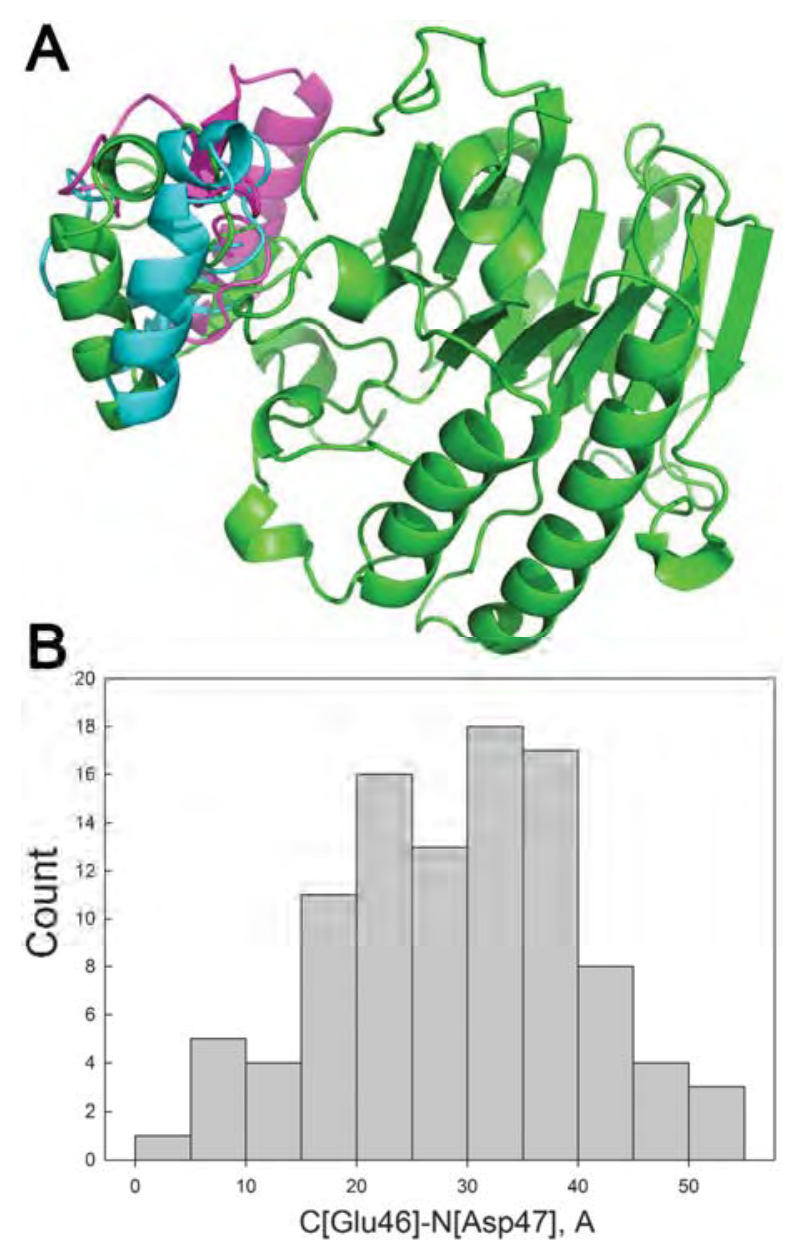

SI Appendix, Figure S9. The shapes of the N-terminal fragment of APE1 obtained by ab initio folding and protein-protein docking. $(A)$ Three best models after docking the folded $\mathrm{APE}_{1-46}$ fragment on the $\mathrm{APE}_{47-318}$ structure. $\mathrm{APE}_{47-318}$ and the best model of $\mathrm{APE}_{1-46}(\mathrm{C}[\mathrm{Glu} 46]-$ $\mathrm{N}$ [Asp47] = 3.82 $\AA$ ) are shown in green, the second-best model $(5.02 \AA)$, in cyan, the third (5.69 $\AA$ ), in magenta. (B) Distribution of C[Glu46]-N[Asp47] in 100 docked pairs of APE $_{1-46}$ model with $\mathrm{APE}_{47-}$ 318 structure. 


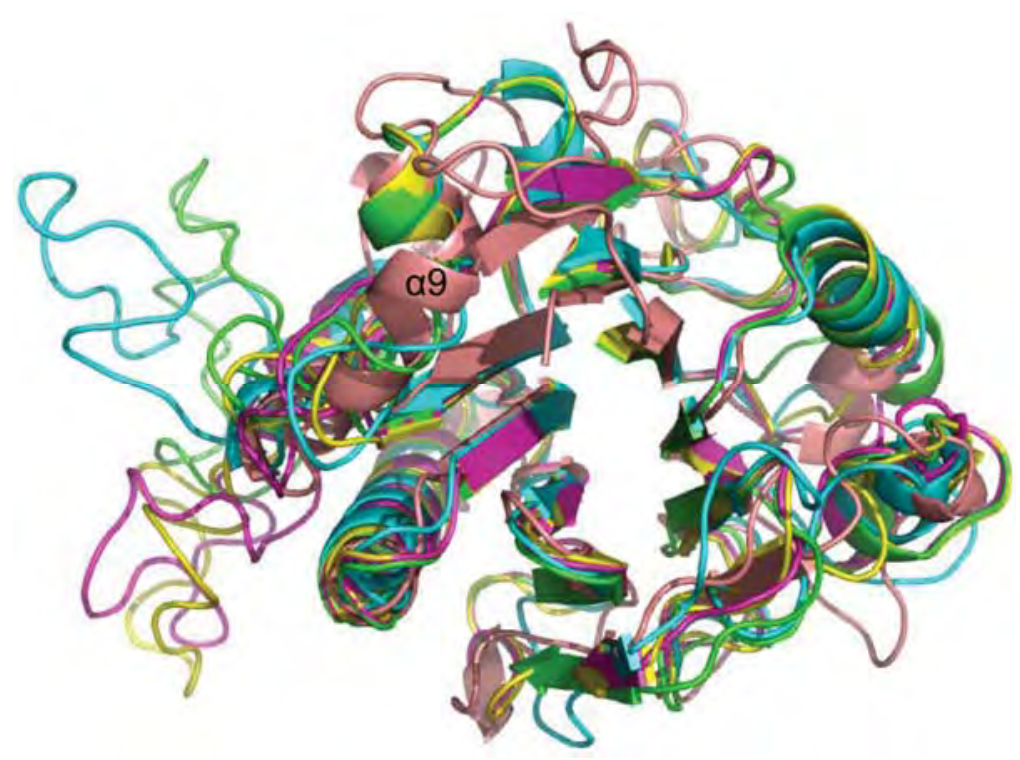

SI Appendix, Figure S10. Superimposition of the X-ray structures. Structure of APE1 (PDB ID 1BIX, colored salmon) superimposed over the homology models of the APE1 catalytic domain built on TDP2 templates (PDB IDs 5INL, green, 5INO, cyan, 5INP, magenta, 5INQ, yellow [49]. The DNA-binding groove is facing the viewer. Note that the most pronounced structural differences between the models are around the $\alpha 9$ helix of 1BIX (left) away from the DNA-binding groove.

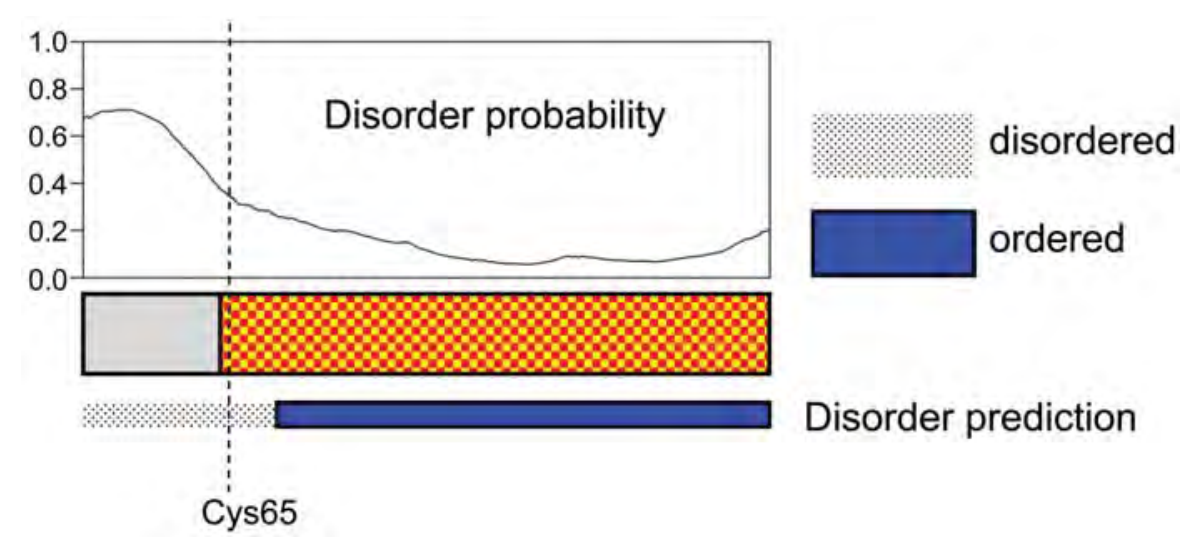

SI Appendix, Figure S11. Disorder prediction in the sequence of APE1. The prediction was performed by ESpritz bi-directional recursive neural network trained on a DisProt set [92]. The checkered pattern marks the catalytic domain of APE1 (Leu62-Leu316). The dashed line marks the position of C65. 


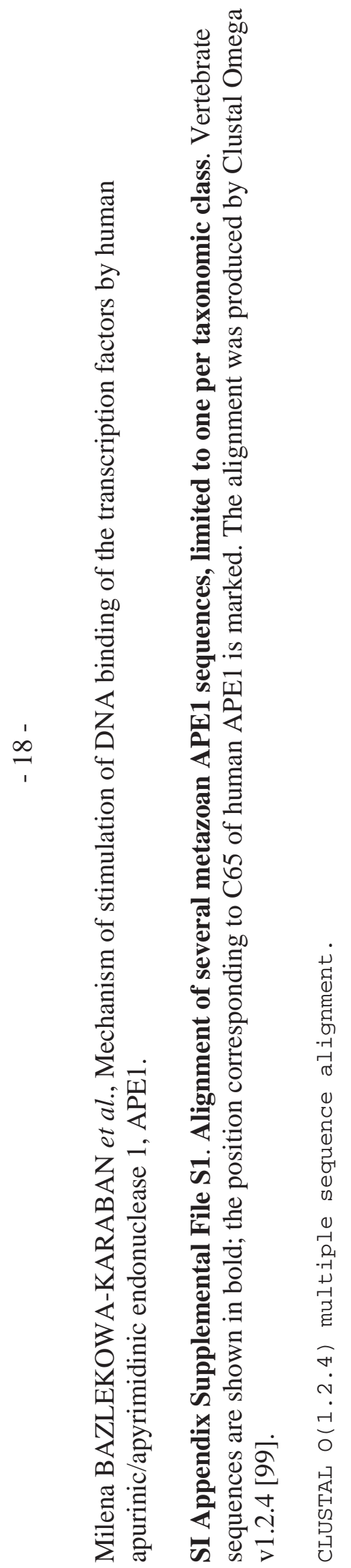

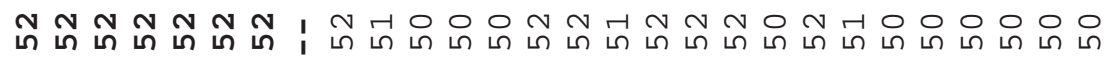

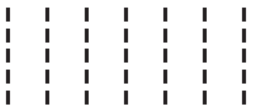

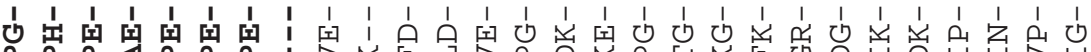

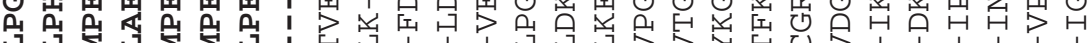

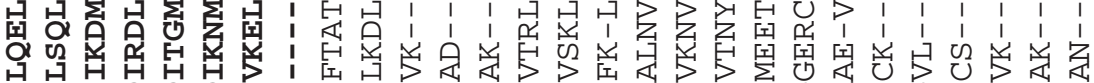

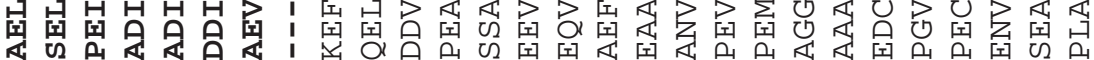
a

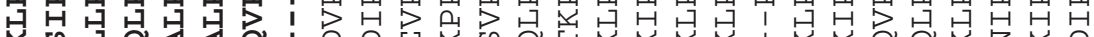

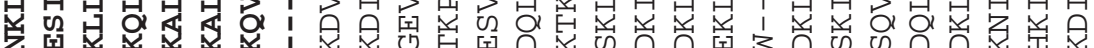

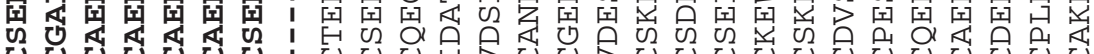

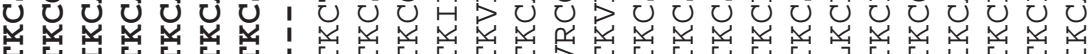

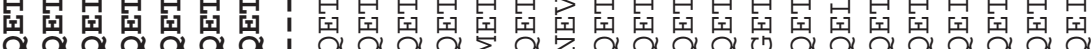

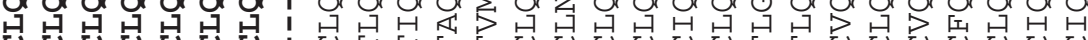

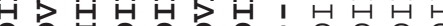

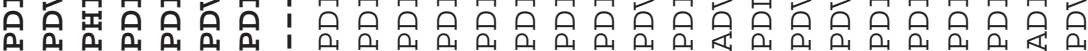

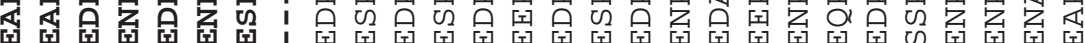

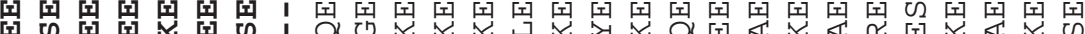

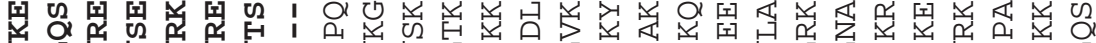

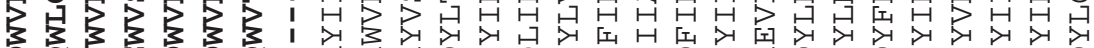

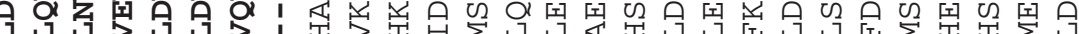

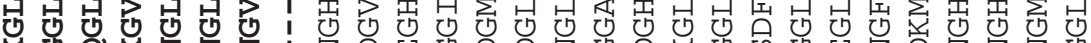

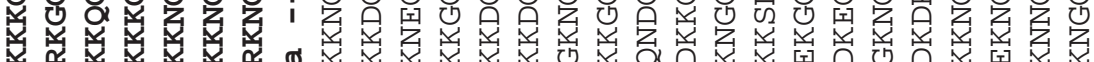

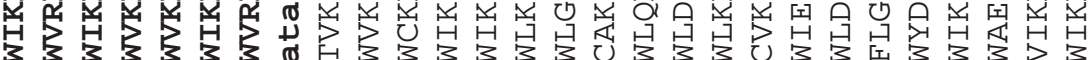

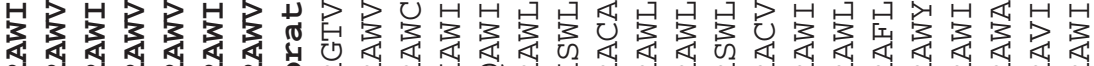

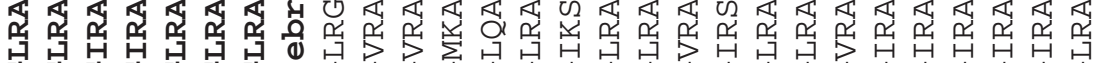
ฮ

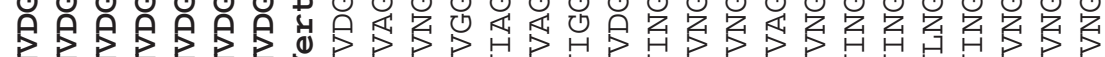

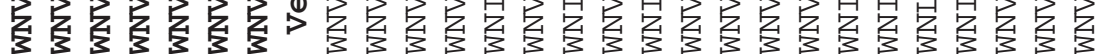

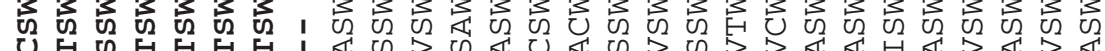
- O

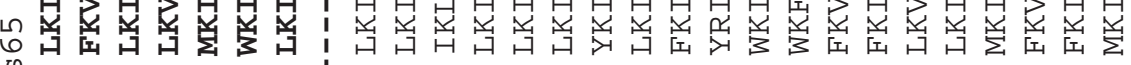

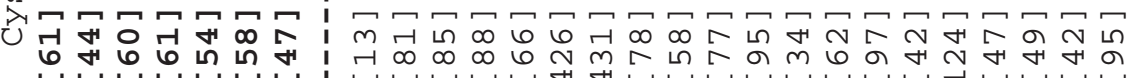

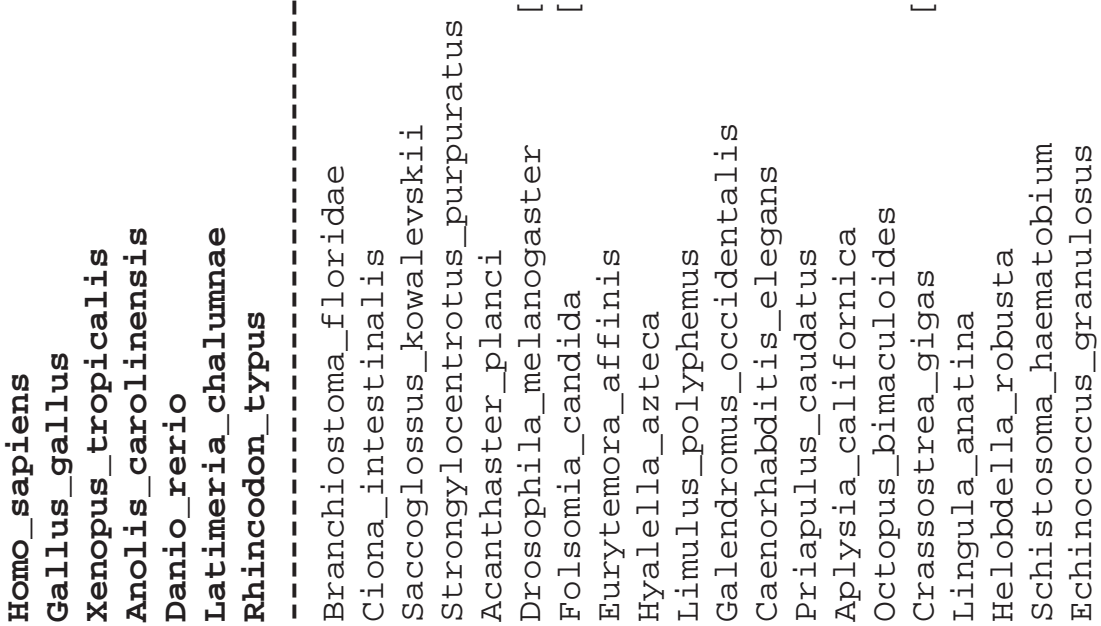


은우벤유

$\begin{aligned} & |c| \\ & \mid\end{aligned} \mid$

出焉

兵要

我留

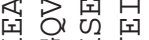

됟에 언돈

a म

只可

岳利

兄包

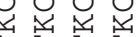

됭되 됭

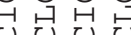

되바

多召

只只是

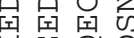

头可同只

只总是

饮号的

兒曷苜

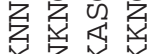

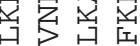

33

在质

णㅓㅁ

出员

点点点

的的

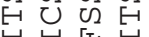

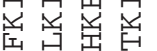

듕

$\wedge$ 드

다

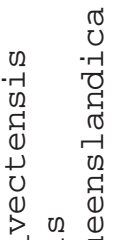

1 -

다

(1) 닫ำ

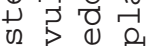

० I E O

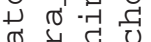

委

品密岱

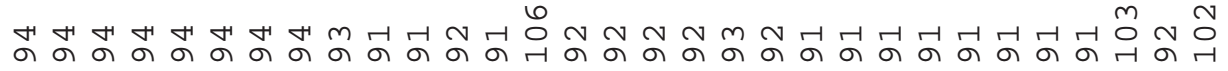

U

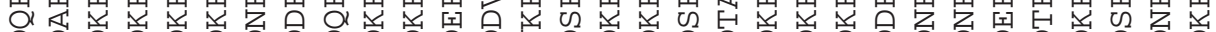

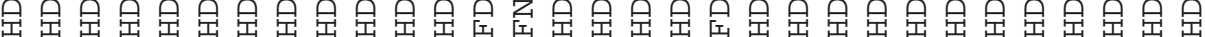

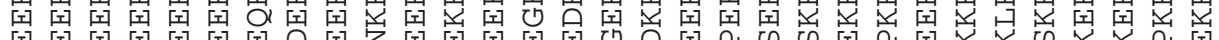

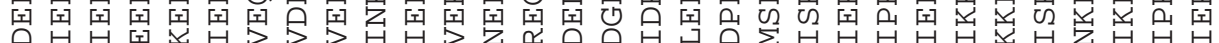

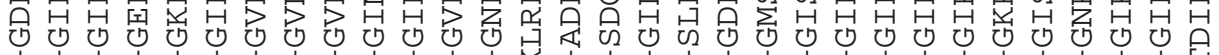
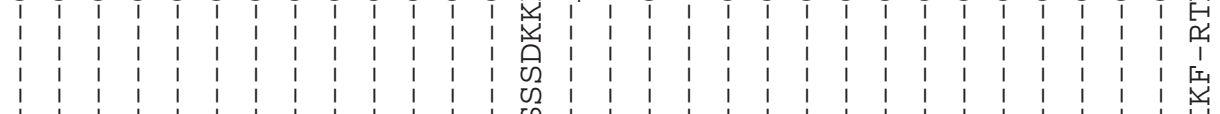

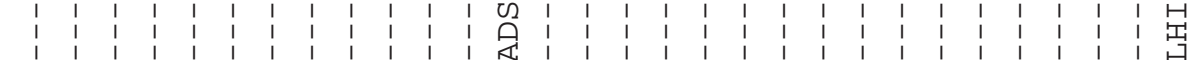

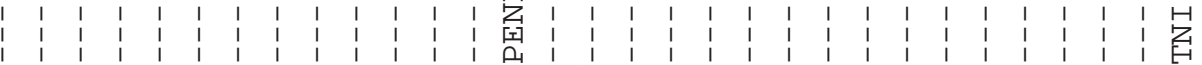

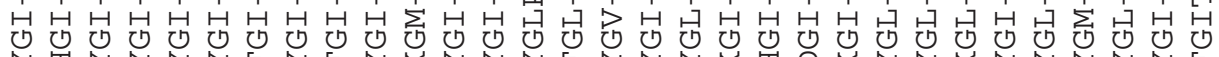

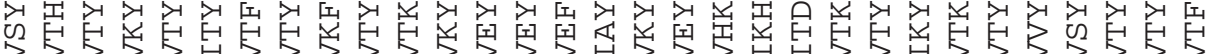

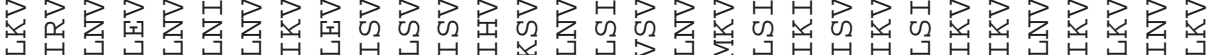
a

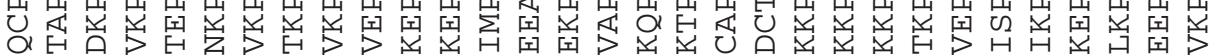

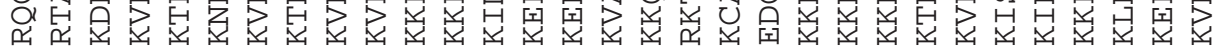

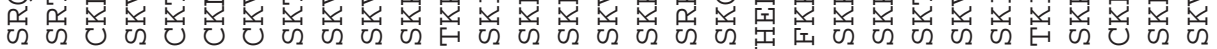

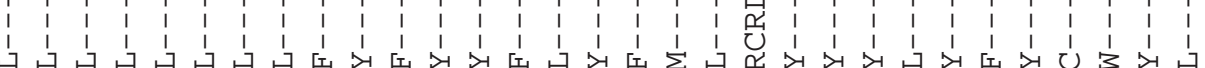

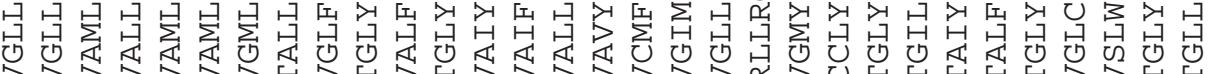

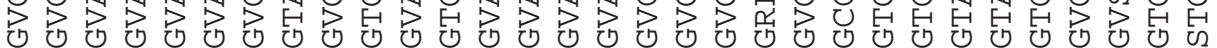
U

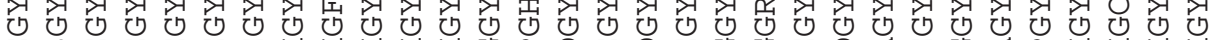

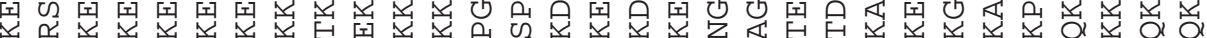

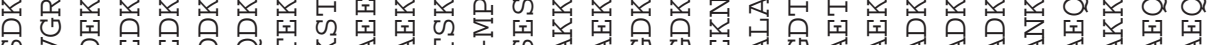

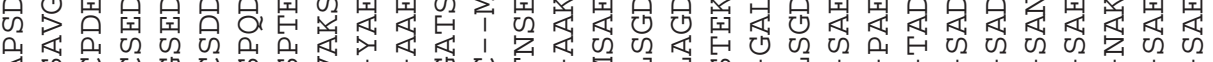

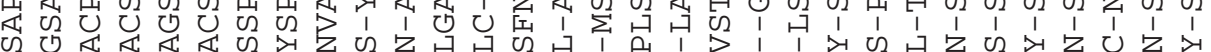

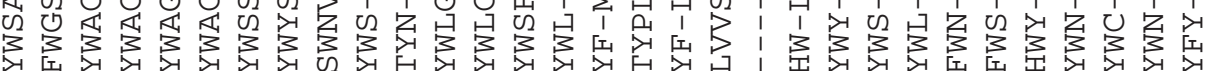

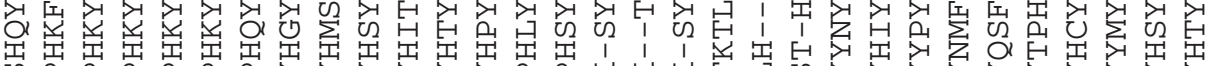

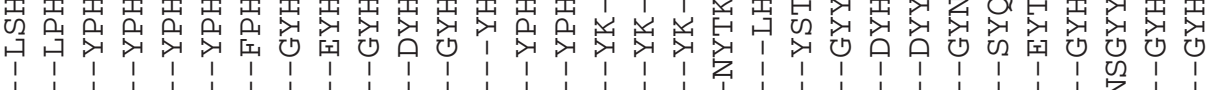

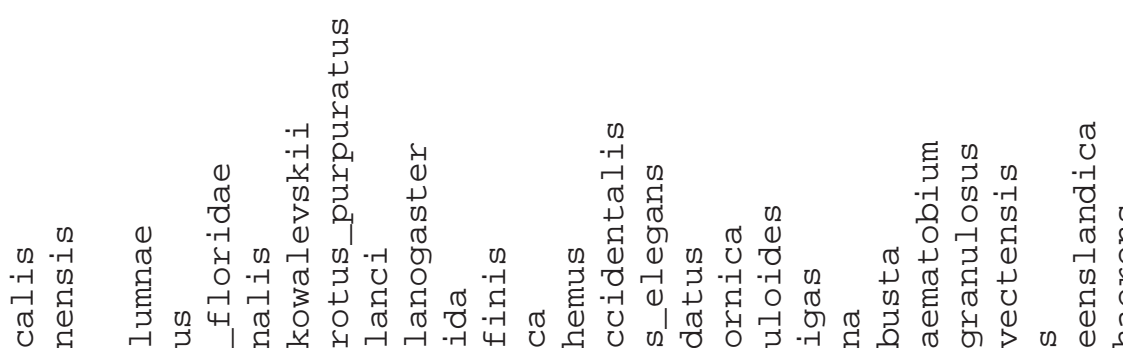

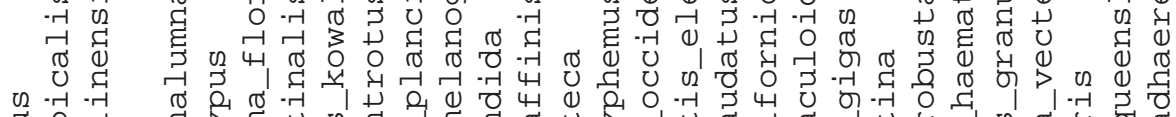

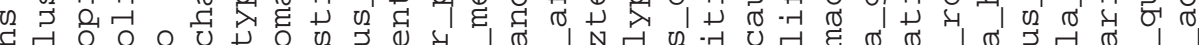

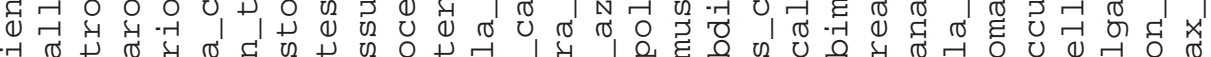

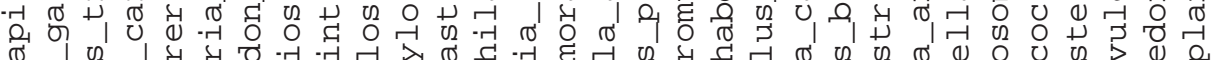

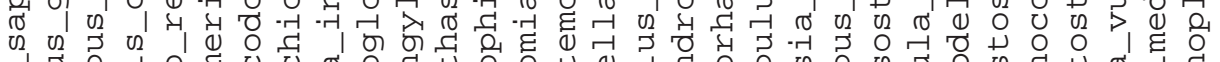

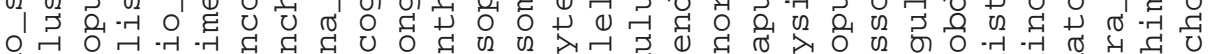

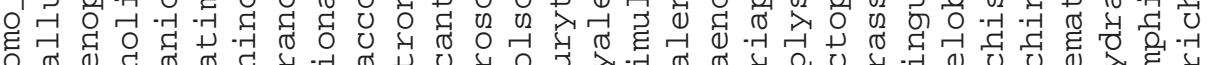

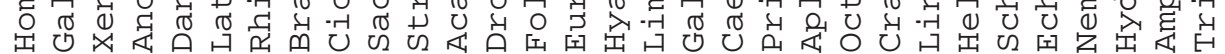

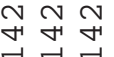

空药

出崖

䙵号

我㟧

桨留

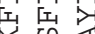

वि तै

兵岳

呇今

会会合

出出

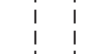

lo d a

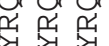

됭

品品

㫔曷曷

品品出

崖饥

क ल

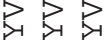

盾芯发

$3 B H$

मे

的只踏

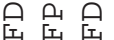

可牙近

芯芯 $\gtrless \stackrel{2}{p}$

म 1 व

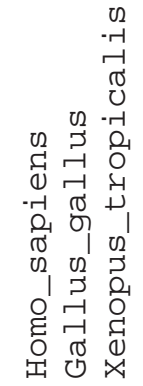




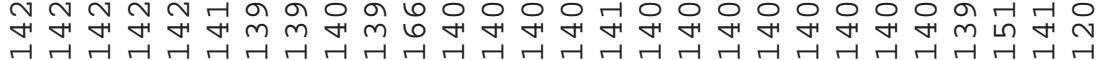

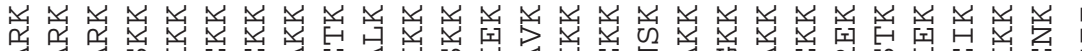

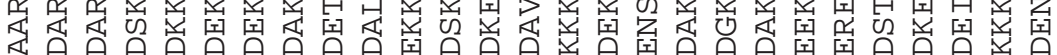

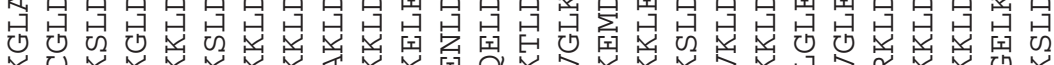

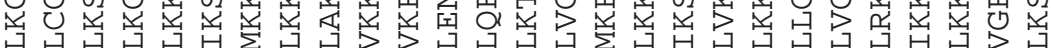

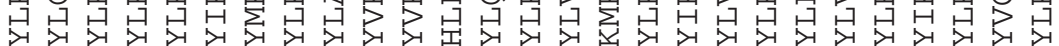

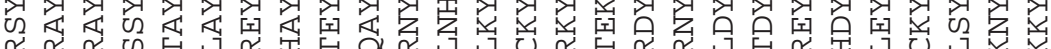

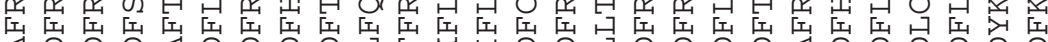

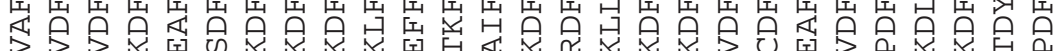

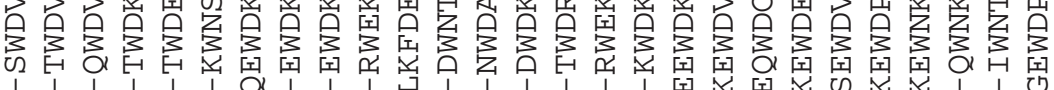

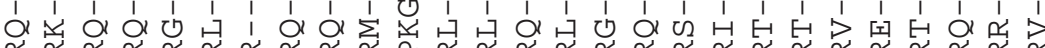

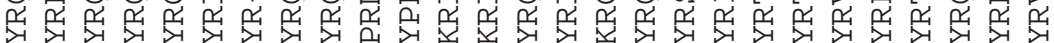

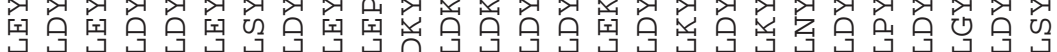

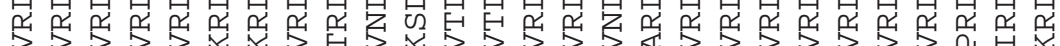

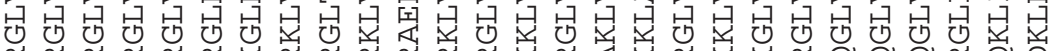

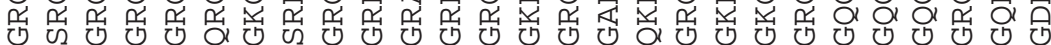

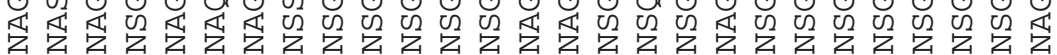

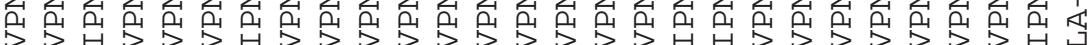

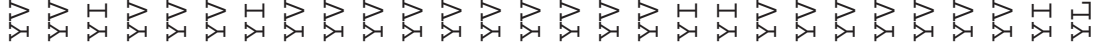

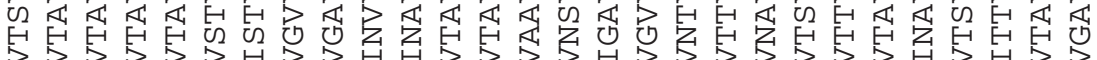

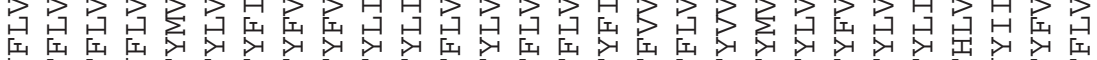

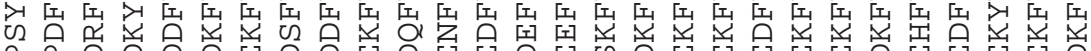

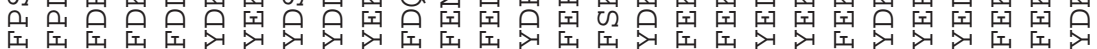

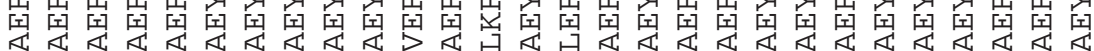

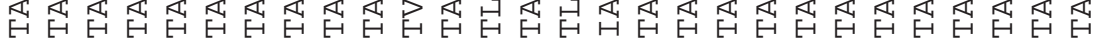

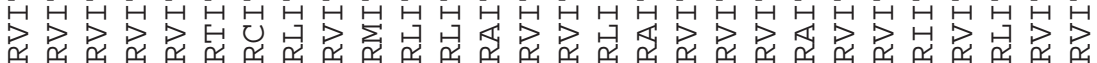

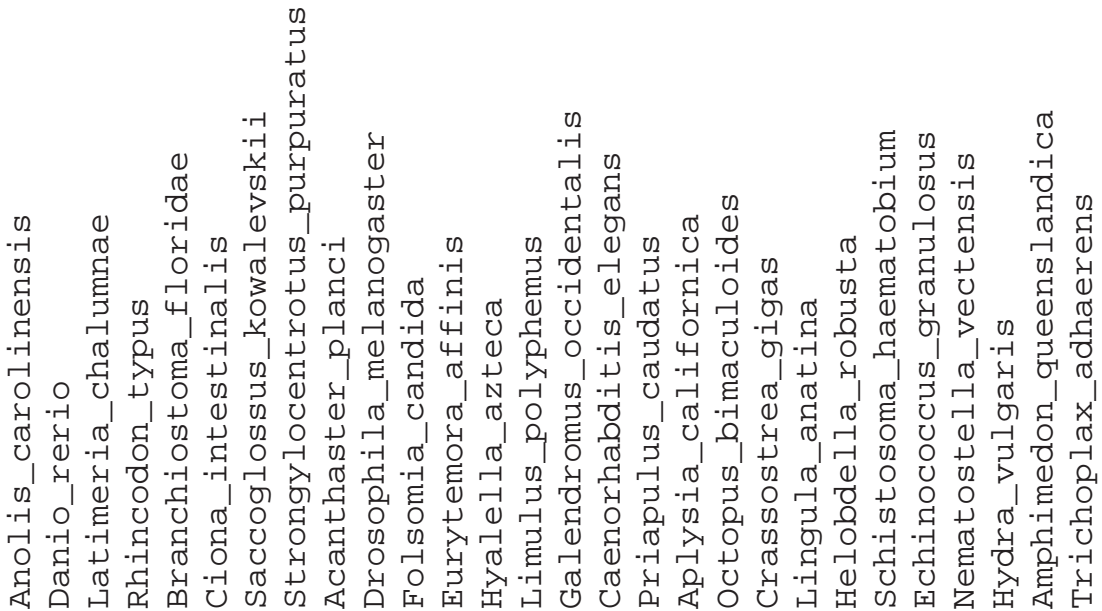

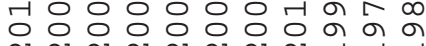
NNNNNNH

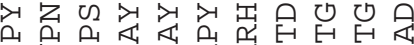

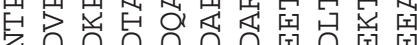

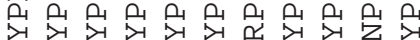
星珀星星星

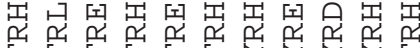

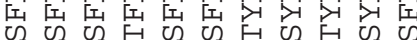
คำ

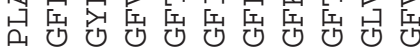

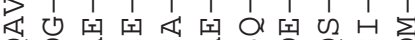

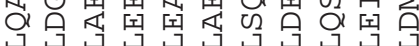

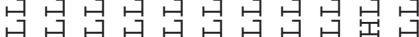

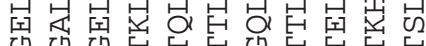

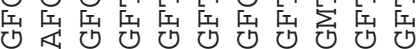

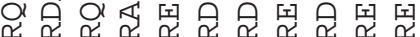

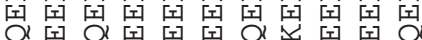
品 $\begin{aligned} & 0 \\ & \mu_{1}\end{aligned}$

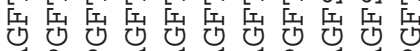

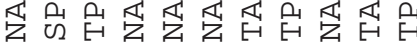

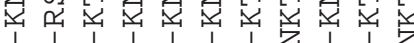

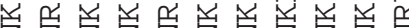

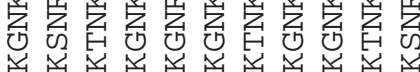

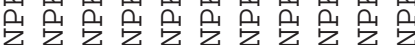

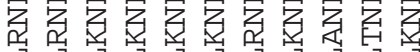

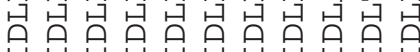

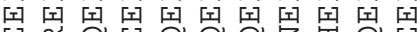

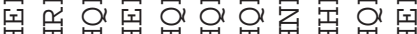

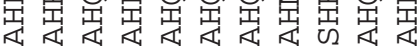

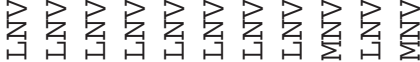

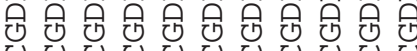

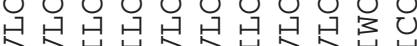

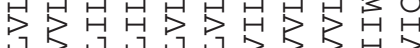

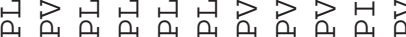

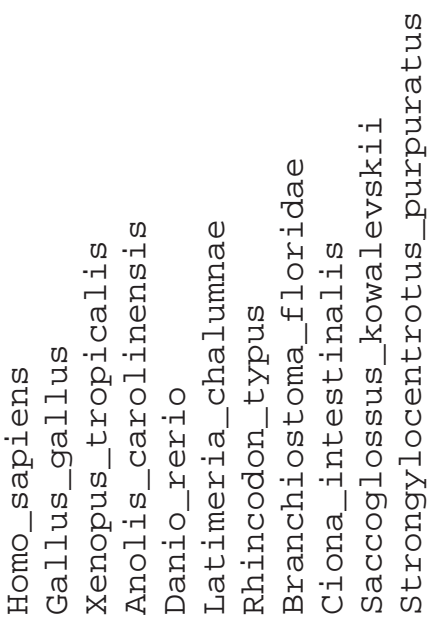




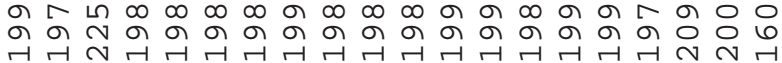

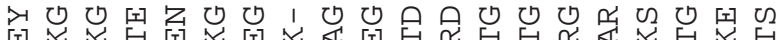

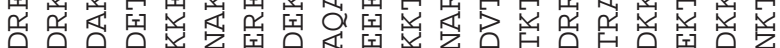

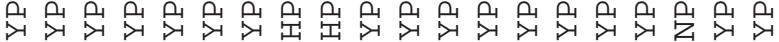

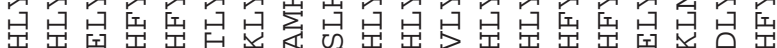

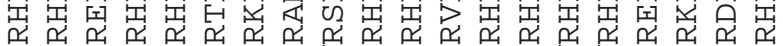

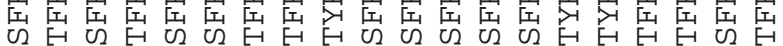

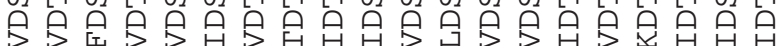

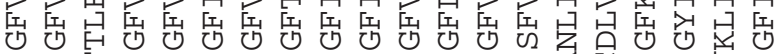

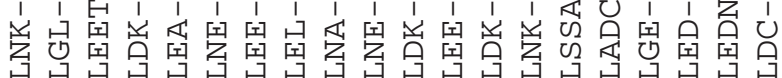

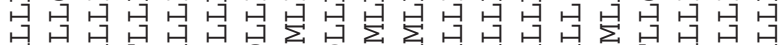

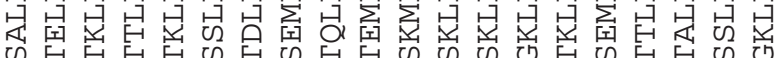

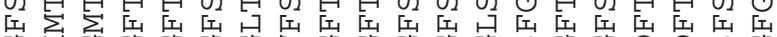

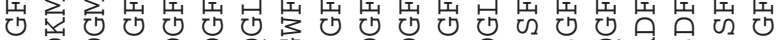
될

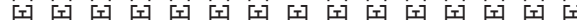

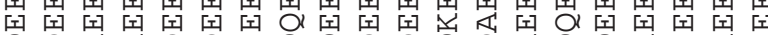

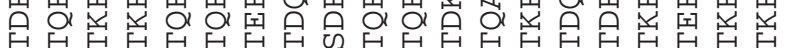

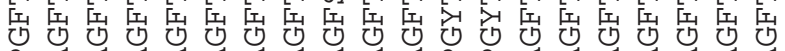

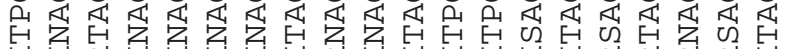

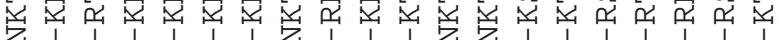

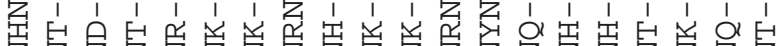

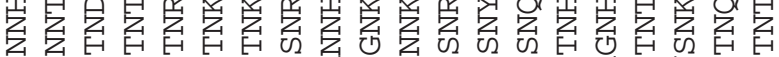

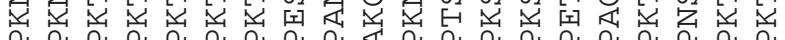

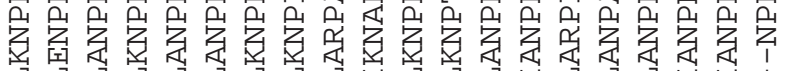

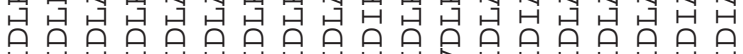

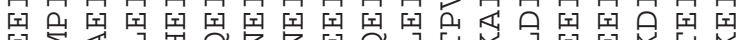

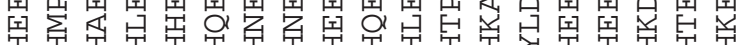

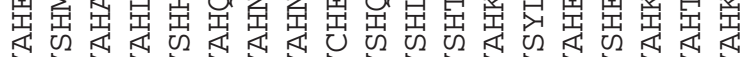
点点点点点点点点点点点点点

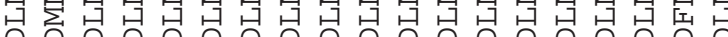

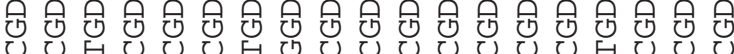

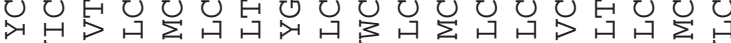

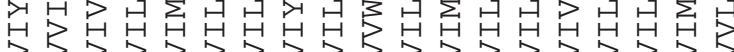

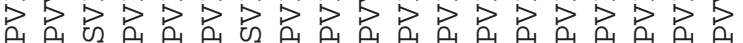

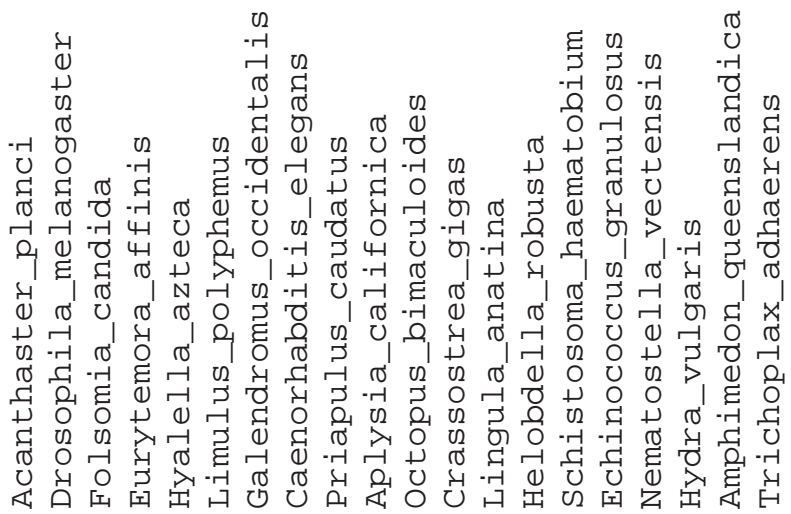

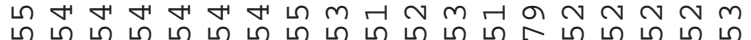

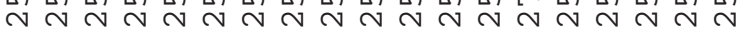

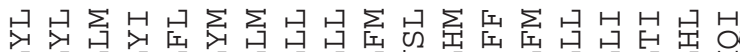

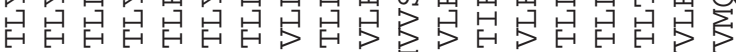

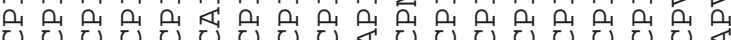

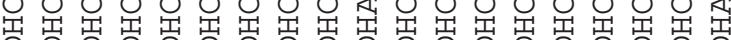

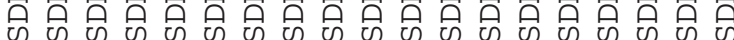

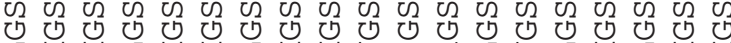

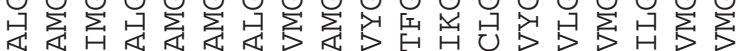

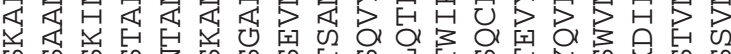
थ थ थ थ 记 थ थ

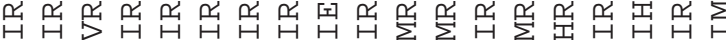

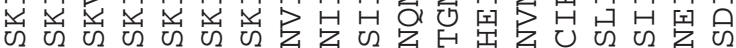

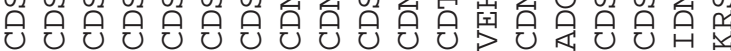

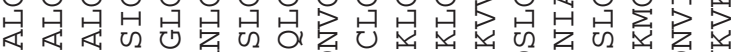

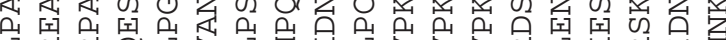
响

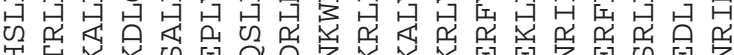
设地

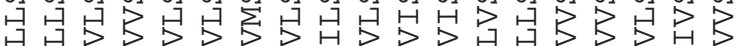

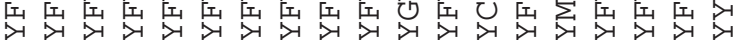

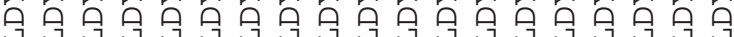

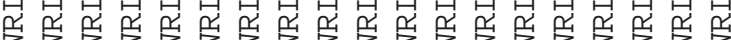

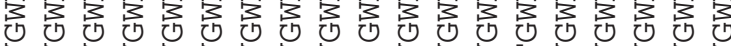
点点点点点点点点点点点点点点

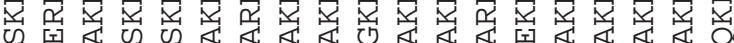

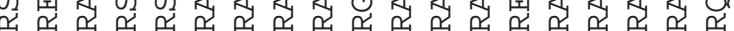

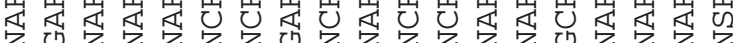

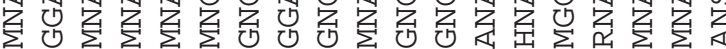

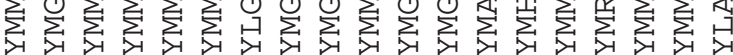

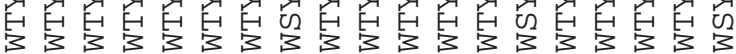

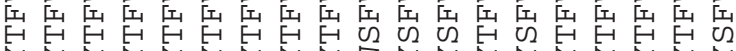

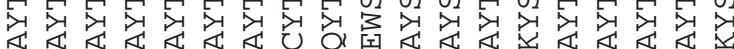

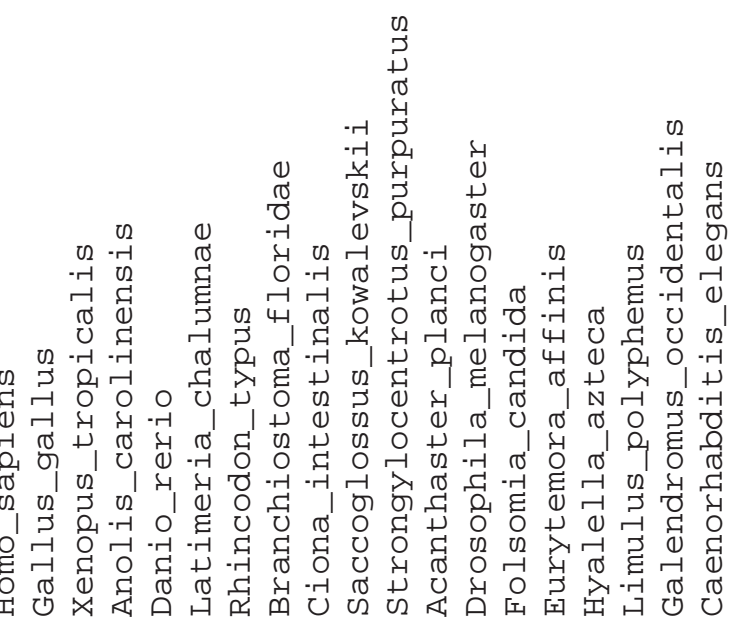




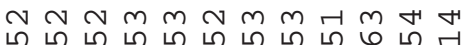

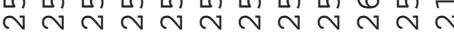

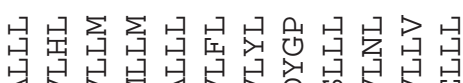

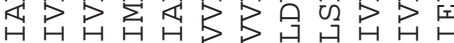

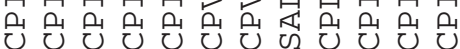

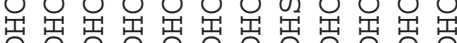

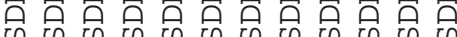

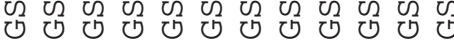

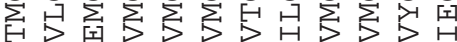

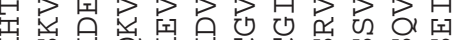
के 1 a 出出出

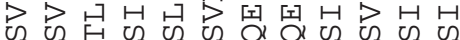

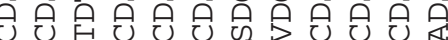

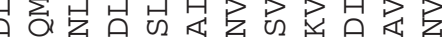

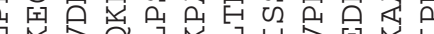

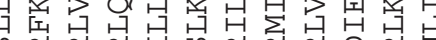
等

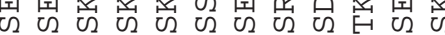
H

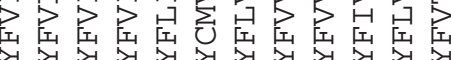

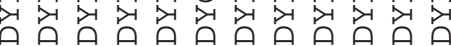

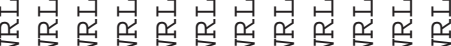

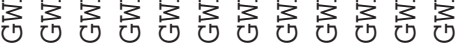

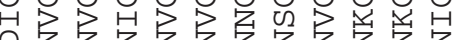

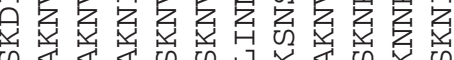

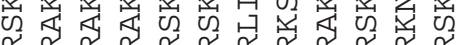
o

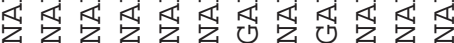

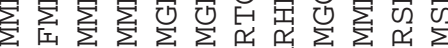

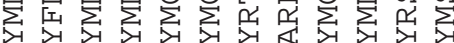

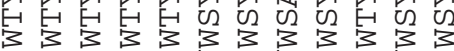

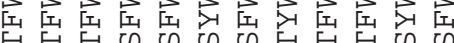

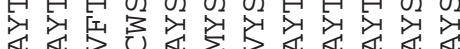

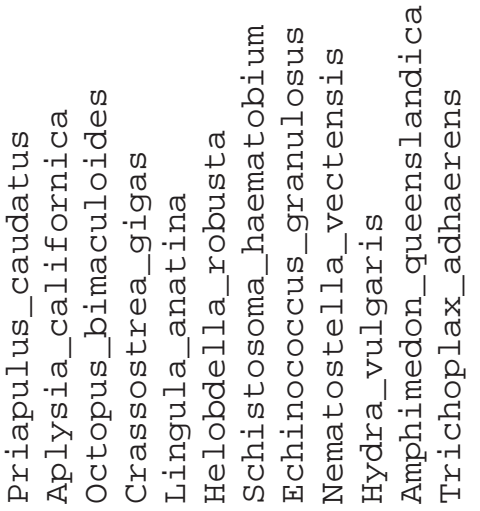


Milena BAZLEKOWA-KARABAN et al., Mechanism of stimulation of DNA binding of the transcription factors by human apurinic/apyrimidinic endonuclease 1, APE1.

\section{Conflict of interest}

The authors: Milena Bazlekowa-Karaban, Paulina Prorok, Sonia Baconnais, Sabira Taipakova, Zhiger Akishev, Dominika Zembrzuska, Alexander V. Popov, Anton V. Endutkin, Regina Groisman, Alexander A. Ishchenko, Bakhyt T. Matkarimov, Amangeldy Bissenbaev, Eric Le Cam, Dmitry O. Zharkov, Barbara Tudek, and Murat Saparbaev of the manuscript entitled "Mechanism of stimulation of DNA binding of the transcription factors by human apurinic/apyrimidinic endonuclease 1, APE1", declare that they have no conflict of interest. 